\title{
Molecular mechanisms and cellular events involved in the neuroprotective actions of estradiol. Analysis of sex differences
}

\author{
Iñigo Azcoitia ${ }^{\mathrm{a}, \mathrm{b}}$, George E. Barreto ${ }^{\mathrm{c}}$, Luis M. Garcia-Segura ${ }^{\mathrm{b}, \mathrm{d}, *}$ \\ ${ }^{a}$ Department of Cell Biology, Faculty of Biology, Universidad Complutense de Madrid, 28040 Madrid, Spain \\ ${ }^{\mathrm{b}}$ Centro de Investigación Biomédica en Red Fragilidad y Envejecimiento Saludables (CIBERFES), Instituto de Salud Carlos III, Avenida Monforte de Lemos, 3-5, 28029 \\ Madrid, Spain \\ ${ }^{\mathrm{c}}$ Department of Biological Sciences, School of Natural Sciences, University of Limerick, Limerick, Ireland \\ d Instituto Cajal, CSIC, Avenida Doctor Arce 37, 28002 Madrid, Spain
}

A R T I C L E I N F O

\section{Keywords:}

Apoptosis

Autophagy

Brain plasticity

Cell signaling

Estrogen receptor

Excitotoxicity

Glia

Mitochondria

Neurogenesis

Neuroinflammation

\begin{abstract}
A B S T R A C T
Estradiol, either from peripheral or central origin, activates multiple molecular neuroprotective and neuroreparative responses that, being mediated by estrogen receptors or by estrogen receptor independent mechanisms, are initiated at the membrane, the cytoplasm or the cell nucleus of neural cells. Estrogen-dependent signaling regulates a variety of cellular events, such as intracellular $\mathrm{Ca}^{2+}$ levels, mitochondrial respiratory capacity, ATP production, mitochondrial membrane potential, autophagy and apoptosis. In turn, these molecular and cellular actions of estradiol are integrated by neurons and non-neuronal cells to generate different tissue protective responses, decreasing blood-brain barrier permeability, oxidative stress, neuroinflammation and excitotoxicity and promoting synaptic plasticity, axonal growth, neurogenesis, remyelination and neuroregeneration. Recent findings indicate that the neuroprotective and neuroreparative actions of estradiol are different in males and females and further research is necessary to fully elucidate the causes for this sex difference.
\end{abstract}

\section{Introduction}

As homeostatic regulators, hormones contribute to preserve a healthy body function under changing developmental and environmental conditions. Thus, in the brain, hormones maintain neural tissue homeostasis by regulating blood flow, the access of nutrients and the physiological activity of the different cell types that constitute the nervous system. This protective action of hormones is also operative when the body is affected by diseases and injuries. Estradiol is a good example of a hormonal signal that impacts on brain function and behavior, regulating neural development and plasticity and the activity of neuronal circuits involved in different endocrine, homeostatic and behavioral tasks. In addition, estradiol protects brain function from alterations caused by disease and/or aging. Neuroprotective actions of estradiol were suggested by early studies showing an improvement in cognitive measures of women that received short-term estrogen therapy after bilateral oophorectomy, compared to placebo treated women (Sherwin, 1988). Since then, basic research has shown that estradiol is neuroprotective in cellular and/or animal models of stroke, perinatal asphyxia-hypoxia, Alzheimer's disease, Parkinson's disease, multiple sclerosis, amyotrophic lateral sclerosis, traumatic brain injury, spinal cord injury, diabetic encephalopathy, hypertensive encephalopathy and cognitive decline, among others (see Tables 1 and 2 and the following sections).

Additional studies in women that received estrogen therapy in the early postmenopausal stage have confirmed that the hormone decreases the risk of cognitive decline and dementia (Scott et al., 2012; Rocca et al., 2014; Engler-Chiurazzi et al., 2017), in agreement with the original observations (Sherwin, 1988). However, they also revealed that estrogen therapy initiated several years after menopause increases the risk of dementia, indicating that there is a critical window of opportunity for estrogen neuroprotection, depending on age and time of initiation of the treatment after menopause. This critical period for estrogen therapy has been confirmed in animal studies, which have demonstrated that both long-term estrogen deprivation and aging impair the neuroprotective actions of estradiol, in association with a down regulation of the expression of estrogen receptors (ERs) in the brain (Scott et al., 2012). Other factors may also contribute to the loss of

\footnotetext{
* Corresponding author at: Centro de Investigación Biomédica en Red Fragilidad y Envejecimiento Saludables (CIBERFES), Instituto de Salud Carlos III, Avenida Monforte de Lemos, 3-5, 28029 Madrid, Spain.

E-mail addresses: azcoitia@ucm.es (I. Azcoitia), George.Barreto@ul.ie (G.E. Barreto), 1mgs@cajal.csic.es (L.M. Garcia-Segura).
} 
Table 1

Examples of neuroprotective mechanisms of estradiol in in vitro models.

\begin{tabular}{ll}
\hline Injury model & Cell type \\
\hline Hypoxia & $\begin{array}{l}\text { Primary cortical astrocytes from n } \\
12 \text { day-old mouse pups and microg } \\
\text { line }\end{array}$ \\
& E19 Primary Hippocampal neurons
\end{tabular}

Oxygen/glucose deprivation (OGD)/ Primary cortical astrocytes reperfusion

bEnd.3 endothelial cells

Potassium superoxide or oxygen/ glucose deprivation

Glucose deprivation

$\beta$-amyloid

Cholinergic cell line

Primary rat cerebrocortical neurons

BV-2 microglial cells and primary neuronal cells

Human fetal olfactory neuroepithelium

Hydrogen peroxide $\left(\mathrm{H}_{2} \mathrm{O}_{2}\right)$ exposure

Cortical neurons

SK-N-BE cells

Striatal neurons

MCF-7 cells

Human retinal pigment epithelial cells (ARPE-

19)

6-hydroxydopamine (6-OHDA)

Lipopolysaccharide

Organotypic mesencephalic cultures from 7 dayold Wistar rat pups

Mouse primary cortical astrocyte cultures

Palmitic acid

Primary astrocytes derived from male and female 2 day-old Wistar rat pups

1-day-old rat primary astrocytes

Primary cortical neurons
Protective mechanisms

Estradiol reduces IL1B in BV-2 microglia cell line, but not in primary astrocytes, under hypoxia. Induction of NLRP3 protein levels by hypoxia is attenuated when BV-2 cells are treated with estradiol.

GPER1 knockdown attenuates estradiol protective effects, while GPER1 overexpression preserves estradiol benefits in primary hippocampal neurons. Estradiol treatment increasea MTT activity, loweres Annexin-V levels and attenuates LDH release. These effects were further potentiated when overexpressing GPER1.

Estradiol pretreatment improves cell viability after $6 \mathrm{~h}$ OGD/ $24 \mathrm{~h}$ reperfusion, attenuates apoptotic cell ratio, $\mathrm{LDH}$ release and oxidative radical generation and protects mitochondrial function. The same outcome is observed when cells are treated with PPT, an ER $\alpha$ agonist.

Estradiol enhances the integrity of tight junctions in endothelial cells submitted to OGD.

Brain slices treated with estradiol have increased superoxide dismutase 1 (SOD1) and attenuated oxidative stress and DNA damage.

Estradiol increases the expression of neuroglobin in glucose deprived cells and this effect is mimicked when cells are treated with the ER $\beta$ agonist DPN. Blockage of neuroglobin reduces estradiol protection in T98G cells.

Estradiol activates Raf-1/MEK/ERK1/2 to promote cell survival in septal derived cholinergic murine cell line (SN56).

Estradiol attenuates JNK activation (decreases JNK phosphorylation) induced by A $25-35$ in neuronal cultures, and this is accompanied by attenuated mitochondrial cytochrome $c$ and Smac release and the upregulation of $\mathrm{Bcl} 2$ family proteins and the inhibition of proapoptotic signaling.

Estradiol induces an attenuation of iNOS, COX-2 and Iba1 levels in BV- 2 cells treated with $\beta$-amyloid, while it reduces NFkB DNA binding activity, cleaved caspase 3 and Bax proteins (proapoptotic proteins) in primary neurons stimulated with $\beta$ amyloid.

Cells pretreated with IGF-1 and estradiol show increased survival and attenuated oxidative stress, and these protective effects are partly lost when blocking estrogen receptors. Protective actions of estradiol are dampened upon blockage of IGF-1R, suggesting a possible crosstalk of estradiol and IGF-1 protective signaling. As a downregulated gene in Alzheimer's Disease, seladin-1 might, at least in part, mediate the neuroprotection by estradiol.

Estradiol acting on GPER increases phosphoERK1/2 and Bcl-2 and reduces oxidative damage by $\mathrm{H}_{2} \mathrm{O}_{2}$.

Estradiol favors the formation of huntingtin-neuroglobin complex in mitochondria and neuroglobin translocation to mitochondria depends upon non-mutated huntingtin. Mutated huntingtin impairs estradiol-induced regulation of neuroglobin and dampens its induced anti-apoptotic actions. Co-stimulation of cells with BDNF and estradiol further increases neuroglobin upregulation.

Estradiol increases autophagy in human retinal pigment epithelial cells exposed to hydrogen peroxide.

Estradiol induces activation of MAPK signaling and upregulation of Bcl-2 expression in dopaminergic neurons. Estradiol preserves neuroglobin levels in astrocytes stimulated with LPS. Blockade of estrogen receptors abolishes estradiol actions on neuroglobin levels. DPN mimics estradiol effects on neuroglobin expression, suggesting an involvement of ER $\beta$. Estradiol reduces IL6 and IP-10 mRNA and protein levels in astrocytes stimulated with LPS

Estradiol increases Hsp70 and IL-10 in astrocytes from male and female pups. Estradiol attenuates pJNK, and TNFa in male astrocytes, but not females, demonstrating a sex dimorphic effect.

Estradiol increases GLT1 and GLAST in primary astrocytes, thus decreasing extracellular glutamate levels. The effect is mediated by GPER.

Glutamate induces a 50\% reduction in phosphatase PP1 levels and estradiol prevents the significant drop in PP1, PP2A, and calcineurin protein levels. Estradiol reduces the decreased PP2 activity induced by glutamate in cortical neurons
Selected references

Slowik et al. (2018)

Zhao et al. (2016)

Guo et al. (2012)

Na et al. (2015)

Rao et al. (2011)

Avila-Rodriguez

et al. $(2014,2016)$

Guerra et al. (2004)

Yao et al. (2007)

Yun et al. (2018)

Luciani et al. (2008,

2012)

Liu et al. (2011)

Nuzzo et al. (2017)

Wei et al. (2018)

Wang et al. (2011)

De Marinis et al.

(2013)

Cerciat et al. (2010)

Frago et al. (2017)

Lee et al. (2012) and

Karki et al. (2014)

Yi and Simpkins

(2008)

(continued on next page) 
Table 1 (continued)

\begin{tabular}{|c|c|c|c|}
\hline Injury model & Cell type & Protective mechanisms & Selected references \\
\hline & $\begin{array}{l}\text { Primary neurons from embryonic day } 18 \\
\text { Sprague-Dawley rat fetuses }\end{array}$ & $\begin{array}{l}\text { Estradiol attenuates neuronal death by excitotoxicity and } \\
\text { apoptotic mechanisms by regulating intracellular calcium } \\
\text { levels. }\end{array}$ & $\begin{array}{l}\text { Zhao and Brinton } \\
\text { et al. (2007) }\end{array}$ \\
\hline & & Estradiol inhibits L-type $\mathrm{Ca}^{2+}$ channel and $\mathrm{Ca}^{2+}$ influx. & Sribnick et al. (2009) \\
\hline $\begin{array}{l}\text { AMPA toxicity and serum } \\
\text { deprivation }\end{array}$ & $\begin{array}{l}\text { Primary astrocytes from spinal cord of } 1-3 \text {-day- } \\
\text { old Sprague-Dawley rats and Cultures of } \\
\text { enriched spinal cord motoneurons }\end{array}$ & $\begin{array}{l}\text { Astrocytic GDNF release, induced by pretreatment with } \\
\text { estradiol, protects spinal cord motoneurons from AMPA- } \\
\text { induced death. }\end{array}$ & Platania et al. (2005) \\
\hline Serum deprivation & $\begin{array}{l}\text { E15 Primary neuronal cultures from fetal rat } \\
\text { hypothalamus }\end{array}$ & $\begin{array}{l}\text { Either IGF-1 or estradiol increase the number of MAP-2 } \\
\text { immunoreactive neurons and neuritic processes. Blockade of } \\
\text { IGF-1 dampens neuroprotective actions of estradiol and } \\
\text { inhibition of estrogen receptors blocks IGF-1 protective effects, } \\
\text { suggesting a crosstalk between both signaling mechanisms. }\end{array}$ & Duenas et al. (1996) \\
\hline
\end{tabular}

neuroprotective actions of estradiol with aging or after a long period of estrogen deprivation (Azcoitia et al., 2011). Therefore, a better understanding on the molecular and cellular mechanisms of estradiol is still necessary to develop improved estrogenic neuroprotective therapies.

Recent papers have reviewed the neuroprotective actions of sex hormones and related synthetic steroids in different central nervous system (CNS) pathologies (Elkabes and Nicot, 2014; Engler-Chiurazzi et al., 2017: Baez-Jurado et al., 2018; Céspedes Rubio et al., 2018; Bourque et al., 2019; Kulkarni et al., 2019; Sohrabji et al., 2019), including some of the specific molecular neuroprotective mechanisms activated by estradiol (Arevalo et al., 2015; Sohrabji, 2015; LabandeiraGarcia et al., 2016; Zup and Madden, 2016; Marin and Diaz, 2018; Thakkar et al., 2018) and the role played by glial cells on the neuroprotective mechanisms of the hormone (Karki et al., 2014; AcazFonseca et al., 2016; Kipp et al., 2016; Martin-Jimenez et al., 2019). Another important issue that has been considered in recent years is the neuroprotective role of estradiol locally synthesized in the CNS (Pedersen et al., 2018; Brocca and Garcia-Segura, 2018). However, it is still necessary to integrate the molecular mechanisms activated by estradiol from central and peripheral origin with the subcellular, cellular and tissue events involved in the neuroprotective and reparative actions of the hormone. In addition, most of the studies dealing with the molecular and cellular mechanisms that mediate neuroprotection by estradiol have been conducted in either male or female animals or in unsexed culture systems. However, the limited available evidence suggests that estradiol has not the same neuroprotective actions in males and females. Therefore, it is important to consider the variable sex in the analysis of the neuroprotective mechanisms of estradiol. In consequence, our aim here is to integrate the reported molecular mechanisms activated by estradiol with the subcellular, cellular and tissue events that participate in the protective and reparative actions of the hormone and to discuss the role of sex differences in these mechanisms.

\section{Molecular mechanism involved in the neuroprotective actions of estradiol}

\subsection{Nuclear- and membrane-initiated estrogen signaling}

As in other body organs, estradiol signaling in the nervous system is mediated by classical ERs, ER $\alpha$ and ER $\beta$, located in the cell nucleus, by ERs located in the plasma membrane or the cytoplasm, including ER $\alpha$, ER $\beta$ and G protein-coupled estrogen receptor-1 (GPER) and by ER independent signaling mechanisms. ERs located in the plasma membrane or the cytoplasm modify the activation of different kinases and phosphatases and other signaling molecules in the nervous system and interact with the signaling pathways of membrane receptors, such as insulin-like growth factor-1 (IGF-1), Wnt and Notch signaling (Fig. 1). In parallel to membrane and cytoplasmic actions, or as a consequence of the activation of membrane or cytoplasm initiated signaling, estradiol regulates transcriptional activity in neurons, glial cells and other cellular elements of the nervous system through nuclear ERs and through other transcription factors, such as nuclear factor kappa-lightchain-enhancer of activated B cells (NFKB), signal transducer and activation of transcription (STAT3) or cAMP response element binding protein (CREB) (Fig. 1). Additional molecules, such as microRNAs (miRNAs), also participate in the transcriptional regulation exerted by estradiol in the brain (Fig. 1).

The transcriptional activity of estradiol results in the regulation of the expression of several neurotrophic and neuroprotective factors, such as neuroglobin, huntingtin, cocaine-and amphetamine-regulated transcript (CART), IGF-1, brain derived neurotrophic factor (BDNF), hypoxia-inducible factor $1 \alpha$ (HIF-1 $\alpha$ ), vascular endothelial growth factor (VEGF), transforming growth factor $\alpha$ (TGF $\alpha)$ and $\beta$ (TGF $\beta$ ) and glial derived neurotrophic factor (GDNF). Estradiol also regulates in neural cells the expression of molecules regulating apoptosis and enzymes involved in cholesterol synthesis or in endocannabinoid metabolism. All these molecular mechanisms regulated by estradiol (Fig. 1), which are exerted in parallel in different neural cell types, participate in the protective actions of the hormone in the nervous system and are reviewed in the following subsections.

\subsubsection{Estrogen receptors $\alpha$ and $\beta$}

ER $\alpha$ and ER $\beta$ are encoded by two different genes, but present some overlapping sequence homology. They are transcription factors that, after being activated by estradiol, directly regulate transcription of target genes by binding to estrogen response elements in their promoters. Unliganded ER $\alpha$ and ER $\beta$ are also activated by protein-kinase signaling pathways and regulate transcription in absence of estradiol activation (Marino et al., 2006). In addition, ER $\alpha$ and ER $\beta$ regulate transcription by interacting with other transcription factors, such as activator protein 1 (AP-1), STAT3, activation transcription factor 2 (ATF-2), transcription factor Sp1 and NFkB (Marino et al., 2006).

Furthermore, ER $\alpha$ and ER $\beta$ are localized in the cytoplasm or the plasma membrane, where they interact with the kinases of different membrane-initiated signaling pathways. In the plasma membrane, ERs are localized in specific domains, the lipid rafts, in which different receptors and signaling proteins are integrated (Marin et al., 2013). This allows the interaction of ERs with other neuroprotective signaling pathways (Marin et al., 2013). Membrane-initiated estrogen signaling is also mediated by the interaction of membrane ERs with G-protein coupled receptors, such as group I mGluRs or group II mGluRs, associated to Gq and Gi/o, respectively, or by GPER (see Section 2.1.2).

The role of ER $\alpha$ in the mediation of the neuroprotective actions of 
Table 2

Examples of neuroprotective mechanisms of estradiol in in vivo models.

\begin{tabular}{l} 
Animal/Injury model \\
\hline 3-months old female Wistar albino rats subject \\
to ovariectomy \\
2-3 months old and 16 months old Sprague- \\
Dawley female rats subject to \\
ovariectomy \\
\\
4-week old Wistar albino female rats ip \\
injected with kainic acid \\
\\
Ovariectomized Sprague Dawley rats subject \\
to transient middle cerebral artery \\
occlusion (MCAO) \\
Adult male Sprague-Dawley rats subject to \\
MCAO \\
Adult male and female rats exposed to \\
bilateral common artery occlusion or \\
MCAO
\end{tabular}

Hippocampus: Hilar interneurons

Ipsi and contralatera ischemic brain hemispheres

Hippocampus and cortex

Hippocampus

Cerebral cortex

6-weeks old female Sprague Dawley rats subject to global ischemia

Female Sprague Dawley rats subject to global ischemia

3-months-old female Sprague Dawley rats subject to global ischemia

4-6 months old C57BL/6 mice subject to global ischemia

Perinatal asphyxia in rats

Traumatic brain injury. 3-months old female Sprague Dawley rats

Male and female adult zebra finches subject to Brain penetrating brain injury

Wistar albino female and male rats subject to penetrating brain injury

14-week old male Wistar rats subject to spinal Spinal cord cord injury
Protective mechanisms

Estradiol inhibits calcium influx, thus attenuating the rise in intracellular calcium, by actions on TRPM2, TRPV1 and TRPA1. Estradiol and activation of G-protein coupled receptor exhibits antidepressant and anxiolytic effects in ovariectomized aged rats. Activation of GPER, using G-1, improves mitochondrial function in the aged hippocampus by preserving mitochondrial membrane potential and antioxidant activity. Activation of GPER augments Bcl-2 and UCP2 levels in the hippocampus of aged animals.

Estradiol protects hilar interneurons in kainic acid injected rats. Coadministration of estradiol with kainic acid improves neuronal survival, a similar outcome when animals are injected with IGF-1. The inhibition of ERs prevented the neuroprotective action of IGF-1 and the inhibition of IGF-1 receptor prevented the neuroprotective action of estradiol.

Estradiol prevents the decrease in phosphatases PP1, PP2A and calcineurin.

Estradiol increases neurogenesis, HIF-1 $\alpha$ and VEGF in the subventricular zone.

Estradiol increases synaptic proteins such as synaptophysin and PSD95 and also the number of dendrites in both CA1 hippocampal region in male and cerebral cortex of ovariectomized female rats.

Targeting miR181a protects female mice from MCAO, and these effects were mediated by ERa.

Treatment with estradiol induces upregulation of cocaine- and amphetamine-regulated transcript (CART) in the cerebral cortex of ischemic animals. Upregulation of CART by estradiol reduces cell death and DNA damage by a mechanism mediated through CREB. Global ischemia induces an increased phosphorylation of STAT3 in CA1, and estradiol further augments its phosphorylation levels in the postischemic CA1. Blockage of STAT3 dampens estradiol-induced protection of CA1 neurons following global ischemia. Silencing of surviving, an antiapoptotic gene regulated by STAT3, abolishes the neuroprotective action of estradiol.

Endogenous and exogenous estradiol protect the CA1 neurons in rats following global ischemia. Estradiol increases phosphorylation of CREB, CAMKII and MAPK.

Estradiol increases the number of $\mathrm{NeuN}^{+}$neurons and the levels of pAkt and pERK and decreased p-JNK levels, in CA1. Akt or ERK inhibitors prevent the neuroprotective action of estradiol. pCREB induction by estradiol was followed by increased BDNF levels in CA1. Estradiol regulates the activation and morphological changes of Iba-1 positive microglia and induces a more M2-like anti-inflammatory microglia phenotype in the hippocampus.

Estradiol attenuates neuronal death and infarct in ischemic animals through ER $\alpha$. These actions of estradiol include reduced superoxide production, and NADPH oxidase activation possibly by a Rac1 signaling mechanism.

Proline-, glutamic acid-, and leucine-rich protein 1 (PELP1), a coregulator of ERs, is critical in mediating estradiol extranuclear protective actions in ischemic animals.

Estradiol treated adult animals subject to perinatal asphyxia show an increase in ER $\alpha$ expression, attenuated anti-apoptotic levels, decreased dendritic alterations, activation of PI3K/Akt/GSK3ß/ $\beta$-catenin signaling and an increase in $\mathrm{Bcl} 2 / \mathrm{Bax}$ ratio in the hippocampus. Estradiol activates ERK and PI3K/AKT and promotes cell survival. Estradiol induces ER $\alpha$ expression and surviving mRNA and attenuates caspase 3 activation.

Brain injury induces NFkB mRNA levels in both male and female zebra finches, regardless the sex or time after injury. Treatment with an aromatase inhibitor (fadrozole) after brain injury induces IkB expression in male, but not in females, and increases IL-1 $\beta$ and IL- 6 expression in both male and females.

Estradiol and the SERMs raloxifene and tamoxifen attenuate reactive astroglia and microglia in the cortex of castrated young and aged rats in comparison to sham animals.

Estradiol lowers glial scar density nearby the wound. Estradiol restores monoacylglycerol lipase and $\mathrm{N}$-acyl phosphatidylethanolamine phospholipase D mRNA levels in the injured cortex. In presence of estradiol, cannabinoid receptors (CB2) are upregulated in the injured cortex.

Estradiol improves behavior and attenuates inflammation and inflammasome parameters in spinal cord injured animals.
Selected references

Yazğan et al. (2017)

Wang et al. (2018)

Azcoitia et al. (1998, 1999)

Yi and Simpkins (2008)

Zheng et al. (2013)

Zhu et al. (2017) and

Khan et al. (2015)

Stary et al. (2017)

Xu et al. (2006)

Sehara et al. (2013)

Raval et al. (2009)

Yang et al. (2010)

Thakkar et al. (2016)

Zhang et al. (2009)

Sareddy et al. (2015)

Saraceno et al. (2018)

Bao et al. (2011)

Cook et al. (2018)

Barreto et al. (2009, 2014)

López Rodríguez et al. (2011)

Zendedel et al. (2018)

(continued on next page) 
Table 2 (continued)

\begin{tabular}{|c|c|c|c|}
\hline Animal/Injury model & CNS region & Protective mechanisms & Selected references \\
\hline $\begin{array}{l}\text { 8-weeks old C57BL-6 female mice subject to } \\
\text { MPTP }\end{array}$ & $\begin{array}{l}\text { Ventral midbrain including the } \\
\text { substantia nigra compacta }\end{array}$ & $\begin{array}{l}\text { MPTP treatment augments dopaminergic neuron death, reduced } \\
\text { dopamine and DOPAC levels in the striatum of ovariectomized mice. } \\
\text { Estradiol reduces Rho activity and mRNA levels, as well as Rock II } \\
\text { mRNA in the nigral region of ovariectomized mice. Estradiol action on } \\
\text { reducing RhoA/Rock activity is associated with the blockage of } \\
\text { angiotensin type } 1 \text { receptors. }\end{array}$ & $\begin{array}{l}\text { Rodriguez-Perez et al. } \\
\text { (2013) }\end{array}$ \\
\hline \multirow[t]{2}{*}{$\begin{array}{l}\text { 10-14 weeks-old C57Bl/6 male mice subject } \\
\text { to MPTP }\end{array}$} & Substantia nigra & $\begin{array}{l}\text { Estradiol increases SOD2 activity and SOD2 immunoreactivity and } \\
\text { reduces nitrotyrosine levels in the substantia nigra. MPTP treatment } \\
\text { reduces Akt/GSK3 } \beta \text { phosphorylation and estradiol prevents this } \\
\text { reduction, possibly through activation of ER } \alpha \text {. }\end{array}$ & $\begin{array}{l}\text { Tripanichkul et al. } \\
\text { (2013) }\end{array}$ \\
\hline & Striatum & $\begin{array}{l}\text { Pre-treatment with estradiol activates increases IGF-1 receptor } \\
\text { expression and PI3K/Akt/GSK3 } \beta \text { signaling. Estradiol, or the ER } \alpha \\
\text { agonist PPT, prevents the decrease in Bcl } 2 / \text { Bad ratio, oxidative stress } \\
\text { and dopaminergic loss induced by MPTP in the striatum. }\end{array}$ & D'Astous et al. (2006) \\
\hline $\begin{array}{l}\text { Adult male Wistar rats subject to intra-striatal } \\
\text { 6-OHDA injection }\end{array}$ & & $\begin{array}{l}\text { Estradiol favors the upregulation of GDNF in the substantia nigra, and } \\
\text { this finding is corroborated in neuron-glia cultures. }\end{array}$ & Campos et al. (2012) \\
\hline $\begin{array}{l}\text { 6-weeks old female Sprague Dawley rats or } \\
\text { C57/B6 mice treated with LPS (icv) }\end{array}$ & Cerebral cortex & $\begin{array}{l}\text { Estradiol attenuates microglia reactivity and mRNA levels of MCP-1, } \\
\text { MIP-2 and TNF- } \alpha \text { in the cerebral cortex of animals treated with LPS. }\end{array}$ & Vegeto et al. (2006) \\
\hline $\begin{array}{l}\text { 9-weeks old female ICR mice infused with } \\
\text { A } \beta 1-42\end{array}$ & $\begin{array}{l}\text { Hippocampus - } \\
\text { Astrocytes } \\
\text { Microglia }\end{array}$ & $\begin{array}{l}\text { Estrogen deficiency (ovariectomized mice) leads to increased memory } \\
\text { impairment and A } \beta 1-42 \text { treated animals presented an augmented } \\
\text { latency in the passive avoidance test. More neuronal death in the CA3, } \\
\text { and higher levels of iNOS, GFAP, Iba1, neprilysin, BACE1, and } \\
\text { amyloidogenesis in the hippocampus of ovariectomized and A } \beta 1-42 \\
\text { treated animals. }\end{array}$ & Yun et al. (2018) \\
\hline $\begin{array}{l}\text { Spontaneously hypertensive 5-months old } \\
\text { male Wistar-Kyoto (WKY) rats }\end{array}$ & Hippocampus & $\begin{array}{l}\text { Estradiol upregulates aromatase, increases the number of dendritic } \\
\text { spines in CA1, the number of doublecortin and proliferating cells and } \\
\text { BDNF mRNA levels and reduces astrogliosis in the hippocampus of } \\
\text { hypertensive rats. }\end{array}$ & Pietranera et al. (2015) \\
\hline $\begin{array}{l}\text { 2-months-old female Wistar rats treated with } \\
\text { trimethyltin }\end{array}$ & Hippocampus & $\begin{array}{l}\text { Estradiol upregulates genes involved in neuroprotection (Bcl2, Bdnf, } \\
\text { trkB) and synaptogenesis (Cdk5 and Cdh2) in the hippocampus of } \\
\text { trimethyltin-treated animals. Estradiol also upregulates markers of } \\
\text { interneurons (glutamic acid decarboxylase } 67 \text {, neuropeptide Y and } \\
\text { parvalbumin. }\end{array}$ & Corvino et al. (2015) \\
\hline $\begin{array}{l}\text { 6-7 months female SD rats subject to blue } \\
\text { light-emitting diode-induced retinal } \\
\text { degeneration }\end{array}$ & Retina & $\begin{array}{l}\text { Pretreatment with estradiol reduces retinal damage by reducing } \\
\text { aopotosis (downregulation of Bax) and increasing autophagy. }\end{array}$ & Wei et al. (2018) \\
\hline $\begin{array}{l}\text { Female C57BL/ } 6 \text { immunized with myelin } \\
\text { oligodendrocyte glycoprotein } \\
\text { (experimental model of EAE) }\end{array}$ & Spinal cord & $\begin{array}{l}\text { Estradiol acting on ER } \alpha \text { in astrocytes induces anti-inflammatory and } \\
\text { neuroprotective action in experimental autoimmune encephalomyelitis } \\
\text { (EAE) in vivo model. }\end{array}$ & Spence et al. (2013) \\
\hline
\end{tabular}

estradiol in different brain injury models is well established. These include cellular and animal models of focal and global ischemia (Suzuki et al., 2009; Zhang et al., 2009, 2017; Guo et al., 2012; Tables 1 and 2), chronic hypertension (Pietranera et al., 2016), Parkinsońs disease (Morissette et al., 2008; Al Sweidi et al., 2012), Alzheimer's disease (Guerra et al., 2004; Table 1) and multiple sclerosis (J. Feng et al., 2013; Spence et al., 2013; Table 2; Fig. 2). In addition to its role as transcription factor, ER $\alpha$ exerts neuroprotective actions by activating membrane-initiated signaling. In response to estradiol, ER $\alpha$ interacts in the brain with the $\mathrm{p} 85$ subunit of the phosphoinositide 3 (PI3) kinase to activate the PI3K/Akt neuroprotective signaling pathway (Mendez et al., 2006; Mannella and Brinton, 2006; Wang et al., 2006). This interaction may happen in the neuronal plasma membrane where ER $\alpha$ forms a macromolecular complex with caveolin-1 and voltage-dependent anion channel (VDAC) in the lipid rafts (Marin et al., 2013). Estradiol inactivates VDAC through protein kinase A and Src-kinase and this mechanism may mediate protective actions of the hormone against $\beta$-amyloid-induced neurotoxicity (Marin et al., 2013). One protein interacting with $\mathrm{ER} \alpha$, Src and the p85 subunit of the PI3K is proline-, glutamic acid- and leucine-rich protein 1 (PELP1) (Sareddy et al., 2015; Thakkar et al., 2018; Table 2). PELP1 is a multi-domain scaffold protein and acts as an ER coregulatory factor that facilitates ER-mediated transcription. Studies from Brann's laboratory have shown that PELP1 plays a critical role in neuroprotective and anti-inflammatory estradiol signaling (Sareddy et al., 2015; Thakkar et al., 2018; Table 2).

ER $\beta$ also participates in the neuroprotective actions of estradiol (Fig. 2). This has been demonstrated using ER $\beta$ KO mice, for instance in the 1-methyl-4-phenyl-1,2,3,6-tetrahydropyridine (МРTP) mouse model of Parkinson's disease (Al Sweidi et al., 2012). Other studies have shown the neuroprotective actions of selective ER $\beta$ agonists. Thus, the selective ER $\beta$ ligand, AC-186, is neuroprotective in a Parkinson model induced by 6-hydroxydopamine injections in the substantia nigra in male rats (McFarland et al., 2013). The selective ER $\beta$ agonist diarylpropionitrile (DPN) reduces brain damage after transient middle cerebral artery occlusion (MCAO) model of stroke (Connell and Saleh, 2011) and after bilateral carotid artery occlusion, a model of global ischemia (Carswell et al., 2004). The selective ER $\beta$ agonist WAY 200,070 is also neuroprotective in transient global cerebral ischemia (Miller et al., 2005) and the specific ERß ligand 4-(1-phenyl-cyclohexyl)-phenol (AC-131) has been shown to exert neuroprotective actions in a model of focal stroke in rats (Madinier et al., 2014). The ER $\beta$ selective agonist DPN is neuroprotective in the hippocampus of chronic hypertensive rats (Pietranera et al., 2016) and increases GFAP expression in astrocytes and decreases neuronal apoptosis in co-cultures of astrocytes and neurons exposed to oxygen glucose deprivation and reperfusion (Ma et al., 2016). Protective actions of DPN and other ER $\beta$ ligands, such has indazole-Cl and WAY-202041, have been also characterized in mouse models of multiple sclerosis, where they stimulate endogenous myelination and functional recovery (Atkinson et al., 2019; Khalaj et al., 2016; Karim et al., 2018, 2019) (see also Section 4.8). Furthermore, ER $\beta$ expressed in astrocytes mediates the protective effect of estradiol on neurons exposed to oxygen-glucose deprivation and reperfusion (Ma et al., 2016) and ER $\beta$ regulates inflammasome activation and protects from global cerebral ischemia in senescent female rats (de Rivero-Vaccari et al., 2016). 


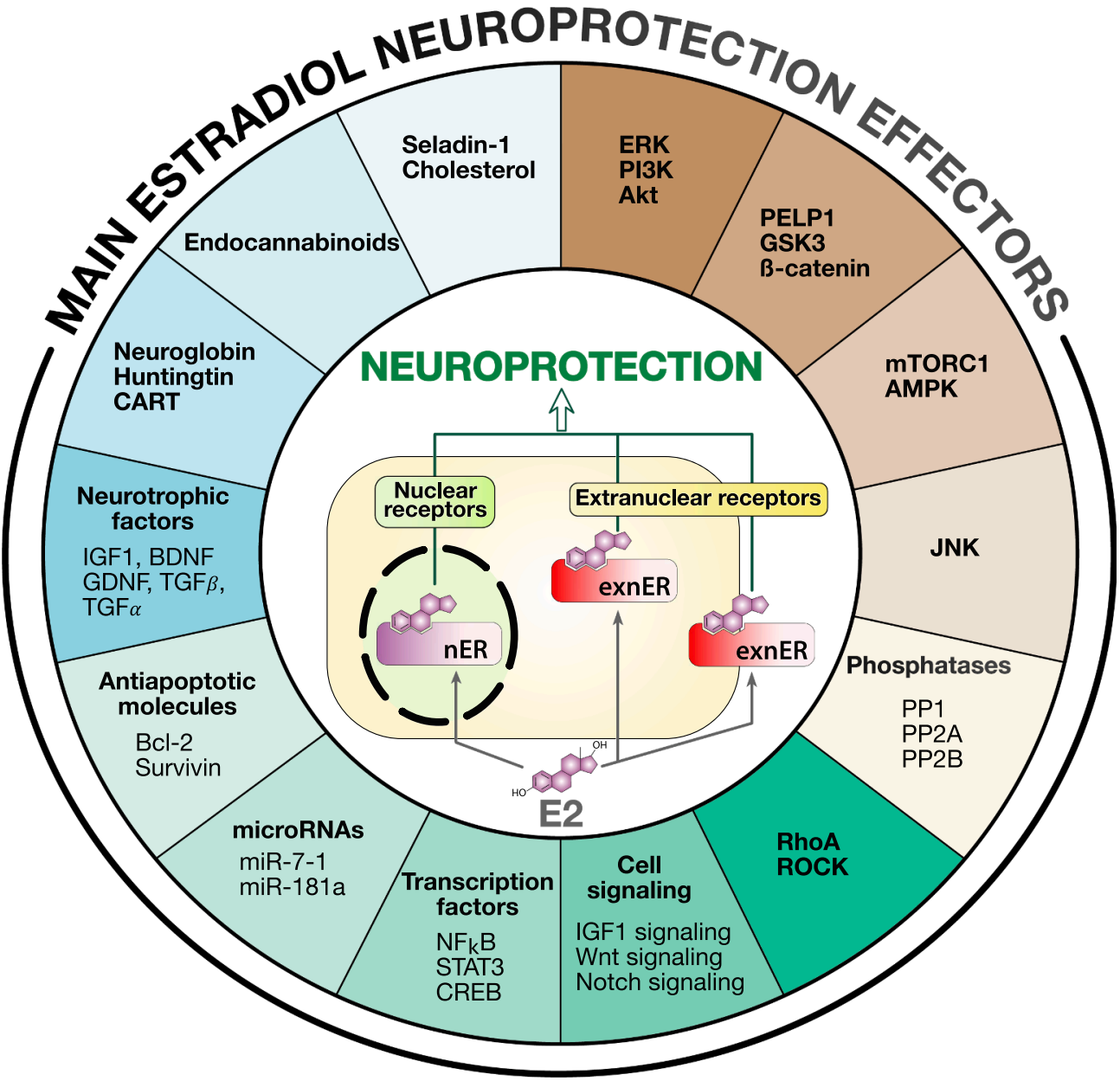

Fig. 1. Main molecular components of neuroprotective estradiol signaling. The protective signaling mechanism of estradiol (E2) in the nervous system are initiated by extranuclear estrogen receptors (exnER) located in the plasma membrane or the cytoplasm and by nuclear receptors (nER), which act as transcription factors. exnERs modify the activation of different kinases, such as ERK, PI3K, Akt, GSK3ß, AMPK and JNK, phosphatases, such as PP1, PP2A and PP2B, and other signaling molecules, such as $\beta$-catenin, mTORC1, RhoA, ROCK and the ER coactivator PELP1. exnERs also interact with other signaling pathways, such as IGF-1, Wnt and Notch signaling. In addition to nERs, other transcription factors, such as NFKB, STAT3 or CREB, and microRNAs, such as miR-7-1 and miR-181a, are involved in the transcriptional regulation induced by estradiol. By the activation of exnERs and nERs, estradiol regulates in the brain the transcription of antiapoptotic molecules, such as Bcl-2 and survivin, the expression of several neurotrophic and neuroprotective proteins, such as IGF-1, BDNF, HIF- $1 \alpha$, VEGF, TGF $\alpha$, TGF $\beta$, GDNF, neuroglobin, huntingtin and CART, and the expression of molecules involved in endocannabinoid signaling and metabolism or in cholesterol synthesis, such as seladin-1. All these molecular mediators participate in the neuroprotective actions of estradiol.

\subsubsection{GPER}

After the identification of GPER as a membrane receptor mediating the actions of estradiol (Srivastava and Evans, 2013), numerous studies have examined its role in the neuroprotective mechanisms of the hormone (Tables 1 and 2; Fig. 2). For instance, it has been shown that GPER mediates protective actions of estradiol in cultured cortical neurons exposed to oxidative stress (Liu et al., 2011; Table 1), in primary hippocampal neurons and in rat motoneurons exposed to oxygenglucose deprivation (Chen et al., 2015; Zhao et al., 2016; Table 1), in primary mouse cortical cultures exposed to NMDA (S.B. Liu et al., 2012) and in dopaminergic neurons of mesencephalic cultures exposed to MPP(+) (Bessa et al., 2015). Furthermore, GPER mediates the upregulation of the expression of the glutamate transporter GLT-1 and the uptake of glutamate in astrocytes (Lee et al., 2012; Table 1), which may decrease excitotoxic neural damage (see Section 4.3).

In vivo studies have shown that the GPER agonist G1 upregulates the expression of ER $\alpha, E R \beta$ and GPER in the hippocampus of aged female rats and counteracts the effects of aging on anxiety and depressive behavior in these animals (J. Wang et al., 2018). GPER is also involved in the neuroprotective actions of estradiol in focal and global ischemia models in male and female rodents (Zhang et al., 2010, 2018; S.B. Liu et al., 2011, 2012; Céspedes Rubio et al., 2018). For instance, G1 and the non-classical ER ligand STX protect against hippocampal neuronal loss induced by ischemia in middle-aged female rats (Lebesque et al., 2010). G1 also decreases infarct size after cerebral artery occlusion in ovariectomized mice (Zhang et al., 2010) and exerts anti-inflammatory effects in the MCAO mouse model of stroke, reducing infarction volume and the release of TNF- $\alpha$, IL- $1 \beta$, and IL- 6 in the ischemic penumbra (Zhang et al., 2018). GPER is also involved in the neuroprotective actions of estradiol on traumatic brain injury in adult male rats (Day et al.,
2013) and in the MPTP mouse model of Parkinson's disease (Bourque et al., 2015). GPER activation is also neuroprotective in the brain of ovariectomized aged rats (Wang et al., 2018; Table 2). The neuroprotective mechanisms of action of GPER can be integrated in the signaling of the classical ERs, since it has been shown that ER $\alpha$ requires GPER to mediate neuroprotective actions of estradiol on dopaminergic neurons in a mouse model of Parkinson's disease (Bourque et al., 2015).

\section{2. $E R K$}

The mitogen-activated protein kinase (MAPK)/extracellular signalregulated kinases (ERK) signaling pathway has been shown to participate in the neuroprotective mechanisms of estradiol in numerous experimental models of neurodegenerative diseases. This signaling pathway is activated by estradiol and is involved in the protective actions of the hormone in septal derived cholinergic cells exposed to $\beta$ amyloid (Guerra et al., 2004; Table 1), in hippocampal neurons exposed to glutamate (Zhao and Brinton, 2007), in cortical neurons exposed to oxidative damage (Liu et al., 2011), in the hippocampus of male rats treated with quinolinic acid (Kuroki et al., 2001) and in in vivo experimental models of brain ischemia (Wang et al., 2006; Zhang et al., 2008; Yang et al., 2010; Table 2) and traumatic brain injury (Bao et al., 2011; Table 2), among others. The activation of ERK by estradiol is associated with the inhibition of neurodegenerative signaling, such as JNK (see Section 2.4). For instance, in the hippocampus, estradiol protects CA1 neurons from global ischemia by a mechanism involving ERK activation and the inhibition of JNK (Yang et al., 2010; Table 2). 


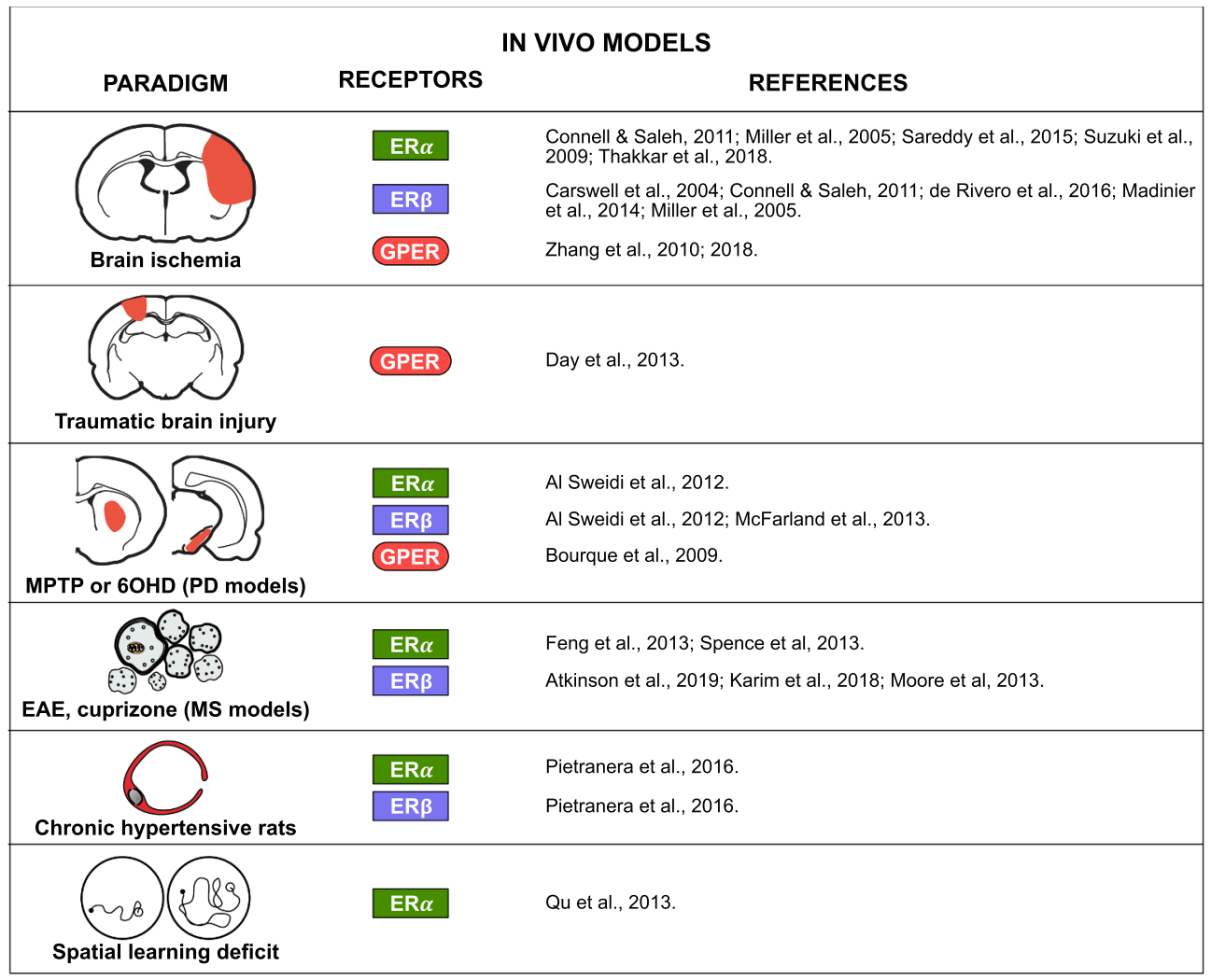

\begin{tabular}{|c|c|c|}
\hline \multicolumn{3}{|c|}{ IN VITRO MODELS } \\
\hline PARADIGM & RECEPTORS & REFERENCES \\
\hline \multirow{3}{*}{$\begin{array}{c}\text { Ischemia (oxygen/glucose } \\
\text { deprivation }\end{array}$} & ER $\alpha$ & Guo et al., 2012. \\
\hline & $E R \beta$ & Ma et al., 2016. \\
\hline & GPER & Chen et al., 2015; Zhao et al., 2016. \\
\hline Excitotoxicity (Glu) & GPER & Lee et al., 2012; Liu et al., 2012. \\
\hline Oxydative damage $\left(\mathrm{H}_{2} \mathrm{O}_{2}\right)$ & GPER & Liu et al., 2011. \\
\hline PD model (MPP+) & GPER & Bessa et al., 2015. \\
\hline AD model ( $\beta$-amyloid) & ER $\alpha$ & Guerra et al., 2004; Marin et al., 2013. \\
\hline
\end{tabular}

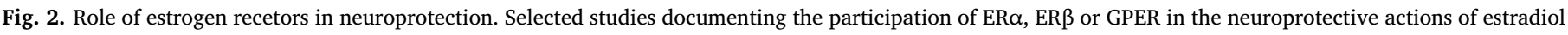
or selective ER ligands.

\section{3. $P I 3 K / A k t$}

We have already mentioned (Section 2.1.1) that estradiol induces the interaction of ER $\alpha$ and the p85 subunit of the PI3K in the brain to activate the PI3K/Akt signaling pathway (Mendez et al., 2006; Mannella and Brinton, 2006; Wang et al., 2006). PI3K/Akt signaling is also activated by estradiol in primary hippocampal neurons through GPER and the inhibition of Notch signaling (Arevalo et al., 2015) and by the ER $\beta$ ligand DPN in the corpus callosum in vivo, in a mouse model of multiple sclerosis (Kumar et al., 2013). Since PI3K/Akt activates survival mechanisms in a variety of cell types, this kinase signaling pathway may be one of the main mediators of the protective actions of estradiol in the nervous system. Indeed, activation of PI3K/Akt signaling by estradiol is associated with the neuroprotective actions of the hormone in the pericontusional region of the cerebral cortex after traumatic brain injury (Bao et al., 2011; Table 2). PI3K/Akt signaling is also involved in the neuroprotective actions of the hormone in the MPTP mouse model of Parkinson's disease (D'Astous et al., 2006;
Morissette et al., 2008; Al Sweidi et al., 2012; Table 2), in models of retinal neuron degeneration (Yu et al., 2004), in rat models of global cerebral ischemia (Wang et al., 2006; Zhang et al., 2008; Yang et al., 2010; Table 2) and in a rat model of perinatal asphyxia (Saraceno et al., 2018; Table 2). Furthermore, the PI3K/Akt signaling pathway mediates the release of the neuroprotective factor TFG $\beta$ by astrocytes in response to estradiol (Dhandapani et al., 2005).

One of the main targets of the neuroprotective mechanisms of estradiol is the regulation of apoptosis (see Section 4.5). Apoptosis is inhibited by the PI3K/Akt signaling pathway, which may therefore mediate the anti-apoptotic actions of estradiol. In fact, the involvement of this pathway in the prevention of apoptosis by estradiol has been demonstrated in primary cortical neurons exposed to ketamine (R. Li et al., 2013) or staurosporine (Honda et al., 2001), in retinal cells exposed to oxidative damage (Y. Feng et al., 2013) and in motoneurons exposed to oxygen glucose deprivation (Chen et al., 2015) or to a neuroinflammatory challenge (Smith et al., 2009). Furthermore, the activation of PI3K signaling by estradiol is associated with the 
upregulation of the anti-apoptotic Bcl-2 gene or with the increase in the ratio of expression of anti-apoptotic and pro-apoptotic genes, such as $\mathrm{Bcl}-2 / \mathrm{Bax}$ or $\mathrm{Bcl}-2 / \mathrm{Bad}$ ratio, in organotypic mesencephalic cultures (Wang et al., 2011; Table 1), in the hippocampus of animals exposed to perinatal asphyxia (Saraceno et al., 2018; Table 2) and in the striatum in a mouse Parkinson's disease model (D'Astous et al., 2006; Table 2).

\subsection{JNK}

In addition to activate neuroprotective kinases, such as PI3K/Akt, estradiol inhibits the activity of kinases that promote neurodegeneration, such as c-Jun N-terminal kinases (JNKs). JNKs are involved in the mediation of stress stimuli and the initiation of apoptosis. Its inhibition by estradiol mediates the neuroprotective action of the hormone in different brain injury models. Thus, estradiol decreases JNK phosphorylation induced by $\beta$-amyloid in primary rat cerebrocortical neurons (Yao et al., 2007), in rat neuronal cortical cells exposed to glutamate (Rong et al., 2012), in the brain of neonatal rats exposed to ethanol (Khan et al., 2018) and in rat models of global cerebral ischemia (Wang et al., 2006; Zhang et al., 2008; Yang et al., 2010; Table 2).

In primary rat cortical neurons exposed to $\beta$-amyloid toxicity, the inhibition of JNK by estradiol is associated with the attenuation of cytochrome $c$ release by the mitochondria and the upregulation of the expression of the antiapoptotic molecule Bcl-2 (Yao et al., 2007; Table 1). The inhibition of JNK by estradiol in the rat hippocampus prevents Wnt/ $\beta$-catenin signaling antagonist Dickkopf-1 elevation after global cerebral ischemia (Wang et al., 2006; Zhang et al., 2008). This enhances neuroprotection mediated by Wnt/ $\beta$-catenin signaling pathway (see next section).

\subsection{PELP1, Wnt, GSK3 $\beta$ and $\beta$-catenin}

Downstream of Akt, estradiol regulates the activity of glycogen synthase kinase $3 \beta$ (GSK3 $\beta$ ) and $\beta$-catenin in neurons (Wandosell et al., 2012; Sareddy et al., 2015; Saraceno et al., 2018; Table 2). Estradiol treatment results in the activation of Akt, which in turn phosphorylates and inhibits GSK3 $\beta$ and this results in the stabilization of $\beta$-catenin. This signaling mechanism is involved in the regulation of neuronal cytoskeleton and neuronal survival and mediates neuroprotective actions of estradiol. Indeed, the regulation of GSK3 $\beta / \beta$-catenin signaling is associated with the protective effects of the hormone in different models of neurodegenerative diseases, including Parkinson's disease, brain ischemia (D'Astous et al., 2006; Céspedes Rubio et al., 2018; Q.G. Zhang et al., 2018) and perinatal asphyxia (Saraceno et al., 2018) (see Table 2). Estradiol regulates GSK3 $\beta$ and $\beta$-catenin not only through PI3K/Akt but also through Wnt signaling (Mendez et al., 2006; Zhang et al., 2008; Wandosell et al., 2012).

In addition, the ER coregulatory factor PELP1, which is also involved in the neuroprotective mechanisms of estradiol (Sareddy et al., 2015; Thakkar et al., 2018), interacts with both ER $\alpha$, PI3K and GSK3 $\beta$ and increases Wnt/ $\beta$-catenin signaling (Sareddy et al., 2015). PELP1 modulates GSK3 $\beta$ activity and in turn GSK3 $\beta$ activity modulates PELP1 phosphorylation. Estradiol regulates PELP1 phosphorylation by regulating GSK3 $\beta$ activity and decreases the interaction of PELP1 and GSK3 $\beta$ (Sareddy et al., 2015; Table 2). All these findings suggest that PELP1, GSK3 $\beta$ and $\beta$-catenin are involved in the neuroprotective molecular mechanisms of estradiol.

\section{6. $m T O R C 1$ and $A M P K$}

Another factor downstream of ERK and PI3K is Mammalian Target of Rapamycin Complex-1 (mTORC1), a protein complex that activates protein translation. mTORC1 is regulated by growth factors that activate the PI3K/Akt signaling pathway, such as IGF-1 and BDNF (PerezAlvarez et al., 2018), which are involved in the neuroprotective mechanisms of estradiol (see Section 2.13). Estradiol activates the PI3K/Akt/mTORC1 pathway in neurons to promote neuritic growth and it has been proposed that MTORC1 may participate in the neuroprotective mechanisms of estradiol after brain ischemia (Perez-Alvarez et al., 2018) and in the remeyelination induced by the ER $\beta$ ligand DPN in an experimental mouse model of multiple sclerosis (Kumar et al., 2013). One of the best characterized functions of mTORC1 is to connect environmental cues, such as nutrient availability, with cellular homeostasis, including the inhibition of autophagy. Since the regulation of autophagy is involved in cell survival mechanisms, it is possible that the regulation of this cellular process by mTORC1 may contribute to the promotion of neuronal survival by estradiol. A key metabolic sensor that regulates mTORC1 and autophagy is AMP-activated protein kinase (AMPK). Interestingly, estradiol exerts neuroprotective actions in neurons exposed to oxygen-glucose deprivation through the activation of AMPK (Guo et al., 2017) and the inhibition of autophagy has been associated with neuroprotective effects of estradiol in animal models of spinal cord injury (Lin et al., 2016) and cerebral ischemia (Li et al., 2017). Therefore, the possible interaction of estradiol, AMPK, mTORC1 and autophagy as a mechanism involved in the neuroprotective actions of estradiol merits to be further explored in detail (see also Section 4.6).

\subsection{RhoA/ROCK}

Estradiol regulates actin cytoskeleton in many cell types, including neurons, through the small GTP-binding protein Rho (Ras homolog gene family, member A (RhoA)/RhoA kinase (ROCK) pathway. This signaling pathway participates in dendritic spine formation and memory and is also involved in the anti-inflammatory and neuroprotective effects of estradiol in the MPTP model of Parkinson's disease in ovariectomized mice (Rodriguez-Perez et al., 2013) and in experimental autoimmune encephalomyelitis, a rat model of multiple sclerosis ( $\mathrm{J}$. Feng et al., 2013). The inhibition of RhoA/ROCK activity by estradiol is associated with the blockage of angiotensin (AT) type 1 receptors (Rodriguez-Perez et al., 2013; Table 2). AT1 receptor activation enhances dopaminergic neuronal loss in the nigro-striatal system, while the inhibition of renin-angiotensin activity and the downregulation of AT1 receptors by estradiol are associated with anti-inflammatory and neuroprotective actions of the hormone in both male and female rats of the 6-hydroxidopamine model of Parkinsońs disease (Rodriguez-Perez et al., 2013; Table 2).

\subsection{Protein phosphatases}

The mediation of protein kinases in the neuroprotective actions of estradiol suggest that protein phosphatases, such as protein phosphatase (PP) 1, PP2A, PP2B, calcineurin and PTEN may also be involved in the neuroprotective mechanisms of the hormone. Indeed, it has been shown that estradiol prevents the decrease in the expression of PP1, PP2A and PP2B induced by transient middle cerebral artery occlusion in the injured brain tissue and by glutamate in primary rat cortical neurons (Yi and Simpkins, 2008; Tables 1 and 2). Furthermore, the inhibition of PP1, PP2A and calcineurin has been shown to partially impair hormonal protection against glutamate-induced excitotoxicity in vitro (Yi and Simpkins, 2008). On the other hand, estradiol has also been shown to down-regulate the expression of PTEN, an inhibitor of PI3K/Akt, allowing the phosphorylation and activation of Akt and the prevention of apoptosis in motoneurons exposed to a neuroinflammatory challenge (Smith et al., 2009). These findings suggest that an adequate function of protein phosphatases is necessary for the activation of the neuroprotective mechanisms of estradiol.

\section{9. $N F \kappa B$}

$\mathrm{NF} \kappa \mathrm{B}$ is a transcription factor that participates in numerous cell functions, including the regulation of the expression of molecules 
involved in inflammation, such cytokines and chemokines, and apoptosis. It is regulated by estradiol and plays a central role in the hormonal control of neuroinflammation (see Section 4.7). The regulation of NFKB activation by estradiol is one of the neuroprotective mechanisms activated by the hormone in animal models of neurodegenerative diseases, such as traumatic brain injury, cerebral ischemia and Alzheimer's disease (Wen et al., 2004; Cook et al., 2018; Yun et al., 2018; Table 2). In these models, estradiol deficiency increases brain damage in parallel with an increased NFkB activation (Cook et al., 2018; Yun et al., 2018; Table 2).

The main cellular populations that participate in the regulation of the inflammatory response in the brain are microglia (see Section 5.5). In these glial cells, as well as in macrophages, estradiol decreases NFkB activation induced by LPS or other proinflammatory signals by a mechanism involving ER $\alpha$ and PI3K activation (Vegeto et al., 2006; Khan et al., 2018). Estrogenic inhibition of NFאB activation and nuclear translocation (Cerciat et al., 2010) or inhibition of NFkB-mediated transcription (Giraud et al., 2010) has also been observed in astrocytes, another glial cell involved in the control of neuroinflammation in the brain (see Section 5.3). However, the effect of estradiol on NFKB activation is not restricted to glial cells, because the hormone decreases also NFKB activation in neurons (F. Liu et al., 2012; Yun et al., 2018) and in cerebral blood vessel endothelial cells (Ospina et al., 2004).

\subsection{STAt3}

Estradiol inhibits neuronal apoptosis by the regulation of the activity of STAT3, a transcription factor that is under the control of the PI3K signaling pathway. STAT3 induces the transcription of antiapoptotic genes, such as Bcl-2 and survivin (see Section 4.5) and is involved in the neuroprotective mechanisms of estradiol (Dziennis et al., 2007; Zhang et al., 2008; Sehara et al., 2013; Table 2). Thus, it has been shown that estradiol regulates the phosphorylation of STAT3 in the brain of ovariectomized female rats after middle cerebral artery occlusion or global cerebral ischemia and that STAT3 is necessary for the neuroprotective action of the hormone (Dziennis et al., 2007; Sehara et al., 2013). For instance, blockage of STAT3 dampens the neuroprotective action of estradiol in CA1 neurons after global ischemia (Sehara et al., 2013; Table 2).

\subsection{CREB and CART}

The ERK signaling pathway activates the transcription factor CREB, which is known to mediate numerous physiological mechanisms in response to estradiol. CREB is also involved in the neuroprotective actions of the hormone. For instance, estradiol increases CREB expression (Raval et al., 2009; Table 2) and prevents the decrease in CREB phosphorylation induced by global cerebral ischemia in female rats (Lebesgue et al., 2009; Yang et al., 2010; Table 2). One of the genes regulated by CREB and that is highly induced by estradiol in the cerebral cortex of ovariectomized female rats exposed to middle cerebral artery occlusion is CART (Xu et al., 2006; Table 2). In primary cortical neurons a CART-neutralizing antibody prevented the protective action of estradiol against oxygen-glucose deprivation (Xu et al., 2006). Thus, a possible signaling pathway including ERK, CREB and CART may be involved in the neuroprotective actions of the hormone through membrane ERs.

\subsection{MicroRNAs}

Non-coding RNAs, including miRNAs, have emerged as a new level of post-transcriptional regulation. In the brain, miRNAs participate in the regulation of neurogenesis, neural development, synaptogenesis and synaptic plasticity and their dysregulation may play a key role in the pathogenesis of neurodegenerative diseases and affective disorders. The intercellular transport of miRNAs by extracellular vesicles represents an additional mechanism for paracrine and endocrine communication and also a promising avenue for the diagnosis of brain alterations and for therapeutic interventions.

miRNAs participate in the transcriptional regulation exerted by ERs in different tissues, including the brain. For instance, the neuroprotective signaling pathways activated by estradiol in the brain, such as the PI3K/Akt pathway, are known to regulate the expression of numerous miRNAs (Recaberren-Leiva and Alarcon, 2018). Thus, in the MCAO model, it has been shown that estradiol controls the expression of genes involved in apoptosis and neuroinflammation by the regulation of miRNAs (Herzoq et al., 2017). In addition, some miRNAs may interfere with the neuroprotective signaling of estradiol. For instance, miR-7-1 potentiates the neuroprotective effect of the hormone in the prevention of apoptosis of spinal cord motoneurons exposed to a calcium ionophore (Chakrabarti et al., 2014), while the inhibition of miR-181a increases the expression of ER $\alpha$ in female astrocytes, facilitating estradiol protective actions against focal cerebral ischemia (Stary et al., 2017; Table 2). Although these studies suggest that miRNAs participate in the neuroprotective mechanisms of estradiol, further investigation is required to accurately determine and generalize the role of non-coding RNAs and extracellular vesicles in the neuroprotective actions of the hormone in different models of neurodegenerative and affective disorders.

\subsection{Neurotrophic factors}

The PI3K/Akt signaling pathway mediates the interaction of estradiol signaling with the signaling of other neuroprotective factors, such as insulin-like growth factor 1 (IGF-1) (Mendez et al., 2006). The interaction of the neuroprotective mechanisms of estradiol and IGF-1 has been identified in hypothalamic rat neurons submitted to serum deprivation in vitro (Duenas et al., 1996; Table 1) and in human fetal neuroblasts exposed to $\beta$-amyloid (Luciani et al., 2008, 2012; Table 1). This interaction has been also identified in studies in vivo, in rodent models of excitotoxicity (Azcoitia et al., 1999; Table 2), Parkinson's disease (Quesada et al., 2008; Bourque et al., 2009), experimental stroke (Sohrabji, 2015) and perinatal asphyxia (Saraceno et al., 2018; Table 2). In addition, recent findings indicate that estradiol and IGF-1 neuroprotective signaling also interact through GPER in the MPTP model of Parkinson's disease (Yuan et al., 2019).

Brain derived neurotrophic factor (BDNF) is involved in numerous physiological actions of estradiol in the brain and also mediates the neuroprotective actions of the hormone. For instance, estradiol increases BDNF expression in the hippocampus in rat models of hypertensive encephalopathy (Pietranera et al., 2015, 2016; Table 2) and BDNF mediates the neuroprotective actions of estradiol against NMDA induced excitotoxicity in cultured hippocampal slices (Aguirre and Baudry, 2009) and in animal models of global cerebral ischemia (Yang et al., 2010; Table 2). Both IGF-1, acting on IGF-1 receptor, and BDNF, acting on TrkB receptor, activate PI3K/Akt and ERK signaling that, as mentioned before, mediate numerous neuroprotective actions of estradiol. Thus, estradiol may exert a redundant activation of the neuroprotective PI3K/Akt and ERK pathways through IGF-1 and BDNF (Arevalo et al., 2015).

Other neurotrophic factors that may mediate the neuroprotective actions of estradiol in the adult rodent brain are HIF-1 $\alpha$, VEGF, TGF $\alpha$, TGF $\beta$ and GDNF. The expression of HIF- $1 \alpha$ and VEGF is increased by the hormone in the rat brain after permanent focal cerebral ischemia (Zheng et al., 2013; Table 2). TGF $\alpha$ mediates the upregulation of glutamate transporter GLT-1 induced by the hormone in rat primary astrocytes (Lee et al., 2012; Table 1). Thus, by mediation of TGFa, estradiol protects neurons and other neural cells from excitotoxicity, by decreasing extracellular glutamate levels as a consequence of the increased extracellular glutamate transport by astrocytes (see Section 4.3). TGF $\beta$ and GDNF are released by astrocytes in response to estradiol and mediate neuroprotective effects of the hormone in different cellular 
models. TGF $\beta$ protects cortical neurons from $\beta$-amyloid toxicity and other neurotoxic insults (Sortino et al., 2004; Dhandapani et al., 2005), whereas the release of GDNF by astrocytes in response to estradiol has been suggested to protect spinal motoneurons from AMPA toxicity (Platania et al., 2005; Table 1). Furthermore, GDNF has been shown to be involved in the protective action of estradiol against 6-OHDA toxicity in the substantia nigra and in neuron-glia cultures (Campos et al., 2012; Table 2).

\subsection{Seladin-1 and cholesterol}

The expression of Selective Alzheimer's disease indicator-1 (Seladin1) gene is strongly reduced in vulnerable brain regions of Alzheimer's disease patients. This gene confers resistance against $\beta$-amyloid toxicity and oxidative stress and mediates the protective effect of estradiol in human fetal neuroepithelial cells exposed to $\beta$-amyloid (Luciani et al., 2008, 2012; Table 1). Seladin-1 gene encodes the enzyme 3- $\beta$-hydroxysterol delta-24-reductase, which catalyzes the synthesis of cholesterol from desmosterol. Cholesterol levels are reduced and $\beta$-amyloid levels are increased in the brain of seladin- 1 deficient mice, while seladin- 1 overexpression increases cholesterol levels and resistance to $\beta$-amyloid toxicity. These findings suggest a possible role of cholesterol in the neuroprotective actions of estradiol (Luciani et al., 2012). Cholesterol is necessary for synaptogenesis and may be required for the reparative effects of estradiol on the damaged synaptic circuits (see Section 4.2). In addition, an adequate cholesterol and lipid composition in the lipid rafts is necessary for the interaction of membrane-associated ERs with other plasma membrane components (Marin et al., 2013). Therefore, changes in cholesterol levels in the neuronal lipid rafts with aging and Alzheimer's disease may impair the neuroprotective signaling of membrane-associated ERs in the brain.

\subsection{Neuroglobin and huntingtin}

The oxygen binding protein neuroglobin is a member of the globin family and has structural similarities to $\alpha$ - and $\beta$-chains of hemoglobin and to myoglobin. Neuroglobin, which is associated with mitochondrial proteins and inhibits mitochondria-dependent apoptotic signaling, is expressed in the nervous system and protects brain cells from oxidative stress, hypoxia/ischemia and mitochondrial dysfunction (Baez et al., 2016). Estradiol has been shown to induce the expression of neuroglobin in neuroblastoma cells, primary hippocampal neurons and astrocytes by means of both nuclear- and membrane-initiated ER $\beta$ signaling (De Marinis et al., 2013; Avila-Rodriguez et al., 2014, 2016; Table 1). Estradiol induces the translocation of neuroglobin to the mitochondria, where neuroglobin exerts its antiapoptotic neuroprotective actions (Nuzzo et al., 2017; Table 1). Furthermore, neuroglobin mediates neuroprotective actions of estradiol in neurons and anti-inflammatory effects of the hormone in astrocytes (De Marinis et al., 2013; Avila-Rodriguez et al., 2014, 2016; Table 1).

Neuroglobin interacts with huntingtin in different cell lines, including neuronal cells (Nuzzo et al., 2017; Table 1). This interaction with huntingtin allows the translocation of neuroglobin from the cytosol to the mitochondria (Nuzzo et al., 2017). Both the expression of huntingtin and the interaction of neuroglobin with huntingtin are significantly increased by estradiol (Nuzzo et al., 2017; Table 1). Huntingtin is a well-known protein, since the presence of an abnormal polyQ expansion in its $\mathrm{N}$-terminal sequence causes the development of Huntington's disease. Non-mutated huntingtin participates in numerous molecular interactions and cellular functions and is necessary for estradiol-induced neuroglobin upregulation and mitochondrial localization (Nuzzo et al., 2017). Thus, mutated huntingtin with 111 glutamine residues in the polyQ region prevents the induction of neuroglobin expression and mitochondrial localization by estradiol and the antiapoptotic effects of the hormone in neuroblastoma cells (Nuzzo et al., 2017). These findings indicate that huntingtin is necessary for the neuroprotective action of the estradiol-neuroglobin pathway (Nuzzo et al., 2017).

\subsection{Notch signaling}

Notch is a transmembrane receptor involved in cell to cell contact communication. Notch receptor is activated by transmembrane ligands, such as Jagged and Delta. The activation of Notch receptor results in the cleavage of its intracellular domain, which is translocated to the cell nucleus and regulates the expression of different transcription factors, such as hairy and enhancer of split (Hes) 1 and 5 (Arevalo et al., 2011).

Estradiol is known to regulate Notch signaling in cancer and endothelial cells (Arevalo et al., 2011). In breast cancer cells, there is a cross-talk between estrogen and Notch signaling. Thus, Notch regulates $E R \alpha$-mediated transcription and in turn estradiol inhibits Notch signaling by an ER $\alpha$-mediated mechanism (Arevalo et al., 2011). Interactions of estradiol and Notch signaling have been also detected in the nervous system. In hippocampal slice cultures, estradiol decreases the levels of the intracellular domain of Notch-1, indicating a reduced activity of Notch signaling (Bender et al., 2010). In addition, estradiol reduces the activity of Notch and the expression of Notch regulated genes, such as Hes-1, in primary mouse hippocampal neurons (Arevalo et al., 2011).

One of the functions of Notch signaling in the brain is the regulation of neuritogenesis. Notch acts as a repressor of neuronal development by the downregulation of neuritogenic genes, such as the transcription factor neurogenin 3 . In primary hippocampal neurons estradiol upregulates the expression of the neuritogenic gene neurogenin 3 and promotes neuritogenesis and dendritogenesis, via the inhibition of Notch signaling (Arevalo et al., 2011). This effect of estradiol is mediated by GPER and the activation of PI3K signaling pathway (Ruiz-Palmero et al., 2013). Therefore, the regulation of Notch signaling by estradiol may be relevant for the neuritogenic effects of the hormone for neuronal regeneration after brain injury (see Section 4.2). However, the role of Notch signaling in the neuroprotective and neuroreparative mechanism activated by estradiol in animal models of neurodegenerative diseases has not been fully explored yet.

\subsection{Endocannabinoids}

Endocannabinoids are a family of molecules that are synthesized in response to physiological stimuli and participate in numerous events in the nervous system, including the regulation of neural development, synaptic transmission, synaptic plasticity, behavior and memory. In addition, the endocannabinoid system maintains brain tissue homeostasis under pathological conditions and the levels of endocannabinoids and the expression of the enzymes involved in endocannabinoid synthesis and metabolism are altered in different models of brain injury and neurodegeneration. Estradiol regulates and interacts with the brain endocannabinoid system in the modulation of inhibitory synaptic transmission under physiological conditions (Tabatadze et al., 2015) and a few reports suggest that the endocannabinoid system may participate in the mechanism of neuroprotection elicited by estradiol.

In rats exposed to MCAO, the neuroprotective actions of estradiol are associated with a decrease in the levels of the endocannabinoid arachidonoylethanolamide, or anandamide in the striatum (Amantea et al., 2007). The levels of this endocannabinoid are increased in the injured tissue, and estradiol prevents this increase. The effect of estradiol may be mediated by decreasing the activity of the enzyme Nacylphosphatidylethanolamide-hydrolyzing phospholipase D (NAPEPLD), which synthesizes anandamide, and by increasing the activity of the enzyme fatty acid amide hydrolase (FAAH), which metabolizes anandamide in arachidonic acid and ethanolamine. Furthermore, the neuroprotective action of estradiol, via ERs, is also accompanied by a reduction in cannabinoid $\mathrm{CB} 1$ receptor binding, suggesting a decreased signaling of endocannabinoids via CB1 receptors (Amantea et al., 
2007).

In a model of traumatic brain injury estradiol reduces gliosis in the cerebral cortex in parallel with the increase in the expression of the enzyme monoacylglycerol lipase (MAGL), involved in the metabolism of 2-arachidonoylglycerol (2-AG), and the expression of the anandamide synthetizing enzyme NAPE-PLD. Furthermore, estradiol increases the expression of CB2 cannabinoid receptors in the injured cerebral cortex and both $\mathrm{CB} 1$ and $\mathrm{CB} 2$ receptor antagonists prevent the antigliotic effect of estradiol after traumatic brain injury (López Rodríguez et al., 2011; Table 2). All these findings indicate that estradiol affects endocannabinoid levels and signaling after ischemic and traumatic brain injuries and suggest that the neuroprotective actions of the hormone, at least in these brain injury models, involve the regulation of the endocannabinoid system. However, further studies are necessary to elucidate the precise role of endocannabinoid signaling in the neuroprotective mechanisms of estradiol.

\section{Role of brain derived estradiol in neuroprotection}

In addition to be a gonadal hormone, estradiol is locally synthesized in different body tissues and acts as a local paracrine or autocrine factor. The enzyme aromatase, which converts testosterone in estradiol, is expressed in the central nervous system. In the mammalian brain and under physiological conditions this enzyme is mainly localized in neurons and participates in the regulation of different brain functions by the regulation of local estradiol levels in the brain tissue. Thus, brain aromatase activity has been shown to be implicated in the regulation of neurogenesis, neuronal differentiation, synaptic function, synaptic plasticity, pain regulation, locomotor activity, sexual behavior, social behavior, affective behavior, locomotor activity and cognition, among other functions (Azcoitia et al., 2018; Brocca and Garcia-Segura, 2018). In addition, under conditions of brain injury, including traumatic brain injury, cerebral ischemia or excitotoxicity, the expression of the enzyme is induced in astrocytes (Garcia-Segura et al., 1999; Saldanha et al., 2009; Zhang et al., 2014; Pedersen et al., 2018) together with an increase in brain aromatase activity (Garcia-Segura et al., 1999) and brain estradiol levels (Q.G. Zhang et al., 2014; Mehos et al., 2016).

The induction of aromatase in astrocytes after brain injury is mediated by acute inflammatory signals and by bone morphogenetic protein 2 (BMP2) originated in microglia (Duncan and Saldanha, 2011; Duncan et al., 2013; Pedersen et al., 2018). Moreover, it is associated with injury-induced glial expression of CREB binding protein CBP (Klores et al., 2017) and with enhanced NFkB signaling (Klores et al., 2017; Cook et al., 2018).

Glial aromatase expression after injury probably represents a natural mechanism of neuroplasticity activated for neuroprotection and repair (Duncan et al., 2013). Indeed, the inhibition of aromatase activity or the silencing of aromatase expression in the brain results in increasing gliosis, neuroinflammation and damage in the injured neural tissue (Azcoitia et al., 2001; McCullough et al., 2003; Sierra et al., 2003; Zhang et al., 2014, 2017), including an increase in apoptotic secondary neurodegeneration (Saldanha et al., 2009; Wynne et al., 2008; Duncan et al., 2013) and a reduction in injury-induced neurogenesis and cell migration (Walters et al., 2011; Duncan et al., 2013).

Aromatase inhibition also prevents the neuroprotective actions of estradiol precursors, such as testosterone or dehydroepiandrosterone (Veiga et al., 2003; Juhász-Vedres et al., 2006). The neuroprotective role of brain estradiol synthesis has been identified in different models of brain injury, including excitotoxicity (Azcoitia et al., 2001), cerebellar ataxia (Sierra et al., 2003), traumatic brain injury (Pedersen et al., 2018), brain ischemia (McCullough et al., 2003; Zhang et al., 2014, 2017), Alzheimer's disease (Yue et al., 2005; Chang et al., 2013) and Parkinson's disease (Gillies and McArthur, 2010b).

It is important to mention that in the injured rodent brain aromatase is not only expressed by astrocytes, but also by neurons and brain endothelial cells. Therefore, a decreased estradiol production by these cells may contribute to the increased brain damage observed after the inhibition of aromatase activity or the silencing of aromatase expression in models of brain injury. Indeed, in some animal models of chronic neurodegeneration, such as in rat models of hypertensive encephalopathy (Pietranera et al., 2015) or chronic sciatic nerve injury (Schaeffer et al., 2010), aromatase expression is increased in hippocampal neurons and dorsal root ganglion cells and not in astrocytes or satellite glial cells, respectively. These findings suggest that increased expression of aromatase in neurons after brain injury may also contribute to neuroprotection.

\section{Subcellular, cellular and tissue events involved in the neuroprotective and reparative actions of estradiol}

\subsection{Neurogenesis}

The actions of estradiol on adult neurogenesis and the regulation of axonal growth, synaptogenesis, dendritic remodeling and synaptic plasticity are well documented. These neuroplastic effects of estradiol are essential for the role that the hormone plays in the maintenance of adult brain homeostasis, including its effects on neuroendocrine events, cognition and memory. The regulation of neuroplasticity may also be involved in the neuroprotective actions of estradiol under pathological circumstances. Indeed, the signaling pathways and molecules involved in the neuroprotective actions of estradiol discussed in the previous sections, such as ERK, PI3K/Akt, Wnt, GSK3ß/ $\beta$-catenin, RhoA/ROCK, IGF-1, BDNF, neuroglobin and endocannabinoids, are known to be involved in the regulation of neuritogenesis, synaptogenesis and adult neurogenesis and may therefore participate in the neuro-reparative processes elicited by the hormone through the enhancement of brain plasticity.

Although the role of the human adult hippocampal neurogenesis is still controversial, the existence of adult neurogenesis in the rodent brain and its regulation by estradiol is well established. The best characterized neurogenic niches in the adult rodent brain are the subgranular cell layer (SGL) in the dentate gyrus and the subventricular zone (SVZ) of the lateral ventricles. Other neurogenic niches have been identified in the olfactory bulbs, the cerebral cortex, the striatum, the hypothalamus and the cerebellum. In addition to physiological basal level of neurogenesis, neurodegenerative stimuli induce its activation in the SGL and the SVZ (Yu et al., 2016). Injury-induced neurogenesis has probably a reparative role (Wu et al., 2017) and, therefore, the regulation of injury-induced neurogenesis by estradiol may participate in the regenerative actions of the hormone (Fig. 3).

Estradiol increases neurogenesis in the SVZ of adult male (Li et al., 2011; Zheng et al., 2013; Table 2) and adult ovariectomized female (Suzuki et al., 2009; Li et al., 2011; Cheng et al., 2013; Khan et al., 2015; Table 2) rats and mice after brain ischemia and in diabetic mice (Saravia et al., 2006). The hormone also increases neurogenesis in the SGL of ovariectomized female mice and rats (Li et al., 2011; Cheng et al., 2013) submitted to brain ischemia, in the SGL of diabetic mice (Saravia et al., 2006) and in the SGL of rats with hypertensive encephalopathy (Pietranera et al., 2015; Table 2). Althoigh both ER $\alpha$ and ER $\beta$ are involved in the regulation of neurogenesis by estradiol, in hypertensive rats the ER $\beta$ agonist DPN is more active in increasing neurogenesis than the ER $\alpha$ agonist 4,4',4"-(4-propyl-[1H]-pyrazole1,3,5-triyl)trisphenol (PPT) (Pietranera et al., 2016).

IGF-1 and BDNF, which are known to upregulate adult neurogenesis in the rodent brain, may mediate the effects of estradiol on adult neurogenesis under physiological conditions and after brain injury (Mendez et al., 2006; Pietranera et al., 2016). In addition, in adult male rats submitted to brain ischemia, estradiol post-stroke treatment induces an increase in neurogenesis in the ischemic ipsilateral SVZ in parallel to an increase in hypoxia-inducible factor $1 \alpha(\mathrm{HIF}-1 \alpha)$ and vascular endothelial growth factor (VEGF) (Zheng et al., 2013; Table 2). Since HIF$1 \alpha$ is known to regulate neurogenesis by increasing the expression of 


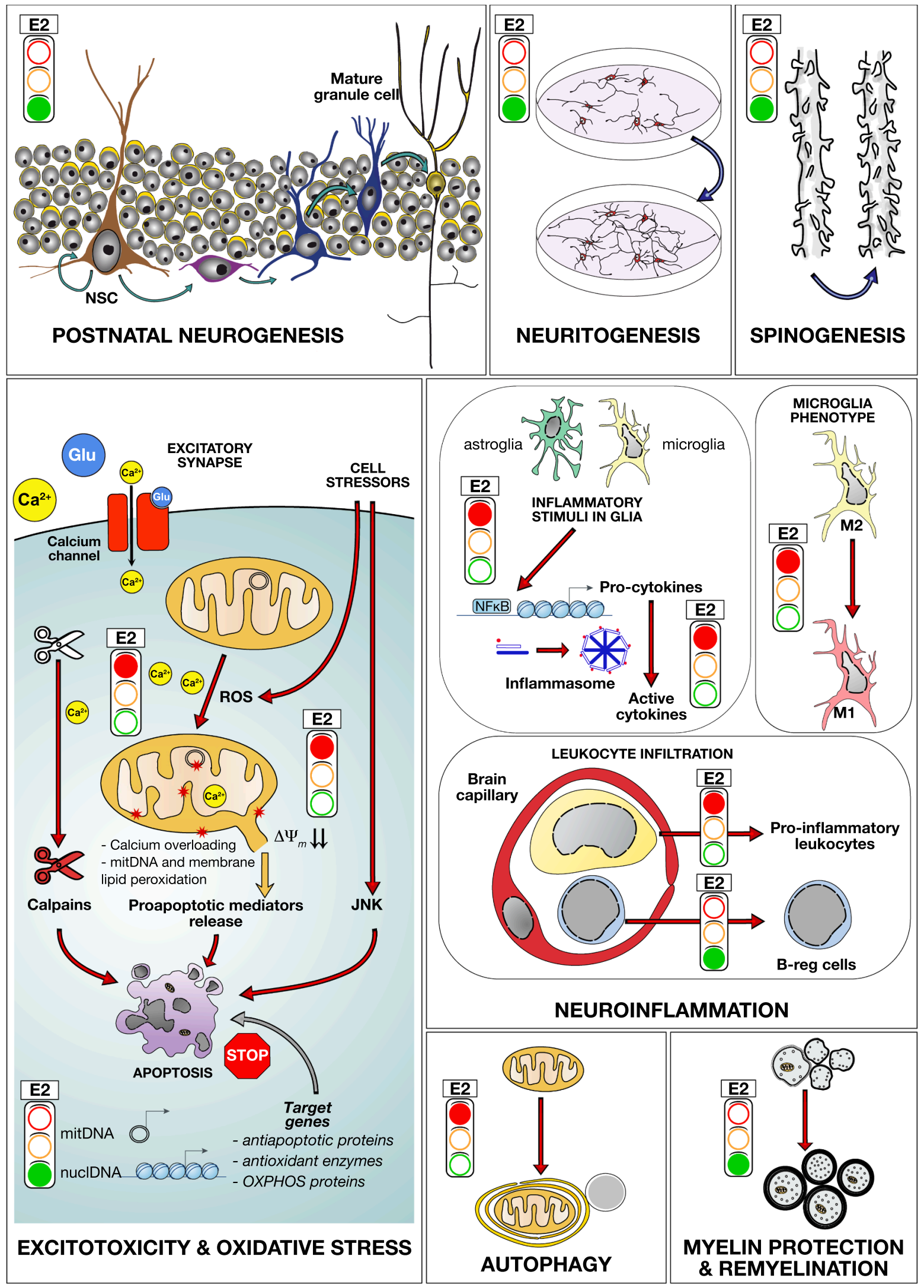




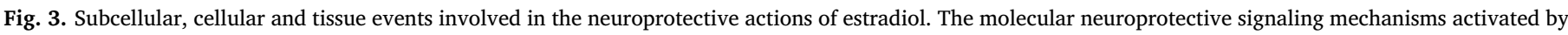

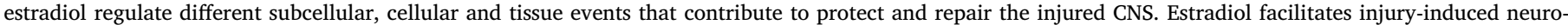

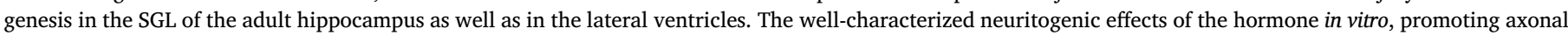

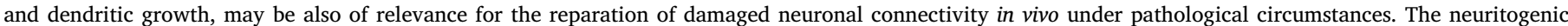

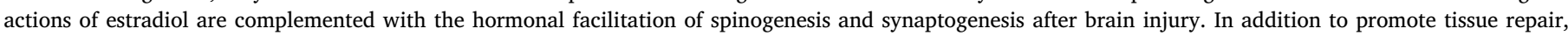

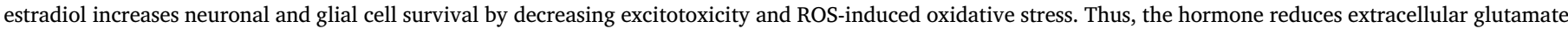

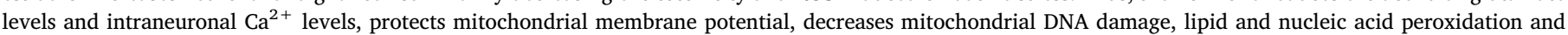

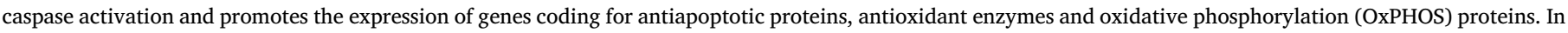

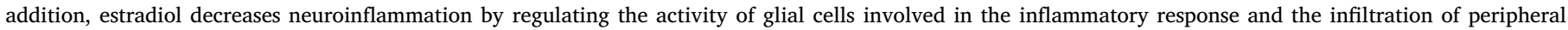

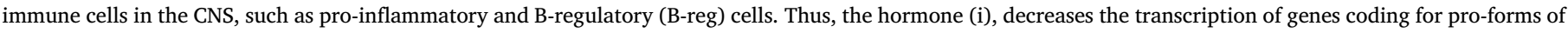

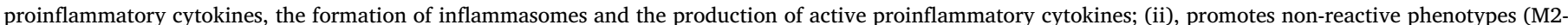

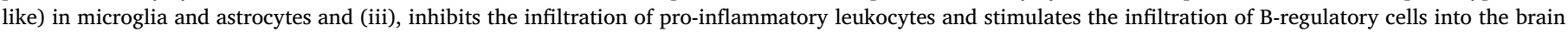

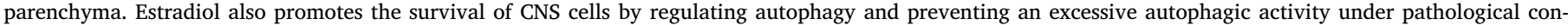
ditions. Finally, estradiol promotes myelin protection and remyelination.

VEGF, the hormonal increase in the expression of these two factors after brain ischemia may be involved in the effect of estradiol on post-ischemic neurogenesis.

\subsection{Neuritogenesis, synaptogenesis and neuronal plasticity}

In addition to enhance injury-induced neurogenesis, estradiol may exert neuroprotective actions by promoting the reparation of the injured neuronal circuits. Estradiol is known to promote neuritogenesis in developing neurons (Arevalo et al., 2011) and also promotes axonal repair after injury (Fig. 3). Thus, estradiol enhances axonal regeneration in peripheral nerves (Acosta et al., 2017) and decreases motoneuron axonal loss and promotes motoneuron dendritic growth in the central nervous system in animal models of spinal cord injury (Sengelaub and $\mathrm{Xu}, 2018$ ). Estradiol also decreases axonal loss in experimental autoimmune encephalomyelitis in rats. In this model of multiple sclerosis, the neuroprotective actions of the hormone were associated with the inhibition of ROCK (J. Feng et al., 2013), which is known to participate in axonal growth and synaptic plasticity.

The role of estradiol from gonadal or neuronal origin in the regulation of synaptic plasticity is well established (Azcoitia et al., 2018). This neuroplastic regulation may participate in the neuroprotective and neuroreparative actions of the hormone. For instance, estradiol synthesized by neuronal aromatase, promotes dendritic spine formation in hippocampal pyramidal neurons in hippocampal slices, prevents spine synapse loss induced by the blockade of $\mathrm{GABA}_{\mathrm{A}}$ receptors and increases glutamate decarboxylase expression and GABA synthesis in hippocampal primary interneurons (Zhou et al., 2007). In the hippocampus, estradiol enhances synaptic sprouting and the expression of the synaptic protein synaptophysin in the molecular layer of the dentate gyrus of ovariectomized female rats in response to entorhinal cortex lesion (Stone et al., 1998). The synaptogenic effect of estradiol in this model was mediated by apolipoprotein $\mathrm{E}$ (apoE), since the effect of the hormone was lost in apoE KO mice (Stone et al., 1998). ApoE induction by estradiol is involved in the promotion of neuritic growth by the hormone in different in vitro and in vivo models (Struble et al., 2008). Since apoE participates in cholesterol homeostasis and transports cholesterol from astrocytes to neurons and since regulation of cholesterol homeostasis may participate in the neuroprotective mechanisms of estradiol (see Section 2.14), a possible role of cholesterol-mediated synaptogenesis (Fester et al., 2009) on the neuroprotective actions of the hormone can be postulated. Furthermore, since the $\varepsilon 4$ allelic variant of apoE is a major genetic risk factor for Alzheimer's disease, the action of estradiol on apoE regulation may be of particular relevance for the hormonal reparative processes in this neurodegenerative condition.

The role of estradiol in the regulation of reactive synaptogenesis under neurodegenerative conditions has also been analyzed in other neuropathological models. In a model of hippocampal neurodegeneration in ovariectomized female rats, induced by the intraperitoneal administration of the neurotoxic trimethylin, the neuroprotective actions of estradiol were associated with the upregulation of the expression of genes involved in synaptogenesis, such as Bcl2, trkB, cadherin 2 and cyclin-dependent-kinase-5 (Corvino et al., 2015; Table 2). However, synaptogenesis was not directly assessed in this study and the upregulated genes also participate in other cellular functions, including the regulation of apoptosis. Nevertheless, the ER $\alpha$ selective agonist PPT improves cognition and hippocampal synapse loss induced by long-term ovariectomy in rats (Qu et al., 2013) and there is evidence that under neurodegenerative conditions estradiol modulates the number of dendritic spines (Fig. 3), which are postsynaptic structures involved in synaptic plasticity. For instance, the number of dendritic spines was assessed in adult male rats exposed to bilateral common carotid artery occlusion. In this model, estradiol enhances expression of synaptic proteins, such as synaptophysin and PSD95 and increases the number of dendritic spines in the CA1 hippocampal region (Zhu et al., 2017; Table 2). Estradiol also increases the number of dendritic spines in the ischemic cerebral cortex of adult ovariectomized female rats (Khan et al., 2015; Table 2), in CA1 neurons in a model of chronic hypertension (Pietranera et al., 2015; Table 2) and counteracts in adult male hippocampus dendritic alterations caused in CA1 by perinatal asphyxia, by a mechanism involving the PI3K/Akt/GSK3 $\beta$ signaling pathway (Saraceno et al., 2018; Table 2).

\subsection{Inhibition of excitotoxicity}

Excitotoxicity is a common cause of cell death in neurodegenerative diseases and mainly affects neurons and oligodendrocytes. High concentrations of extracellular glutamate result in the overstimulation of AMPA, kainate and NMDA receptors in neurons (AMPA and kainate receptors in oligodendrocytes). The overstimulation of these $\mathrm{Ca}^{2+}$ permeable receptors generates an increased influx of $\mathrm{Ca}^{2+}$ and, consequently, a rise in intracellular $\mathrm{Ca}^{2+}$ concentration, which activates calpain-mediated neuronal death. $\mathrm{Ca}^{2+}$ is also accumulated in mitochondria and this result in mitochondrial depolarization, increased production of oxygen free radicals, the activation of apoptotic signaling and finally cell death by necrosis or apoptosis.

Estradiol may exert neuroprotective actions against excitotoxicity (Azcoitia et al., 1998; Velísková, 2006) by several complementary mechanisms (Fig. 3). One is the decrease of extracellular glutamate levels. This is allowed by increasing glutamate uptake by astrocytes, because the hormone increases the expression of glutamate transporters, such as glutamate transporter-1 (GLT-1) and the glutamate aspartate transporter GLAST, in these cells (Lee et al., 2012; Acaz-Fonseca et al., 2014; Karki et al., 2014; Table 1). Estradiol may also protect neurons from excitotoxicity by inducing the release of protective factors by astrocytes, such as GDNF, which has been shown to protect spinal motoneurons from AMPA toxicity (Platania et al., 2005; Acaz-Fonseca et al., 2014; Table 1).

In addition, estradiol regulates neuronal excitability and prevents excitotoxicity and apoptosis by the control of intracellular $\mathrm{Ca}^{2+}$ levels in neurons and astrocytes (Zhao and Brinton, 2007; Zup and Madden, 2016; Table 1; Fig. 3). Under basal conditions estradiol regulation of 
intracellular calcium signaling coordinates multiple physiological actions of the hormone (Zup and Madden, 2016). This regulation may be associated with an increase in calcium uptake by neurons. For instance, estradiol potentiates neuronal L-type $\mathrm{Ca}^{2+}$ channels in parallel to rapid intracellular signaling to modulate synaptic plasticity and memory (Zhao and Brinton, 2007). However, under pathological circumstances, estradiol blocks the excessive rise in intracellular calcium as a protective mechanism. Thus, the hormone protects motoneurons from glutamate-induced excitotoxicity by inhibiting L-type $\mathrm{Ca}^{2+}$ channels and $\mathrm{Ca}^{2+}$ influx (Sribnick et al., 2009; Table 1). Estradiol and selective estrogen receptor modulators (SERMs) have been also shown to inhibit $\mathrm{Ca}^{2+}$ flux, preventing intracellular $\mathrm{Ca}^{2+}$ accumulation, through TRPA1, TRPM2 and TRPV1, in neurons of ovariectomized rats (Yazğan and Nazıroğlu, 2017; Table 2). Finally, estradiol may prevent excitotoxicity by regulating the excitatory/inhibitory balance and protecting inhibitory neurons (see Section 5.1).

\subsection{Mitochondrial protection and oxidative stress}

A by-product of oxidative phosphorylation in the mitochondria is the formation of reactive oxygen species (ROS). Under physiological conditions the antioxidant system of the brain, composed by antioxidant defense enzymes and small antioxidant molecules, prevents mitochondrial nucleic acid, protein and lipid peroxidation by ROS. However, the neural tissue, which has a high metabolic activity and is rich in lipid content, is particularly vulnerable to oxidative stress. Thus, under pathological conditions with high ROS production, such as brain ischemia and other neurodegenerative insults and neurological disorders, oxidative damage of neural tissue may result in the functional impairment of neurons and glial cells. Uncontrolled oxidative stress initiates a vicious circle in the brain tissue, causing mitochondrial dysfunction that in turn provokes more oxidative stress. Finally, the imbalance between ROS production and the expression of antioxidant defense enzymes results in the induction of apoptosis.

Estradiol has been shown to decrease oxidative damage and lipid peroxidation in neural cells in vitro (Nilsen, 2008; Liu et al., 2011; Guo et al., 2012; Rettberg et al., 2014; Sørvik et al., 2018; Table 1) and in rat models of hypoxia-ischemia, traumatic brain injury and Parkinson's disease (Zhang et al., 2009; Zhu et al., 2012; Aguirre-Vidal et al., 2017; Lu et al., 2018). The antioxidant effect of the hormone is mediated by the increase in the brain expression of oxidative stress response enzymes, such as catalase, glutathione peroxidase, superoxide dismutase (SOD), peroxiredoxin 5 and glutaredoxin (Nilsen, 2008; Rettberg et al., 2014). For instance, estradiol increases the expression of SOD1 and decreases protein and DNA damage in brain slices exposed to oxygen glucose deprivation, suggesting that SOD1, which decreases the mitochondrial release of cytochrome $c$, may be involved in the protective action of the hormone (Rao et al., 2011; Table 1). Estradiol has been also shown to increase SOD1 and SOD2 immunoreactivity in the substantia nigra in the MPTP mouse model of Parkinson's disease (Tripanichkul et al., 2007; Table 2). Furthermore, the hormone increases the expression of apurinic endonuclease, a protein involved in DNA repair and redox regulation, in the cerebral cortex of ovariectomized mice exposed to hypoxia (Dietrich et al., 2013).

The protective mechanisms activated by estradiol against oxidative stress in the brain involve the protection of mitochondrial function (Tables 1 and 2; Fig. 3). Mitochondria are affected by membrane and nuclear initiated estradiol signaling and are also direct targets of estradiol, since ERs are also located in the mitochondria (Simpkins et al., 2010; Vasconsuelo et al., 2013; Rettberg et al., 2014). Estradiol regulates the expression of several mitochondrial genes, including genes encoding for proteins of the mitochondria respiratory chain (Simpkins et al., 2010; Vasconsuelo et al., 2013; Rettberg et al., 2014). The hormone regulates the activity of the mitochondria respiratory chain through ER $\beta$ (Vasconsuelo et al., 2013), although both ER $\alpha$ and ER $\beta$ are involved in the actions of estradiol on mitochondrial function (Rettberg et al., 2014). Thus, the hormone increases both mitochondrial respiratory capacity (Yao et al., 2011) and ATP production (Guo et al., 2010; Rettberg et al., 2014), maintains mitochondria membrane potential (Simpkins et al., 2010; Guo et al., 2010, 2012), and reduces the mitochondrial production of reactive oxygen species (Guo et al., 2010) and the amount of oxidative damage to mitochondrial DNA (Nilsen, 2008) in neural cells exposed to different insults and reduces mitochondrial dysfunction in cellular models of Alzheimer's disease (Grimm et al., 2016a).

\subsection{Apoptosis}

The mitochondria play a central role in the integration and activation of cell death signaling pathways. Therefore, the protective actions of estradiol by regulating oxidative stress and preventing mitochondria dysfunction result in a decrease in caspase activation and the inhibition of apoptosis, which is a common final neuroprotective event in the action of estradiol in numerous models of neural injury and neurodegeneration (Tables 1 and 2; Fig. 3). Thus estradiol prevents apoptosis in neurons exposed to oxygen glucose deprivation (Chen et al., 2015; Guo et al., 2017), $\mathrm{H}_{2} \mathrm{O}_{2}$ (Liu et al., 2011; De Marinis et al., 2013; Nuzzo et al., 2017), glutamate (Sribnick et al., 2009), $\beta$-amyloid (Yao et al., 2007) or neuroinflammatory molecules (Smith et al., 2009) and in animal models of cerebral ischemia (Ma et al., 2016), traumatic brain injury (Bao et al., 2011; Lu et al., 2018), spinal cord injury (Rong et al., 2012) and retinal degeneration (Nixon and Simpkins, 2012), among others. The protective action of estradiol not only involves the intrinsic apoptotic pathway, since the hormone reduces Fas ligand expression induced by transient global cerebral ischemia in the CA1 subfield of the hippocampus of male rats (Wang et al., 2006) and inhibits Fas-mediated apoptosis in the cerebral cortex of ovariectomized mice exposed to middle cerebral artery occlusion (Jia et al., 2009).

The antiapoptotic action of estradiol is mediated by JNK inhibition (see Section 2.4), followed by the upregulation of antiapoptotic proteins, such as those of the Bcl-2 family members and survivin, and the consequent inhibition of cytochrome $c$ release by the mitochondria and the activation of the caspase cascade. The upregulation of antiapoptotic Bcl-2 family members in the brain is necessary for the neuroprotective action of the hormone in different models of neurodegeneration (Alkayed et al., 2001; D'Astous et al., 2006; Morissette et al., 2008; Saraceno et al., 2018; Table 2) and it has been detected by numerous laboratories. For instance, in vitro studies have shown that estradiol increases the expression of Bcl-2 in mesencephalic organotypic cultures (Wang et al., 2011; Table 1), hippocampal primary neurons (Zhao and Brinton, 2007; Table 1) and spinal cord motoneurons (CardonaRossinyol et al., 2013). In addition, the hormone upregulates Bcl-w in primary cortical neurons exposed to $\beta$-amyloid (Yao et al., 2007). These in vitro studies have also shown that the upregulation of antiapoptotic molecules by estradiol is accompanied by the downregulation of proapoptotic Bcl-2 family members, such as Bax (Wei et al., 2018; Table 2) and Bim (Yao et al., 2007).

Studies in vivo have documented that estradiol counteracts the decrease in the expression of antiapoptotic Bcl-2 family members, Bcl-2 and Bcl-XL, and the decrease in Bcl-2/Bax ratio induced by ovariectomy in the rat hypothalamus and hippocampus (Garcia-Segura et al., 1998; Sharma and Mehra, 2008; Qu et al., 2013). In middle cerebral artery occlusion stroke models, the hormone promotes Bcl-2 expression in peri-infarct region of the female rat brain (Alkayed et al., 2001; Zhang et al., 2017) and upregulates Bcl-2 expression in the brain of male rats via the microRNA miR-375 (Herzog et al., 2017). Estradiol also increases the $\mathrm{Bcl}-2 / \mathrm{Bax}$ ratio in the hippocampus of male rats exposed to perinatal asphyxia (Saraceno et al., 2018; Table 2) and the Bcl-2/Bad ratio in rodent models of Parkinson's disease (D'Astous et al., 2006; Morissette et al., 2008; Table 2).

In addition to $\mathrm{Bcl}-2$ family proteins, another molecule regulated by estradiol in the brain to prevent apoptosis and that mediates the 
neuroprotective effect of the hormone is survivin, a member of the inhibitor-of-apoptosis family of proteins. For instance, estradiol increases survivin expression in the hippocampus of female rats submitted to global cerebral ischemia (Zhang et al., 2008; Sehara et al., 2013; Table 2) and in the pericontusional area in the brain of female rats after traumatic brain injury (Bao et al., 2011; Table 2). Furthermore, the knockdown of survivin in the hippocampus blocks the neuroprotective action of estradiol (Sehara et al., 2013; Table 2).

\subsection{Autophagy}

Autophagy is a cellular process involved in the production of energy under metabolic stress conditions and involves the recycling of damaged cell organelle and large macromolecules. Different stimuli, including oxidative stress and mitochondrial dysfunction, induce the formation of double-membrane structures that engulf the cellular material to be degraded after fusion with lysosomes. These double-membrane structures are known as autophagosomes. The formation and degradation of autophagosomes is a dynamic process and an adequate equilibrium in autophagy activity is necessary to maintain cell homeostasis.

Several of the signaling pathways and molecules regulated by estradiol after brain injury are known to modulate autophagy. These include ERK, the PI3K/Akt/mTORC1 pathway, AMPK, JNK, IGF-1, BDNF, CREB and Bcl-2. Indeed, recent studies have shown that estradiol regulates autophagy in different cell types, including cancer cells (Xiang et al., 2018). As expected for the homeostatic role of estradiol, the hormone increases or decreases autophagy, depending on the cellular model and the physiological conditions. The possible role of autophagy in the neuroprotective actions of estradiol has been explored in human retinal pigment epithelial cells exposed to hydrogen peroxide (Wei et al., 2018; Table 1) and in in vivo models of retinal injury (Wei et al., Table 2), spinal cord injury (Lin et al., 2016) and cerebral ischemia (Li et al., 2017). In human retinal pigment epithelial cells estradiol reduces ROS levels and promotes cell survival in parallel to an increase in autophagosomes (Wei et al., 2018; Table 1). Protective effects of estradiol in the in vivo models of spinal cord injury and cerebral ischemia are associated with an inhibition of autophagy (Lin et al., 2016; Li et al., 2017) (Fig. 3). The estradiol metabolite, 2-methoxyestradiol, also reduces neural injury and autophagy after global cerebral ischemia (Xin et al., 2011). Further studies are necessary to determine the precise role that autophagy regulation plays in the neuroprotective actions of estradiol.

\subsection{Neuroinflammation}

Inflammation is a homeostatic mechanism that maintains tissue integrity after infection or injury and that is activated in the nervous system, as in other organs, under pathological circumstances. Although inflammation of the nervous tissue, or neuroinflammation, is a reparative process, it contributes to enhance neural degeneration if it is not properly controlled. Indeed, there is evidence that the mechanism that regulate neuroinflammation are deteriorated with aging and under chronic neurodegenerative pathologies and that this impairment in the control of neuroinflammation contributes to increase neural damage under these circumstances. Glial cells, mainly astrocytes and microglia in the CNS, are the main cellular elements that participate in the neuroinflammatory response.

Control of neuroinflammation is a common protective mechanism of estradiol in animal models of neurodegenerative diseases. This action of estradiol has been detected in different models of neurodegeneration, such as traumatic brain injury (López Rodríguez et al., 2011; Barreto et al., 2014; Pedersen et al., 2018; Table 2), spinal cord injury (Zendedel et al., 2018; Table 2), experimental autoimmune encephalomyelitis (Benedek et al., 2016), Alzheimer's disease (Vegeto et al., 2006; Table 2) and brain ischemia (Pérez-Álvarez et al., 2012; de
Rivero Vaccari et al., 2016; Zhang et al., 2018).

Estradiol controls neuroinflammation by the regulation of $\mathrm{NF}_{\kappa} \mathrm{B}$ activity (see Section 2.9), reducing the reactive activation of astrocytes (López Rodríguez et al., 2011; Pérez-Álvarez et al., 2012) and microglia (Pérez-Álvarez et al., 2012; Arevalo et al., 2013; Habib et al., 2014) and the downregulation of the expression of pro-inflammatory cytokines, such as TNF- $\alpha$, IL- $1 \beta$ and IL- 6 , in astrocytes and microglia (Vegeto et al., 2006; Cerciat et al., 2010; Giraud et al., 2010; Arevalo et al., 2013; Zhang et al., 2018) (see Tables 1 and 2). In addition to regulate the activity of glial cells involved in the inflammatory response, estradiol also regulates the infiltration of peripheral immune cells in the CNS (Fig. 3). Thus, the hormone prevents the infiltration of activated leukocytes in the CNS, but promotes the infiltration of regulatory B cells (Benedek et al., 2016).

The control of neuroinflammation by estradiol is exerted through the regulation of inflammasomes, which are multiprotein cytoplasmic complexes that play a central role in the activation of the inflammatory response (Fig. 3). Several classes of inflammasomes have been described in the nervous system, such as the NOD-, leucine-rich-repeats and pyrin domain containing 3 (NLRP3) inflammasome. After activation, NLRP3 form oligomers and recruit apoptosis-associated speck-like protein containing a caspase recruitment domain (ASC), an adaptor protein that interacts with pro-caspase 1 . Then caspase 1 is activated and converts pro-forms of pro-inflammatory cytokines, such as pro-IL$1 \beta$, in active forms, such as IL-1 $\beta$ (Heneka et al., 2018).

Estradiol has been shown to reduce inflammasome activation in microglia in vitro (Slowik et al., 2018; Table 1), in the hippocampus of ovariectomized rats and mice in vivo (Thakkar et al., 2016; Table 2) and in the injured CNS in different models of neurodegeneration, including models of amyotrophic lateral sclerosis in mouse (Heitzer et al., 2017) and rat models of global cerebral ischemia (de Rivero Vaccari et al., 2016) and spinal cord injury (Zendedel et al., 2018; Table 2). Functional improvement induced by estradiol in these models are associated with a reduced expression of several inflammasome components, including ASC and NLRP3 (Thakkar et al., 2016; Heitzer et al., 2017; Slowik et al., 2018; Zendedel et al., 2018), and of caspase-1 and proinflammatory cytokines (Thakkar et al., 2016; de Rivero Vaccari et al., 2016; Heitzer et al., 2017; Zendedel et al., 2018).

\subsection{Myelin protection and remyelination}

Myelin is essential for the proper propagation of action potentials and therefore, for the normal function of the CNS. Myelin structure and function are altered not only in demyelinating diseases, such as multiple sclerosis, but also in other CNS pathologies, such as traumatic brain and spinal cord injuries, stroke, microvascular ischemic damage and vascular dementia. White matter and myelin lesions are also a frequent outcome of perinatal asphyxia and preterm birth and myelin function is altered in psychiatric disorders and neurodegenerative diseases, such as Parkinson's and Alzheimer's diseases. Myelin protection and remyelination are, therefore, relevant components of the neuroprotective actions of estradiol.

Estradiol protects myelin sheaths and myelinated axons in the CA1 hippocampal subfield (Xiao et al., 2018) and in the white matter of the cerebral hemispheres (He et al., 2018) of ovariectomized middle-aged rats. The hormone also prevents oligodendrocyte cell death induced by peroxynitrite generator 3-(4-morpholinyl)-sydnonimine (Takao et al., 2004), hyperoxia (Gerstner et al., 2007) or oxygen/glucose deprivation (Gerstner et al., 2007) and protects myelin sheaths and oligodendrocytes in the hippocampus of adult male rats exposed to bilateral common artery occlusion (Zhu et al., 2017) and in the corpus callosum of male mice in the cuprizone model of demyelination (Acs et al., 2009; Taylor et al., 2010). Estradiol, in combination with progesterone, also protects myelin in the mouse experimental autoimmune encephalomyelitis model of multiple sclerosis (Garay et al., 2008).

The protective actions of estradiol on myelin are in part mediated by 
ER $\beta$, as it has been shown by using selective ER $\beta$ agonists, such as DPN, WAY-202041 and indazole- $\mathrm{Cl}$, which also induce remyelination and modulate the immune system in EAE models (Karim et al., 2019), and in the cuprizone diet model of multiple sclerosis (Atkinson et al., 2019). The remyelination mechanisms of ER $\beta$ ligands may be mediated by the activation of the PI3K/Akt/mTOR signaling pathway (Kumar et al., 2013).

\section{Cell types involved in the neuroprotective and reparative actions of estradiol}

\subsection{Excitatory and inhibitory neurons}

Numerous studies on primary neuronal cultures and neuronal cell lines have shown that estradiol exerts direct protective actions on neurons. In vivo studies have shown that ERs are expressed in different neuronal populations, including long distance projecting neurons and interneurons. Therefore, acting on ERs estradiol may directly activate protective mechanisms in neurons. Indeed, studies in vivo using neuronspecific ER $\alpha$ KO mice have shown that the absence of this ER in neurons impairs the neuroprotective action of estradiol in the MCAO model of stroke (Elzer et al., 2010). Furthermore, the neuroprotection of hippocampal pyramidal neurons by estradiol in a model of global cerebral ischemia is lost in parallel to a decrease in the expression of ER $\alpha$ in these neurons induced by long-term estrogen deprivation in female rats (Zhang et al., 2009).

The protective actions of estradiol on pyramidal neurons are well characterized in different models of neurodegeneration, where the hormone promotes synaptic connectivity (see Section 4.2), activates neuroprotective signaling pathways and promotes the expression of antiapoptotic molecules in these cells (Zhang et al., 2008; Sehara et al., 2013; Table 2). In addition to the direct effects of estradiol on pyramidal neurons, the protective actions of the hormone on these cells may be also in part mediated by interneurons. It should be noted that estradiol not only potentiates glutamatergic synaptic transmission but also regulates the efficacy of synaptic inhibition.

Several lines of evidence indicate that interneurons participate in the neuroprotective mechanisms of estradiol. In the kainic acid rat model of excitotoxic injury, the hormone promotes the survival of somatostatin and neuropetide $\mathrm{Y}$ immunoreactive hilar interneurons in ovariectomized rats (Azcoitia et al., 1998; Velísková, 2006; Table 2). In another hippocampal model of neurodegeneration, the administration of trimethylin to ovariectomized rats, estradiol increases the expression of the interneuronal markers glutamic acid decarboxylase 67, neuropeptide Y and parvalbumin (Corvino et al., 2015; Table 2). Estradiol also prevents the reduction in parvalbumin expression in ovariectomized rats submitted to MCAO ischemic brain injury and in hippocampal neuronal cultures exposed to glutamate (Koh, 2014). By protecting interneurons, the hormone may contribute to maintain the balance between excitation and inhibition, decreasing the excitotoxic damage of neurons and oligodendrocytes under pathological conditions.

\subsection{Oligodendrocytes}

Oligodendrocytes provide metabolic support for neuronal cell bodies and axonal processes, release different neurotrophic factors to regulate neuronal function and generate the myelin sheaths that cover myelinated axons in the white matter, which are essential for saltatory conduction of action potentials. In the human brain, white matter loss is a key component in the functional deficits caused by stroke and demyelinated diseases, such as multiple sclerosis. Oligodendrocytes have a high metabolic rate and are very sensitive to metabolic stress, oxidative stress and mitochondrial injury. Oligodendrocytes and proliferating oligodendrocyte precursor cells are also susceptible to excitotoxic cell death and are affected by inflammatory cytokines and cytotoxic T-lymphocytes. Therefore, the antioxidant activity of estradiol, the homeostatic actions of the hormone on mitochondria, the hormonal prevention of excitotoxicity and the estrogenic anti-inflammatory actions on astrocytes and microglia may be highly relevant for the protection of oligodendrocytes under different pathological conditions.

The neuroprotective actions of estradiol in the white matter (see Section 4.8) may be in part mediated by actions of the hormone in other cell types, such as astrocytes, microglia and infiltrating inflammatory cells (Spence et al., 2013; Benedek et al., 2016; Pansiot et al., 2016; Table 2). However, estradiol directly acts on ERs expressed by oligodendrocytes, such as ER $\alpha$, ER $\beta$ and GPER (Takao et al., 2004; Hirahara et al., 2009, 2013; Khalaj et al., 2016) and activate neuroprotective signaling, such as ERK and the PI3K/Akt/GSK3 and mTOR signaling pathways in these cells (Hirahara et al., 2009; Kumar et al., 2013; Khalaj et al., 2016). A direct proof for the implication of oligodendrocytes in the neuroprotective actions of estrogen receptors has been obtained in experimental autoimmune encephalomyelitis, where these cells mediate endogenous myelination and functional recovery stimulated by the ER $\beta$ agonist DPN (Khalaj et al., 2016).

\subsection{Astrocytes}

Astrocytes play an essential role in the maintenance of brain tissue homeostasis. They contribute to the control of cerebral blood flow, the function of blood brain barrier and the composition of the extracellular milieu, keeping the necessary environment for the proper function of neurons and other glial cells. Their role in the modulation of neuronal metabolism, by providing neurons with nutrients, such as lactate, and neurotrophic factors is well characterized. In addition, astrocytes modulate neuronal excitability by regulating the extracellular concentration of ions, such as $\mathrm{K}^{+}$, and neurotransmitters, such as glutamate. Furthermore, they participate in synaptic function, expressing receptors for neurotransmitters and releasing molecules (gliotransmitters) that regulate synaptic transmission, and convey information between different synapses through glial dynamic networks connected by gap junctions.

Astrocytes participate in brain plasticity under physiological and pathological conditions, being involved in adult neurogenesis, synaptogenesis, synaptic plasticity, myelin formation and the repair of the damaged neural tissue after injury. Under neurodegenerative conditions, astrocytes acquire a reactive phenotype, are involved in the inflammatory response and contribute to decrease excitotoxic cell death of neurons and oligodendrocytes by decreasing extracellular glutamate levels and by releasing neurotrophic factors.

Estradiol regulates the activity of astrocytes under physiological and pathological conditions (Acaz-Fonseca et al., 2016). These cells are direct targets of the hormone, expressing ER $\alpha$, ER $\beta$ and GPER (AcazFonseca et al., 2016). In addition, the expression of ERs in astrocytes is upregulated under conditions of brain injury (Acaz-Fonseca et al., 2014) and it has been shown that ERs expressed in astrocytes mediate the activation of neuroprotective mechanisms elicited by estradiol in different models of brain pathology. Depending on the model, the implication of ER $\alpha$ (Bains et al., 2007; Spence et al., 2013), ER $\beta$ (Ma et al., 2016) and GPER (Lee et al., 2012) expressed in astrocytes in the neuroprotective actions of the hormone has been documented. For instance, deletion of ER $\alpha$ in astrocytes prevents the neuroprotective action of estradiol in experimental autoimmune encephalomyelitis (Spence et al., 2013; Table 2). ER $\alpha$ expressed in astrocytes also mediates neuroprotective actions of estradiol on dopaminergic neurons in mesencephalic cultures treated with MPP(+) (Bains et al., 2007), while ER $\beta$ expressed by astrocytes mediates the neuroprotective action of estradiol against brain ischemia (Ma et al., 2016) and GPER is involved in the regulation of glutamate transporter in astrocytes (Lee et al., 2012; Table 1).

Under pathological conditions estradiol elicits different responses in 
astrocytes that contribute to neuroprotection (Table 1). Thus, the hormone decreases gliosis, reducing the number of reactive astrocytes in brain injured regions (Barreto et al., 2009; López Rodríguez et al., 2011; Table 2), the activation of NFאB in these cells and their expression of proinflammatory molecules (Cerciat et al., 2010; Giraud et al., 2010; De Marinis et al., 2013). In addition, estradiol promotes the release of different factors by astrocytes, such as GDNF, TGF- $\beta 1$, TGF- $\beta 2$, IGF-1, VEGF, ApoE and neuroglobin, which protect neurons from excitotoxicity, hypoxia-ischemia, 6-OHDA toxicity, $\beta$-amyloid neurotoxicity and other neurotoxic insults (Sortino et al., 2004; Dhandapani et al., 2005; Platania et al., 2005; De Marinis et al., 2013; Acaz-Fonseca et al., 2014; Sohrabji, 2015; Table 1). In addition, astrocytes mediate estrogenic actions in the control of blood brain barrier under neuroinflammatory conditions and in the regulation of cerebral edema after ischemia, at least in part by the regulation of the expression of aquaporin 4 in perivascular astrocytes (Acaz-Fonseca et al., 2014) and participate in the neuroprotective actions of the hormone against excitotoxicity by decreasing extracellular glutamate levels (Lee et al., 2012; Acaz-Fonseca et al., 2014; Karki et al., 2014; Table 1). Estradiol also exerts direct protective actions on astrocytes, increasing glucose transport, improving mitochondrial function and decreasing oxidative stress and oxidative cell death (Rettberg et al., 2014; Guo et al., 2012; Table 1). Finally, reactive astrocytes are a source of endogenous estradiol, which exerts neuroprotective actions after brain injury (see Section 3).

\subsection{Brain capillary endothelial cells and blood brain barrier}

The blood brain barrier (BBB) regulates the entry of ions, molecules and cells into the brain parenchyma and is composed by capillary endothelial cells, the associated basal lamina, pericytes and endfeet processes from astrocytes. Brain capillary endothelial cells have specific structural properties, such as lack of fenestrations and the presence of highly organized tight and adherens junctions, that contribute to the maintenance of the barrier, together with the expression of specific receptors and transporter systems that allow the selective bidirectional transcytosis of molecules to be transported through the barrier. In addition, astrocytes and pericytes release different molecules that contribute to develop and maintain barrier properties of brain capillary endothelial cells during physiological and pathological conditions. Furthermore, astrocytic endfeet express channels, transporters and receptors that contribute to barrier selectivity.

BBB dysfunction and increased permeability is associated with aging and it also occurs in different neurological disorders. Estradiol controls BBB function and this action may be highly relevant for its neuroprotective mechanisms. For instance, estradiol attenuates BBB disruption and decreases leakiness and brain edema induced by brain ischemic injury, traumatic brain injury, spinal cord injury and other insults and protects against tight junction disruption in brain capillary endothelial cells subjected to oxygen glucose deprivation/reperfusion injury (Na et al., 2015; Sohrabji, 2015; Table 1). These effects are mediated by direct protective actions of estradiol on brain capillary endothelial cells (Guo et al., 2010) and by indirect actions on astrocytes and microglia, decreasing inflammation and oxidative stress. In addition, estradiol enhances brain angiogenesis, contributing to tissue repair after stroke (Sohrabji, 2015).

\subsection{Microglia}

In contrast to astrocytes, which have an ectodermal origin, microglia derive from a pool of yolk sac derived macrophages that enter the brain during development. Microglia are the main players in the initiation and resolution of the immune response in the CNS. Under resting conditions, they scan the tissue environment and become activated by the presence of pathogens or injured cells. Then, microglial cells migrate towards the injured site to restore tissue homeostasis by the coordinated release of pro-inflammatory and anti-inflammatory molecules and by phagocyting infectious agents, cellular debris and damaged cells. In addition, the phagocytic activity of microglia participates in the physiological remodeling of neural tissue during neurogenesis, synaptogenesis and synaptic plasticity.

Although the activation of microglia is aimed to repair the damaged tissue, in chronic neurodegenerative diseases and psychiatric disorders microglia may present functional abnormalities that impair their restorative function. Under these conditions, they may contribute to increase neural tissue damage. Microglial cells may also present a senescent phenotype in aged brains, being unable to properly respond to damage signals and contributing to tissue deterioration. Estradiol regulates microglia activation (Table 2), promoting the acquisition of reparative phenotypes (M2-like) by these cells (Arevalo et al., 2013) (Fig. 3). Thus, the hormone promotes protective responses of microglia and decreases microglia reactivity in experimental models of multiple sclerosis (Benedek et al., 2016), amyotrophic lateral sclerosis (Heitzer et al., 2017) stroke (Pérez-Álvarez et al., 2012; Habib et al., 2014; Slowik et al., 2018; Zhang et al., 2018), traumatic brain injury (Barreto et al., 2014; Table 2), spinal cord injury (Zendedel et al., 2018; Table 2) or Alzheimer's disease (Vegeto et al., 2006; Table 2), among others (Arevalo et al., 2013). By regulating the inflammatory response and the reactive molecular phenotype of microglia, estradiol protects other cellular components of the CNS, such as oligodendrocytes, neurons and the blood brain barrier.

\section{Sex differences in the neuroprotective actions of estradiol: Cellular and molecular mechanisms}

\subsection{Sex differences in the neuroprotective action of estradiol}

In the previous sections we have analyzed the neuroprotective actions of estradiol regardless to sex, although many of the reviewed studies have been performed in female animals. It is important to consider, however, that the neuroprotective action of estradiol may be different in males and females. It is well known that most pathological alterations of the nervous system present sex differences in the incidence, prevalence, age of onset, progression, severity and/or response to medication (Melcangi et al., 2016). Sex differences in the response to estradiol in different models of brain pathology have been also reported (Gillies, and McArthur, 2010a; Giatti et al., 2018). For instance, circulating estradiol promotes neuroprotection from striatal lesions in females but has no effect or a deleterious action in males (Bourque et al., 2011; Gillies and McArthur, 2010b). In contrast, in a Parkinson model induced by 6-hydroxydopamine injections in the substantia nigra, AC186, an ER $\beta$ ligand, prevents motor, sensorimotor, and cognitive deficits and reduces loss of dopaminergic neurons in male rats, but not in females (McFarland et al., 2013). Furthermore, estradiol is protective against experimental stroke in older male mice but losses its neuroprotective potency in older female mice (F. Liu et al., 2012).

\subsection{Participation of estrogen signaling in the generation of sex differences in the neuroprotective actions of estradiol}

Sex differences in the distribution of ERs (Bourque et al., 2011), together with a different role of ER subtypes in brain plasticity, neuroprotection and repair in male and female neurons (Bryant and Dorsa, 2010; W. Wang et al., 2018) may participate in the generation of sex differences in the neuroprotective actions of estradiol. In addition, there are differences in ER signaling in the brain of males and females (Tabatadze et al., 2015; Oberlander and Woolley, 2016; Koss et al., 2018; Jain et al., 2019; Meitzen et al., 2019; Zafer et al., 2019), which are in part mediated by epigenetic modifications in ER encoding genes (Schwarz et al., 2010; Giatti et al., 2018) and micro RNAs (Giatti et al., 2018) and are also dependent on sexually differentiated interactions with the signaling mechanisms of other neuroprotective factors, such as 
BDNF (Scharfman and MacLusky, 2014), IGF-1 (Munive et al., 2016) or the endocannabinoid system (Tabatadze et al., 2015), which in turn also present sex differences in the brain. All these sexually differentiated molecular mechanisms cause different responses to estradiol in the brain of male and female animals (Tabatadze et al., 2015; Munive et al., 2016; Koss et al., 2018) and may determine sex differences in the neuroprotective actions of the hormone.

\subsection{Subcellular and cellular contributions to sex differences in the neuroprotective actions of estradiol}

Functional sex differences in brain subcellular organelle, including the mitochondria (Acaz-Fonseca et al., 2017; Gaignard et al., 2018; Giatti et al., 2018), or in the action of sex hormones on these organelle (Grimm et al., 2016b), may also contribute to divergent neuroprotective outcomes of estrogen therapy. For instance, mitochondria contribute to sex differences in oxidative stress under neurodegenerative conditions (Ruszkiewicz et al., 2019) and may generate sex differences in the neuroprotective actions of estradiol.

The different neuroprotective action of estradiol in male and female animals may be also partially determined by the sex dimorphic structural and functional organization of specific neuronal circuits (Gillies and McArthur, 2010b) and by sex differences in neuronal function and plasticity in response to the hormone (Hyer et al., 2018; Krentzel and Meitzen, 2018). In these sex differences also participate the associated glial cells. Indeed, sex differences in the function of astrocytes, oligodendrocytes and microglia have been reported (Cerghet et al., 2009; Acaz-Fonseca et al., 2016; Kodama and Gan, 2019), including sex differences in phagocytic and migratory activity of microglia (Nelson et al., 2017; Yanguas-Casás et al., 2018; VanRyzin et al., 2019), which may potentially contribute to different reparative processes after injury in male and female brains. In addition, estradiol activates different neuroprotective mechanisms in male and female glial cells (AcazFonseca et al., 2016; Stary et al., 2017; Table 1), which may therefore contribute to the generation of sex differences in the response of CNS tissue to injury and in the protective and reparative actions of the hormone, modulating neuroinflammation, excitotoxicity, remyelination, cerebral blood flow, blood brain barrier integrity and edema formation (Section 5).

\subsection{Contribution of brain-derived estradiol to sex differences in neuroprotection}

Another potential source of sex differences in the neuroprotective effects of the pharmacological administration of estradiol is the difference in the endogenous basal levels of the hormone in males and females. Estradiol levels present sex differences not only in plasma, but also in the CNS (Barker and Galea, 2009), allowing, therefore, a sex dimorphic interactions of endogenous and exogenous estradiol in the activation of ER signaling in brain tissue.

Sex differences in the brain estradiol levels partially reflect the differences in plasma, but are largely determined by its local synthesis and metabolism (Caruso et al., 2013; Hojo and Kawato, 2018). Brain estradiol synthesis generates sex differences in neurogenesis, synaptic plasticity and behavior (Bowers et al., 2010; Bender et al., 2017; Borbélyová et al., 2017; Brocca and Garcia-Segura, 2018; Kokras et al., 2018; Shay et al., 2018; Brandt and Rune, 2019) and, as it has been discussed in Section 3, contributes to the activation of neuroprotective mechanisms after CNS injury.

There are several possible levels of interaction of pharmacologically administered estradiol with locally produced estradiol in neuroprotection. From one side, pharmacological administration of estradiol upregulates brain aromatase expression in the brain under neurodegenerative conditions (Pietranera et al., 2015; Table 2). On the other hand, local brain estradiol synthesis may influence the neuroprotective outcome of peripheral estradiol and of pharmacological estrogen therapy.
Some studies suggest that estradiol synthesis in the brain is not only an endogenous mechanism of neuroprotection but it is also essential for the neuroprotective action of plasma estradiol or estradiol therapies. Thus, in H19-7 hippocampal cells, the inhibition of aromatase prevents the neuroprotective action of exogenous estradiol (Chamniansawat and Chongthammakun, 2012). In addition, the neuroprotective action of circulating estradiol in a mouse model of Alzheimer's disease is significantly reduced in aromatase $\mathrm{KO}$ female mice that have undetectable levels of brain estradiol (Li et al., 2013). It may be postulated that since estradiol exerts a positive-feedback action on the expression of brain aromatase and ER $\alpha$ in neurons, aromatase induction after brain injury may initiate a cycle that potentiates in parallel brain estradiol synthesis and the neuroprotective signaling of estradiol originated in both local and peripheral sources. However, this hypothesis needs experimental confirmation.

\subsection{Sex chromosome effects in the neuroprotective actions of estradiol}

The use of the four core genotypes mouse model, in which sex chromosome complement is unrelated to gonadal sex, has shown that sex differences in brain structure are the result of an interplay between the sex chromosome complement and the pre- and post-pubertal action of gonadal hormones (Cambiasso et al., 2017; Vousden et al., 2018). Such an interplay between sex chromosome genes and gonadal hormones may also determine sex differences in mood disorders (Seney et al., 2013), in the outcome of stroke in aged mice (McCullough et al., 2016) and in the remyelination of the corpus callosum in a mouse model of demyelination (Moore et al., 2013) and may explain the higher pathology in males and the higher susceptibility of females to multiple sclerosis. Thus, in the EAE mouse model of multiple sclerosis, a $\mathrm{XY}$ complement in the CNS determines an increased pathology compared to CNS XX animals (Du et al., 2014). In addition, the sex chromosome complement determines a higher expression of the $\mathrm{X}$ chromosome gene Kdm6a in XX animals. This gene codes for a histone demethylase that escapes $\mathrm{X}$ inactivation and its deletion in CD4 $+\mathrm{T}$ cells protects mice from EAE. Therefore, the higher expression of Kdm6a in females may contribute to their higher susceptibility for multiple sclerosis (Itoh et al., 2019).

The studies with the four core genotypes mouse model also suggest that sex differences in the immune system that are determined by sex chromosome complement may influence the manifestation of sex differences in brain pathology. Thus, in addition to the mentioned effects of sex differences in the expression of Kdm6a in CD4 + T cells in the susceptibility to EAE (Itoh et al., 2019), increased levels of proinflammatory cytokines may contribute to the higher brain infarct size and the higher microglia activation observed in male and female $\mathrm{XX}$ mice, compared to male and female XY mice, after middle cerebral artery occlusion (McCullough et al., 2016).

The interaction between the sex chromosome complement and gonadal hormones also determines the expression of aromatase and estrogen receptors (Cisternas et al., 2015, 2017; Cambiasso et al., 2017) in the brain and, therefore, may contribute to the different effects of estrogen therapy in males and females. However, this possibility needs to be experimentally explored. Thus, further studies should determine whether the interaction of sex chromosome complement and the endogenous levels of estradiol influence the neuroprotective actions of estrogen therapy in different models of brain pathology.

\section{Conclusions and perspectives}

The studies reviewed here show that estradiol activates multiple molecular and cellular mechanisms that act in concert to promote neural protection and repair after acute CNS injuries and chronic neurodegenerative conditions. Different molecular protective mechanisms activated by the hormone in a single neural cell converge to promote survival of this individual cell by the regulation of intracellular events, 
such as mitochondrial activity, antioxidant capacity, autophagy and apoptosis. In addition, the neuroprotective mechanisms activated by estradiol in one cell type will impact on other cells. For instance, the action of estradiol on astrocytes (Section 5.3), decreasing uptake of extracellular glutamate by these cells, prevents the excitotoxic effects of the excess of this neurotransmitter on neurons and oligodendrocytes (Section 4.3). The transcriptional control of neurotrophic factors and inflammatory molecules exerted by estradiol on astrocytes and microglia also impact on the survival of other cell types, on the function of blood-brain barrier (Section 5.4), on myelin integrity (Section 4.8) and on the regeneration of damaged neuronal circuits (Section 4.2). In a similar way, the estrogenic protection of interneurons (Section 5.1) contributes to maintain the excitation/inhibition balance, which is essential to maintain the homeostasis of all cell types in the CNS. Further research is needed to systematically determine the role of the different neuronal and glial populations in different brain regions and pathological conditions in the neuroprotective actions of estradiol. In addition to classical forms of cell to cell communication, it is also necessary to explore in detail the role of miRNAs and extracellular vesicles in the integration of the neuroprotective responses of different cell types and CNS regions in response to estradiol.

In the present paper we have limited our focus to the discussion of molecular, cellular and tissue neuroprotective events elicited by estradiol within the CNS. However, it is essential to consider that the neuroprotective mechanisms that are directly activated in the CNS by estradiol, are exerted in an organism also primed by the hormone. Estradiol receptors are expressed in different tissues and organs, such as the bone, skeletal muscle, hearth, skin, liver, kidney, pancreas, gastrointestinal tract and the adipose tissue. Thus, estradiol exerts a peripheral control of the immune, endocrine, metabolic, cardiovascular and locomotor systems. These peripheral actions of estradiol, promoting general body health, may also contribute to neuroprotection. For instance, the estrogenic regulation of peripheral immune responses (Morales et al., 2006; Karim et al., 2018) may impact on the protective actions of the hormone on autoimmune demyelinating diseases; the estrogenic regulation of adiposity and peripheral body metabolism (Rettberg et al., 2014) may improve brain bioenergetics; and the estrogenic signaling on peripheral organs may induce the release of tissue-specific cytokines with neuroprotective actions. Estradiol also affects gut microbiome composition (Kaliannan et al., 2018), which in turn may change the microbiota-gut-brain axis communication under brain neurodegenerative conditions. On the other hand, estrogenic effects in brain regions involved in the control of glucose and lipid metabolism, food intake, energy balance, temperature, blood pressure, respiration and other autonomic functions (Xu and López, 2018), participate in the maintenance of body homeostasis under pathological conditions. Also, estradiol actions on brain regions controlling mood, motivation, motor control and locomotor activity, contribute to increase physical activity (Xu et al., 2015) and may potentially improve the bioenergetics of skeletal muscles, which in turn, has positive effects for brain health and cognition. Therefore, the protective actions of estradiol in the CNS cannot be dissociated from the protective actions of the hormone in the other parts of the body. This is particularly relevant when considering the outcomes of estrogen therapy in postmenopausal women. Thus, in future research we need to implement new mechanistic approaches to unravel the details of brain-body interactions in estrogenic neuroprotection.

An important question that needs to be explored more systematically is the role of sex differences in the neuroprotective actions of estradiol. Although estradiol has been shown to be neuroprotective in both sexes, there is evidence that, at least for some pathological models, the hormonal effect may diverge in males and females. As previously discussed, one of the causes of this may be possible sex differences in estradiol synthesis or metabolism within the CNS. However, new studies are necessary to validate this possibility; for instance, using animal models with selective modifications in the expression and/or activity of aromatase in specific brain regions. Brain estradiol synthesis may be particularly relevant in women after the abrupt fall in plasma estradiol levels with menopause. The importance of aromatase and estradiol signaling for women healthy brain function is suggested by the identification of several variants of the genes encoding for aromatase and ERs that increase the risk of $\mathrm{AD}$, specifically in women (FernándezMartinez et al., 2013; Medway et al., 2014). However, the precise role of brain estradiol synthesis and signaling on brain healthy aging, in men and women, needs to be adequately investigated.

The analysis of the molecular mechanisms activated by estradiol to promote neuroprotection reveals a high level of complexity, including the interaction of estradiol signaling with the signaling activated by other factors. However, it is unknown whether the activation of this complex signaling is a general phenomenon under all pathological conditions and CNS regions or presents some degree of selectivity. In particular, it is unclear whether all these signaling mechanisms operate in a similar way in both sexes. Thus, we cannot exclude possible differences in estradiol neuroprotective signaling between males and females that would also contribute the sex differences in the outcome of estrogenic therapy. However, this possibility remains basically unexplored. The complexity of the estrogenic signaling mechanisms reviewed in this paper also predicts that alterations in some of its components with aging or under pathological conditions may impair the neuroprotective action of the hormone. Some studies in animal models have revealed the downregulation of ER $\alpha$ in the hippocampus with aging (Scott et al., 2012), suggesting that age may impair the neuroprotective action of estradiol. In addition, aging and brain pathology may also affect other components of estrogen neuroprotective signaling. For instance, plasma levels of IGF-1, which as we have discussed in this paper is a factor interacting with estradiol neuroprotective signaling, are decreased with aging and are altered under different neurological conditions in humans (Busiguina et al., 2000). In addition, a dissociation of the molecular interactions of ERs and IGF-1 receptors in caveolae has been detected in the brain of $\mathrm{AD}$ patients, suggesting an altered estradiol signaling in this pathology (Canerina-Amaro et al., 2017). The implications of such an impairment of estrogen neuroprotective signaling for the cognitive outcome of estrogen therapy in postmenopausal women are obvious. Therefore, new research is necessary to fully identify the components of estradiol signaling that are affected by aging or brain disease and new estrogenic therapeutic approaches should take in consideration this information.

\section{Funding}

This work was supported by Agencia Estatal de Investigación (BFU2017-82754-R), CIBERFES and Fondos FEDER. The funding sources had no involvement in study design, collection, analysis, interpretation of data, writing of the report or in the decision to submit the article for publication.

\section{Declaration of Competing Interest}

None.

\section{Acknowledgements}

Authors acknowledge funding from Agencia Estatal de Investigación (BFU2017-82754-R), CIBERFES and Fondos FEDER.

\section{References}

Acaz-Fonseca, E., Sanchez-Gonzalez, R., Azcoitia, I., Arevalo, M.A., Garcia-Segura, L.M., 2014. Role of astrocytes in the neuroprotective actions of $17 \beta$-estradiol and selective estrogen receptor modulators. Mol. Cell. Endocrinol. 389, 48-57. https://doi.org/10. 1016/j.mce.2014.01.009.

Acaz-Fonseca, E., Avila-Rodriguez, M., Garcia-Segura, L.M., Barreto, G.E., 2016. Regulation of astroglia by gonadal steroid hormones under physiological and 
pathological conditions. Prog. Neurobiol. 144, 5-26. https://doi.org/10.1016/j. pneurobio.2016.06.002.

Acaz-Fonseca, E., Ortiz-Rodriguez, A., Lopez-Rodriguez, A.B., Garcia-Segura, L.M., Astiz, M., 2017. Developmental sex differences in the metabolism of cardiolipin in mouse cerebral cortex mitochondria. Sci. Rep. 7, 43878. https://doi.org/10.1038/ srep43878.

Acosta, M.C., Copley, P.A., Harrell, J.R., Wilhelm, J.C., 2017. Estrogen signaling is necessary for exercise-mediated enhancement of motoneuron participation in axon regeneration after peripheral nerve injury in mice. Dev. Neurobiol. 77, 1133-1143. https://doi.org/10.1002/dneu.22501.

Acs, P., Kipp, M., Norkute, A., Johann, S., Clarner, T., Braun, A., Berente, Z., Komoly, S., Beyer, C., 2009. 17beta-estradiol and progesterone prevent cuprizone provoked demyelination of corpus callosum in male mice. Glia 57, 807-814. https://doi.org/10. 1002/glia.20806.

Aguirre, C.C., Baudry, M., 2009. Progesterone reverses 17beta-estradiol-mediated neuroprotection and BDNF induction in cultured hippocampal slices. Eur. J. Neurosci. 29, 447-454. https://doi.org/10.1111/j.1460-9568.2008.06591.x.

Aguirre-Vidal, Y., Monroy-Noyola, A., Anaya-Ramos, L., Arteaga-Silva, M., MendezArmenta, M., Ostoa-Saloma, P., Díaz-Zaragoza, M., Morales-Montor, J., Ríos, C., Montes, S., 2017. $\beta$-Estradiol-3-benzoate confers neuroprotection in Parkinson MPP rat model through inhibition of lipid peroxidation. Steroids 126, 7-14. https://doi. org/10.1016/j.steroids.2017.08.001.

Al Sweidi, S., Sánchez, M.G., Bourque, M., Morissette, M., Dluzen, D., Di Paolo, T., 2012. Oestrogen receptors and signalling pathways: implications for neuroprotective effects of sex steroids in Parkinson's disease. J. Neuroendocrinol. 24, 48-61. https://doi.org/ 10.1111/j.1365-2826.2011.02193.x.

Alkayed, N.J., Goto, S., Sugo, N., Joh, H.D., Klaus, J., Crain, B.J., Bernard, O., Traystman, R.J., Hurn, P.D., 2001. Estrogen and Bcl-2: gene induction and effect of transgene in experimental stroke. J. Neurosci. 21, 7543-7550.

Amantea, D., Spagnuolo, P., Bari, M., Fezza, F., Mazzei, C., Tassorelli, C., Morrone, L.A., Corasaniti, M.T., Maccarrone, M., Bagetta, G., 2007. Modulation of the en docannabinoid system by focal brain ischemia in the rat is involved in neuropro tection afforded by 17beta-estradiol. FEBS J. 274, 4464-4775.

Arevalo, M.A., Ruiz-Palmero, I., Simon-Areces, J., Acaz-Fonseca, E., Azcoitia, I., GarciaSegura, L.M., 2011. Estradiol meets notch signaling in developing neurons. Front. Endocrinol. (Lausanne) 2, 21. https://doi.org/10.3389/fendo.2011.00021.

Arevalo, M.A., Santos-Galindo, M., Acaz-Fonseca, E., Azcoitia, I., Garcia-Segura, L.M., 2013. Gonadal hormones and the control of reactive gliosis. Horm. Behav. 63 (2), 216-221. https://doi.org/10.1016/j.yhbeh.2012.02.021.

Arevalo, M.A., Azcoitia, I., Garcia-Segura, L.M., 2015. The neuroprotective actions of oestradiol and oestrogen receptors. Nat. Rev. Neurosci. 16, 17-29. https://doi.org/ 10.1038/nrn3856.

Atkinson, K.C., Lee, J.B., Hasselmann, J.P.C., Kim, S.H., Drew, A., Soto, J., Katzenellenbogen, J.A., Harris, N.G., Obenaus, A., Tiwari-Woodruff, S.K., 2019. Diffusion tensor imaging identifies aspects of therapeutic estrogen receptor $\beta$ ligandinduced remyelination in a mouse model of multiple sclerosis. Neurobiol. Dis. 130, 104501. https://doi.org/10.1016/j.nbd.2019.104501.

Avila-Rodriguez, M., Garcia-Segura, L.M., Cabezas, R., Torrente, D., Capani, F., Gonzalez, J., Barreto, G.E., 2014. Tibolone protects T98G cells from glucose deprivation. J. Steroid Biochem. Mol. Biol. 144 Pt B, 294-303. https://doi.org/10.1016/j.jsbmb. 2014.07.009.

Avila-Rodriguez, M., Garcia-Segura, L.M., Hidalgo-Lanussa, O., Baez, E., Gonzalez, J., Barreto, G.E., 2016. Tibolone protects astrocytic cells from glucose deprivation through a mechanism involving estrogen receptor beta and the upregulation of neuroglobin expression. Mol. Cell. Endocrinol. 433, 35-46. https://doi.org/10.1016/ j.mce.2016.05.024.

Azcoitia, I., Sierra, A., Garcia-Segura, L.M., 1998. Estradiol prevents kainic acid-induced neuronal loss in the rat dentate gyrus. Neuroreport 9, 3075-3079.

Azcoitia, I., Sierra, A., Garcia-Segura, L.M., 1999. Neuroprotective effects of estradiol in the adult rat hippocampus: interaction with insulin-like growth factor-I signalling. J. Neurosci. Res. 58, 815-822.

Azcoitia, I., Sierra, A., Veiga, S., Honda, S., Harada, N., Garcia-Segura, L.M., 2001. Brain aromatase is neuroprotective. J. Neurobiol. 47, 318-329.

Azcoitia, I., Arevalo, M.A., De Nicola, A.F., Garcia-Segura, L.M., 2011. Neuroprotective actions of estradiol revisited. Trends Endocrinol. Metab. 22, 467-473. https://doi. org/10.1016/j.tem.2011.08.002.

Azcoitia, I., Arevalo, M.A., Garcia-Segura, L.M., 2018. Neural-derived estradiol regulates brain plasticity. J. Chem. Neuroanat. 89, 53-59. https://doi.org/10.1016/j. jchemneu.2017.04.004.

Baez, E., Echeverria, V., Cabezas, R., Ávila-Rodriguez, M., Garcia-Segura, L.M., Barreto, G.E., 2016. Protection by neuroglobin expression in brain pathologies. Front. Neurol. 7, 146. https://doi.org/10.3389/fneur.2016.00146.

Baez-Jurado, E., Rincón-Benavides, M.A., Hidalgo-Lanussa, O., Guio-Vega, G., Ashraf, G.M., Sahebkar, A., Echeverria, V., Garcia-Segura, L.M., Barreto, G.E., 2018. Molecular mechanisms involved in the protective actions of Selective Estrogen Receptor Modulators in brain cells. Front. Neuroendocrinol. 52, 44-64. https://doi org/10.1016/j.yfrne.2018.09.001.

Bains, M., Cousins, J.C., Roberts, J.L., 2007. Neuroprotection by estrogen against MPP + -induced dopamine neuron death is mediated by ERalpha in primary cultures of mouse mesencephalon. Exp. Neurol. 204, 767-776.

Bao, Y.J., Li, L.Z., Li, X.G., Wang, Y.J., 2011. 17Beta-estradiol differentially protects cortical pericontusional zone from programmed cell death after traumatic cerebral contusion at distinct stages via non-genomic and genomic pathways. Mol. Cell. Neurosci. 48, 185-194. https://doi.org/10.1016/j.mcn.2011.07.004.

Barker, J.M., Galea, L.A., 2009. Sex and regional differences in estradiol content in the prefrontal cortex, amygdala and hippocampus of adult male and female rats. Gen.
Comp. Endocrinol. 164, 77-84. https://doi.org/10.1016/j.ygcen.2009.05.008.

Barreto, G., Santos-Galindo, M., Diz-Chaves, Y., Pernia, O., Carrero, P., Azcoitia, I. Garcia-Segura, L.M., 2009. Selective estrogen receptor modulators decrease reactive astrogliosis in the injured brain: effects of aging and prolonged depletion of ovarian hormones. Endocrinology 150, 5010-5015. https://doi.org/10.1210/en.2009-0352.

Barreto, G.E., Santos-Galindo, M., Garcia-Segura, L.M., 2014. Selective estrogen receptor modulators regulate reactive microglia after penetrating brain injury. Front. Aging Neurosci. 6, 132. https://doi.org/10.3389/fnagi.2014.00132.

Bender, R.A., Zhou, L., Wilkars, W., Fester, L., Lanowski, J.S., Paysen, D., König, A., Rune, G.M., 2010. Roles of $17 ß$-estradiol involve regulation of reelin expression and synaptogenesis in the dentate gyrus. Cereb. Cortex 20, 2985-2995. https://doi.org/10. 1093/cercor/bhq047.

Bender, R.A., Zhou, L., Vierk, R., Brandt, N., Keller, A., Gee, C.E., Schäfer, M.K., Rune, G.M., 2017. Sex-dependent regulation of aromatase-mediated synaptic plasticity in the basolateral amygdala. J. Neurosci. 37, 1532-1545. https://doi.org/10.1523/ JNEUROSCI.1532-16.2016.

Benedek, G., Zhang, J., Bodhankar, S., Nguyen, H., Kent, G., Jordan, K., Manning, D., Vandenbark, A.A., Offner, H., 2016. Estrogen induces multiple regulatory B cell subtypes and promotes M2 microglia and neuroprotection during experimental autoimmune encephalomyelitis. J. Neuroimmunol. 293, 45-53. https://doi.org/10. 1016/j.jneuroim.2016.02.009.

Bessa, A., Campos, F.L., Videira, R.A., Mendes-Oliveira, J., Bessa-Neto, D., Baltazar, G., 2015. GPER: a new tool to protect dopaminergic neurons? Biochim. Biophys. Acta 1852, 2035-2041. https://doi.org/10.1016/j.bbadis.2015.07.004.

Borbélyová, V., Domonkos, E., Csongová, M., Kačmárová, M., Ostatníková, D., Celec, P., Hodosy, J., 2017. Sex-dependent effects of letrozole on anxiety in, middle-aged rats. Clin. Exp. Pharmacol. Physiol. 44 (Suppl 1), 93-98. https://doi.org/10.1111/14401681.12731

Bourque, M., Dluzen, D.E., Di Paolo, T., 2009. Neuroprotective actions of sex steroids in Parkinson's disease. Front. Neuroendocrinol. 30, 142-157. https://doi.org/10.1016/ j.yfrne.2009.04.014.

Bourque, M., Dluzen, D.E., Di Paolo, T., 2011. Male/Female differences in neuroprotection and neuromodulation of brain dopamine. Front. Endocrinol. (Lausanne) 2 (35). https://doi.org/10.3389/fendo.2011.00035.

Bourque, M., Morissette, M., Di Paolo, T., 2015. Neuroprotection in Parkinsonian-treated mice via estrogen receptor $\alpha$ activation requires Gprotein-coupled estrogen receptor 1. Neuropharmacology 95, 343-352. https://doi.org/10.1016/j.neuropharm.2015. 04.006.

Bourque, M., Morissette, M., Di Paolo, T., 2019. Repurposing sex steroids and related drugs as potential treatment for Parkinson's disease. Neuropharmacology 147, 37-54. https://doi.org/10.1016/j.neuropharm.2018.04.005.

Bowers, J.M., Waddell, J., McCarthy, M.M., 2010. A developmental sex difference in hippocampal neurogenesis is mediated by endogenous oestradiol. Biol. Sex. Differ. 1, 8. https://doi.org/10.1186/2042-6410-1-8.

Brandt, N., Rune, G.M., 2019. Sex dependency of estrogen-induced structural synaptic plasticity: inhibition of aromatase versus application of estradiol in rodents. Eur. J. Neurosci. https://doi.org/10.1111/ejn.14541.

Brocca, M.E., Garcia-Segura, L.M., 2018. Non-reproductive functions of aromatase in the central nervous system under physiological and pathological conditions. Cell. Mol. Neurobiol. https://doi.org/10.1007/s10571-018-0607-4.

Bryant, D.N., Dorsa, D.M., 2010. Roles of estrogen receptors alpha and beta in sexually dimorphic neuroprotection against glutamate toxicity. Neuroscience 170 1261-1269. https://doi.org/10.1016/j.neuroscience.2010.08.019.

Busiguina, S., Fernandez, A.M., Barrios, V., Clark, R., Tolbert, D.L., Berciano, J., Torres Aleman, I., 2000. Neurodegeneration is associated to changes in serum insulin-like growth factors. Neurobiol. Dis. 7 (6 Pt B), 657-665.

Cambiasso, M.J., Cisternas, C.D., Ruiz-Palmero, I., Scerbo, M.J., Arevalo, M.A., Azcoitia I., Garcia-Segura, L.M., 2017. Interaction of sex chromosome complement, gonadal hormones and neuronal steroid synthesis on the sexual differentiation of mammalian neurons. J. Neurogenet. 31, 300-306. https://doi.org/10.1080/01677063.2017. 1390572.

Campos, F.L., Cristovão, A.C., Rocha, S.M., Fonseca, C.P., Baltazar, G., 2012. GDNF contributes to oestrogen-mediated protection of midbrain dopaminergic neurones. J. Neuroendocrinol. 24, 1386-1397. https://doi.org/10.1111/j.1365-2826.2012. 02348.x.

Canerina-Amaro, A., Hernandez-Abad, L.G., Ferrer, I., Quinto-Alemany, D., Mesa-Herrera, F., Ferri, C., Puertas-Avendano, R.A., Diaz, M., Marin, R., 2017. Lipid raft ER signalosome malfunctions in menopause and Alzheimer's disease. Front. Biosci. (Schol Ed) 9, 111-126.

Cardona-Rossinyol, A., Mir, M., Caraballo-Miralles, V., Lladó, J., Olmos, G., 2013. Neuroprotective effects of estradiol on motoneurons in a model of rat spinal cord embryonic explants. Cell. Mol. Neurobiol. 33, 421-432. https://doi.org/10.1007/ s10571-013-9908-9.

Carswell, H.V., Macrae, I.M., Gallagher, L., Harrop, E., Horsburgh, K.J., 2004. Neuroprotection by a selective estrogen receptor beta agonist in a mouse model of global ischemia. Am. J. Physiol. Heart Circ. Physiol. 287, H1501-H1504.

Caruso, D., Pesaresi, M., Abbiati, F., Calabrese, D., Giatti, S., Garcia-Segura, L.M., Melcangi, R.C., 2013. Comparison of plasma and cerebrospinal fluid levels of neuroactive steroids with their brain, spinal cord and peripheral nerve levels in male and female rats. Psychoneuroendocrinology 38, 2278-2290. https://doi.org/10.1016/j. psyneuen.2013.04.016.

Cerciat, M., Unkila, M., Garcia-Segura, L.M., Arevalo, M.A., 2010. Selective estrogen receptor modulators decrease the production of interleukin- 6 and interferon-gammainducible protein-10 by astrocytes exposed to inflammatory challenge in vitro. Glia 58, 93-102. https://doi.org/10.1002/glia.20904.

Cerghet, M., Skoff, R.P., Swamydas, M., Bessert, D., 2009. Sexual dimorphism in the white 
matter of rodents. J. Neurol. Sci. 286, 76-80. https://doi.org/10.1016/j.jns.2009.06. 039.

Céspedes Rubio, Á.E., Pérez-Alvarez, M.J., Lapuente Chala, C., Wandosell, F., 2018. Sex steroid hormones as neuroprotective elements in ischemia models. J. Endocrinol. 237, R65-R81. https://doi.org/10.1530/JOE-18-0129.

Chakrabarti, M., Banik, N.L., Ray, S.K., 2014. MiR-7-1 potentiated estrogen receptor agonists for functional neuroprotection in VSC4.1 motoneurons. Neuroscience 256, 322-333. https://doi.org/10.1016/j.neuroscience.2013.10.027.

Chamniansawat, S., Chongthammakun, S., 2012. A priming role of local estrogen on exogenous estrogen-mediated synaptic plasticity and neuroprotection. Exp. Mol. Med. 44, 403-411. https://doi.org/10.3858/emm.2012.44.6.046.

Chang, P.K., Boridy, S., McKinney, R.A., Maysinger, D., 2013. Letrozole Potentiates Mitochondrial and Dendritic Spine Impairments Induced by $\beta$ Amyloid. J. Aging Res. 2013, 538979. https://doi.org/10.1155/2013/538979.

Chen, J., Hu, R., Ge, H., Duanmu, W., Li, Y., Xue, X., Hu, S., Feng, H., 2015. G-proteincoupled receptor 30-mediated antiapoptotic effect of estrogen on spinal motorneurons following injury and its underlying mechanisms. Mol. Med. Rep. 12, 1733-1740. https://doi.org/10.3892/mmr.2015.3601.

Cheng, Y., Su, Q., Shao, B., Cheng, J., Wang, H., Wang, L., Lin, Z., Ruan, L., ZhuGe, Q., Jin, K., 2013. $17 \beta$-Estradiol attenuates poststroke depression and increases neurogenesis in female ovariectomized rats. Biomed. Res. Int. 2013, 392434. https://doi. org/10.1155/2013/392434.

Cisternas, C.D., Tome, K., Caeiro, X.E., Dadam, F.M., Garcia-Segura, L.M., Cambiasso, M.J., 2015. Sex chromosome complement determines sex differences in aromatase expression and regulation in the stria terminalis and anterior amygdala of the developing mouse brain. Mol. Cell. Endocrinol. 414, 99-110. https://doi.org/10.1016/ j.mce.2015.07.027.

Cisternas, C.D., Cabrera Zapata, L.E., Arevalo, M.A., Garcia-Segura, L.M., Cambiasso, M.J., 2017. Regulation of aromatase expression in the anterior amygdala of the developing mouse brain depends on ER $\beta$ and sex chromosome complement. Sci. Rep. 7, 5320. https://doi.org/10.1038/s41598-017-05658-6.

Connell, B.J., Saleh, T.M., 2011. Differential neuroprotection of selective estrogen receptor agonists against autonomic dysfunction and ischemic cell death in permanent versus reperfusion injury. Adv. Pharmacol. Sci. 2011, 976951. https://doi.org/10. 1155/2011/976951.

Cook, S., Hung, V., Duncan, K.A., 2018. Crosstalk between Estrogen Withdrawal and NFkB Signaling following Penetrating Brain Injury. Neuroimmunomodulation 25, 193-200. https://doi.org/10.1159/000493506.

Corvino, V., Di Maria, V., Marchese, E., Lattanzi, W., Biamonte, F., Michetti, F., Geloso, M.C., 2015. Estrogen administration modulates hippocampal GABAergic subpopulations in the hippocampus of trimethyltin-treated rats. Front. Cell. Neurosci. 9, 433. https://doi.org/10.3389/fncel.2015.00433.

D'Astous, M., Mendez, P., Morissette, M., Garcia-Segura, L.M., Di Paolo, T., 2006. Implication of the phosphatidylinositol-3 kinase/protein kinase B signaling pathway in the neuroprotective effect of estradiol in the striatum of 1-methyl-4-phenyl1,2,3,6-tetrahydropyridine mice. Mol. Pharmacol. 69, 1492-1498.

Day, N.L., Floyd, C.L., D'Alessandro, T.L., Hubbard, W.J., Chaudry, I.H., 2013. 17ß-estradiol confers protection after traumatic brain injury in the rat and involves activation of G protein-coupled estrogen receptor 1. J. Neurotrauma 30, 1531-1541. https://doi.org/10.1089/neu.2013.2854.

De Marinis, E., Acaz-Fonseca, E., Arevalo, M.A., Ascenzi, P., Fiocchetti, M., Marino, M., Garcia-Segura, L.M., 2013. 17ß-Oestradiol anti-inflammatory effects in primary astrocytes require oestrogen receptor $\beta$-mediated neuroglobin up-regulation. J. Neuroendocrinol. 25, 260-270. https://doi.org/10.1111/jne.12007.

de Rivero Vaccari, J.P., Patel, H.H., Brand, F.J., Perez-Pinzon, M.A., Bramlett, H.M., Raval, A.P., 2016. Estrogen receptor beta signaling alters cellular inflammasomes activity after global cerebral ischemia in reproductively senescence female rats. J. Neurochem. 136, 492-496. https://doi.org/10.1111/jnc.13404.

Dhandapani, K.M., Wade, F.M., Mahesh, V.B., Brann, D.W., 2005. Astrocyte-derived transforming growth factor- $\beta$ mediates the neuroprotective effects of $17 \beta$-estradiol: involvement of nonclassical genomic signaling pathways. Endocrinology 146, 2749-2759.

Dietrich, A.K., Humphreys, G.I., Nardulli, A.M., 2013. 17ß-estradiol increases expression of the oxidative stress response and DNA repair protein apurinic endonuclease (Ape1) in the cerebral cortex of female mice following hypoxia. J. Steroid Biochem. Mol. Biol. 138, 410-420. https://doi.org/10.1016/j.jsbmb.2013.07.007.

Du, S., Itoh, N., Askarinam, S., Hill, H., Arnold, A.P., Voskuhl, R.R., 2014. XY sex chromosome complement, compared with XX, in the CNS confers greater neurodegeneration during experimental autoimmune encephalomyelitis. Proc. Natl. Acad. Sci. USA 111, 2806-2811. https://doi.org/10.1073/pnas.1307091111.

Duenas, M., Torres-Aleman, I., Naftolin, F., Garcia-Segura, L.M., 1996. Interaction of insulin-like growth factor-I and estradiol signaling pathways on hypothalamic neuronal differentiation. Neuroscience 74, 531-539.

Duncan, K.A., Saldanha, C.J., 2011. Neuroinflammation induces glial aromatase expression in the uninjured songbird brain. J. Neuroinflammation. 8, 81. https://doi.org/ 10.1186/1742-2094-8-81.

Duncan, K.A., Walters, B.J., Saldanha, C.J., 2013. Traumatized and inflamed-but resilient: glial aromatization and the avian brain. Horm. Behav. 63, 208-215. https:// doi.org/10.1016/j.yhbeh.2012.02.026.

Dziennis, S., Jia, T., Rønnekleiv, O.K., Hurn, P.D., Alkayed, N.J., 2007. Role of signal transducer and activator of transcription-3 in estradiol-mediated neuroprotection. J. Neurosci. 27, 7268-7274.

Elkabes, S., Nicot, A.B., 2014. Sex steroids and neuroprotection in spinal cord injury: a review of preclinical investigations. Exp. Neurol. 259, 28-37. https://doi.org/10. 1016/j.expneurol.2014.01.008.

Elzer, J.G., Muhammad, S., Wintermantel, T.M., Regnier-Vigouroux, A., Ludwig, J.,
Schütz, G., Schwaninger, M., 2010. Neuronal estrogen receptor-alpha mediates neuroprotection by 17beta-estradiol. J. Cereb. Blood Flow Metab. 30, 935-942. https://doi.org/10.1038/jcbfm.2009.258.

Engler-Chiurazzi, E.B., Brown, C.M., Povroznik, J.M., Simpkins, J.W., 2017. Estrogens as neuroprotectants: estrogenic actions in the context of cognitive aging and brain injury. Prog. Neurobiol. 157, 188-211. https://doi.org/10.1016/j.pneurobio.2015.12. 008.

Fester, L., Zhou, L., Bütow, A., Huber, C., von Lossow, R., Prange-Kiel, J., Jarry, H., Rune, G.M., 2009. Cholesterol-promoted synaptogenesis requires the conversion of cholesterol to estradiol in the hippocampus. Hippocampus 19, 692-705. https://doi.org/ 10.1002/hipo.20548.

Feng, Y., Wang, B., Du, F., Li, H., Wang, S., Hu, C., Zhu, C., Yu, X., 2013a. The involvement of PI3K-mediated and L-VGCC-gated transient Ca2 + influx in 17ß-estradiol-mediated protection of retinal cells from $\mathrm{H} 2 \mathrm{O} 2$-induced apoptosis with $\mathrm{Ca} 2+$ overload. PLoS One 8, e77218. https://doi.org/10.1371/journal.pone.0077218.

Feng, J., Zhang, G., Hu, X., Si Chen, C., Qin, X., 2013b. Estrogen inhibits estrogen receptor $\alpha$-mediated rho-kinase expression in experimental autoimmune encephalomyelitis rats. Synapse 67, 399-406. https://doi.org/10.1002/syn.21650.

Fernández-Martínez, M., Elcoroaristizabal Martín, X., Blanco Martín, E., Galdos Alcelay, L., Ugarriza Serrano, I., Gómez Busto, F., Alvarez-Álvarez, M., Molano Salazar, A., Bereincua Gandarias, R., Inglés Borda, S., Uterga Valiente, J.M., Indakoetxea Juanbeltz, B., Gómez Beldarraín, M.Á., Moraza López, J., Barandiarán Amillano, M., de Pancorbo, M.M., 2013. Oestrogen receptor polymorphisms are an associated risk factor for mild cognitive impairment and Alzheimer disease in women APOE $\varepsilon 4$ carriers: a case-control study. BMJ Open. 3, e003200. https://doi.org/10.1136/ bmjopen-2013-003200.

Gaignard, P., Fréchou, M., Liere, P., Thérond, P., Schumacher, M., Slama, A., Guennoun, R., 2018. Sex differences in brain mitochondrial metabolism: influence of endogenous steroids and stroke. J. Neuroendocrinol. 30, e12497. https://doi.org/10.1111/jne. 12497.

Garay, L., Gonzalez Deniselle, M.C., Gierman, L., Meyer, M., Lima, A., Roig, P., De Nicola, A.F., 2008. Steroid protection in the experimental autoimmune encephalomyelitis model of multiple sclerosis. Neuroimmunomodulation 15, 76-83. https://doi.org/10. $1159 / 000135627$.

Garcia-Segura, L.M., Cardona-Gomez, P., Naftolin, F., Chowen, J.A., 1998. Estradiol upregulates Bcl-2 expression in adult brain neurons. Neuroreport 9, 593-597.

Garcia-Segura, L.M., Wozniak, A., Azcoitia, I., Rodriguez, J.R., Hutchison, R.E. Hutchison, J.B., 1999. Aromatase expression by astrocytes after brain injury: implications for local estrogen formation in brain repair. Neuroscience 89, 567-578.

Gerstner, B., Sifringer, M., Dzietko, M., Schüller, A., Lee, J., Simons, S., Obladen, M., Volpe, J.J., Rosenberg, P.A., Felderhoff-Mueser, U., 2007. Estradiol attenuates hyperoxia-induced cell death in the developing white matter. Ann. Neurol. 61, 562-573.

Giatti, S., Garcia-Segura, L.M., Barreto, G.E., Melcangi, R.C., 2018. Neuroactive steroids, neurosteroidogenesis and sex. Prog. Neurobiol. 2, 2. https://doi.org/10.1016/j. pneurobio.2018.06.007.

Gillies, G.E., McArthur, S., 2010a. Estrogen actions in the brain and the basis for differential action in men and women: a case for sex-specific medicines. Pharmacol. Rev. 62, 155-198. https://doi.org/10.1124/pr.109.002071.

Gillies, G.E., McArthur, S., 2010b. Independent influences of sex steroids of systemic and central origin in a rat model of Parkinson's disease: a contribution to sex-specific neuroprotection by estrogens. Horm. Behav. 57, 23-34. https://doi.org/10.1016/j yhbeh.2009.06.002.

Giraud, S.N., Caron, C.M., Pham-Dinh, D., Kitabgi, P., Nicot, A.B., 2010. Estradiol inhibits ongoing autoimmune neuroinflammation and NFkappaB-dependent CCL2 expression in reactive astrocytes. Proc. Natl. Acad. Sci. USA 107, 8416-8421. https://doi.org/ 10.1073/pnas.0910627107.

Grimm, A., Biliouris, E.E., Lang, U.E., Götz, J., Mensah-Nyagan, A.G., Eckert, A., 2016a. Sex hormone-related neurosteroids differentially rescue bioenergetics deficits induced by amyloid- $\beta$ or hyperphosphorylated tau protein. Cell. Mol. Life Sci. 73, 201-215. https://doi.org/10.1007/s00018-015-1988-x.

Grimm, A., Mensah-Nyagan, A.G., Eckert, A., 2016b. Alzheimer, mitochondria and gender. Neurosci. Biobehav. Rev. 67, 89-101. https://doi.org/10.1016/j.neubiorev. 2016.04.012.

Guerra, B., Díaz, M., Alonso, R., Marin, R., 2004. Plasma membrane oestrogen receptor mediates neuroprotection against beta-amyloid toxicity through activation of Raf-1/ MEK/ERK cascade in septal-derived cholinergic SN56 cells. J. Neurochem. 91 99-109.

Guo, J., Krause, D.N., Horne, J., Weiss, J.H., Li, X., Duckles, S.P., 2010. Estrogen-receptormediated protection of cerebral endothelial cell viability and mitochondrial function after ischemic insult in vitro. J. Cereb. Blood Flow Metab. 30, 545-554. https://doi. org/10.1038/jcbfm.2009.226.

Guo, J., Duckles, S.P., Weiss, J.H., Li, X., Krause, D.N., 2012. 17ß-Estradiol prevents cell death and mitochondrial dysfunction by an estrogen receptor-dependent mechanism in astrocytes after oxygen-glucose deprivation/reperfusion. Free Radic. Biol. Med. 52, 2151-2160. https://doi.org/10.1016/j.freeradbiomed.2012.03.005.

Guo, J.M., Shu, H., Wang, L., Xu, J.J., Niu, X.C., Zhang, L., 2017. SIRT1-dependent AMPK pathway in the protection of estrogen against ischemic brain injury. CNS Neurosci. Ther. 23, 360-369. https://doi.org/10.1111/cns.12686.

Habib, P., Slowik, A., Zendedel, A., Johann, S., Dang, J., Beyer, C., 2014. Regulation of hypoxia-induced inflammatory responses and M1-M2 phenotype switch of primary rat microglia by sex steroids. J. Mol. Neurosci. 52, 277-285. https://doi.org/10. 1007/s12031-013-0137-y.

He, Q., Luo, Y., Lv, F., Xiao, Q., Chao, F., Qiu, X., Zhang, L., Gao, Y., Xiu, Y., Huang, C., Tang, Y., 2018. Effects of estrogen replacement therapy on the myelin sheath ultrastructure of myelinated fibers in the white matter of middle-aged ovariectomized 
rats. J. Comp. Neurol. 526, 790-802. https://doi.org/10.1002/cne.24366.

Heitzer, M., Kaiser, S., Kanagaratnam, M., Zendedel, A., Hartmann, P., Beyer, C., Johann, S., 2017. Administration of $17 \beta$-estradiol improves motoneuron survival and downregulates inflammasome activation in male SOD1(G93A) ALS mice. Mol. Neurobiol. 54, 8429-8443. https://doi.org/10.1007/s12035-016-0322-4.

Heneka, M.T., McManus, R.M., Latz, E., 2018. Inflammasome signalling in brain function and neurodegenerative disease. Nat. Rev. Neurosci. 19, 610-621. https://doi.org/10. 1038/s41583-018-0055-7.

Herzog, R., Zendedel, A., Lammerding, L., Beyer, C., Slowik, A., 2017. Impact of 17 betaestradiol and progesterone on inflammatory and apoptotic microRNA expression after ischemia in a rat model. J. Steroid Biochem. Mol. Biol. 167, 126-134. https:// doi.org/10.1016/j.jsbmb.2016.11.018.

Hirahara, Y., Matsuda, K., Gao, W., Arvanitis, D.N., Kawata, M., Boggs, J.M., 2009. The localization and non-genomic function of the membrane-associated estrogen receptor in oligodendrocytes. Glia 57, 153-165. https://doi.org/10.1002/glia.20742.

Hirahara, Y., Matsuda, K.I., Yamada, H., Saitou, A., Morisaki, S., Takanami, K., Boggs, J.M., Kawata, M., 2013. G protein-coupled receptor 30 contributes to improved re myelination after cuprizone-induced demyelination. Glia 61, 420-431. https://doi. org/10.1002/glia.22445.

Hojo, Y., Kawato, S., 2018. Neurosteroids in adult hippocampus of male and female rodents: biosynthesis and actions of sex steroids. Front. Endocrinol. (Lausanne) 9, 183. https://doi.org/10.3389/fendo.2018.00183.

Honda, K., Shimohama, S., Sawada, H., Kihara, T., Nakamizo, T., Shibasaki, H., Akaike, A., 2001. Nongenomic antiapoptotic signal transduction by estrogen in cultured cortical neurons. J. Neurosci. Res. 64, 466-475.

Hyer, M.M., Phillips, L.L., Neigh, G.N., 2018. Sex differences in synaptic plasticity: hormones and beyond. Front. Mol. Neurosci. 11, 266. https://doi.org/10.3389/fnmol. 2018.00266.

Itoh, Y., Golden, L.C., Itoh, N., Matsukawa, M.A., Ren, E., Tse, V., Arnold, A.P., Voskuhl, R.R., 2019. The X-linked histone demethylase Kdm6a in CD4 + T lymphocytes modulates autoimmunity. J. Clin. Invest. 130https://doi.org/10.1172/JCI126250. pii: 126250.

Jain, A., Huang, G.Z., Woolley, C.S., 2019. Latent sex differences in molecular signaling that underlies excitatory synaptic potentiation in the hippocampus. J. Neurosci. 39, 1552-1565. https://doi.org/10.1523/JNEUROSCI.1897-18.2018.

Jia, J., Guan, D., Zhu, W., Alkayed, N.J., Wang, M.M., Hua, Z., Xu, Y., 2009. Estrogen inhibits Fas-mediated apoptosis in experimental stroke. Exp. Neurol. 215, 48-52. https://doi.org/10.1016/j.expneurol.2008.09.015.

Juhász-Vedres, G., Rózsa, E., Rákos, G., Dobszay, M.B., Kis, Z., Wölfling, J., Toldi, J., Párducz, A., Farkas, T., 2006. Dehydroepiandrosterone sulfate is neuroprotective when administered either before or after injury in a focal cortical cold lesion model. Endocrinology 147, 683-686.

Kaliannan, K., Robertson, R.C., Murphy, K., Stanton, C., Kang, C., Wang, B., Hao, L., Bhan, A.K., Kang, J.X., 2018. Estrogen-mediated gut microbiome alterations influence sexual dimorphism in metabolic syndrome in mice. Microbiome 6, 205. https://doi. org/10.1186/s40168-018-0587-0.

Karim, H., Kim, S.H., Lapato, A.S., Yasui, N., Katzenellenbogen, J.A., Tiwari-Woodruff, S.K., 2018. Increase in chemokine CXCL1 by ER $\beta$ ligand treatment is a key mediator in promoting axon myelination. Proc. Natl. Acad. Sci. USA 115, 6291-6296. https:// doi.org/10.1073/pnas.1721732115.

Karim, H., Kim, S.H., Lauderdale, K., Lapato, A.S., Atkinson, K., Yasui, N., YamateMorgan, H., Sekyi, M., Katzenellenbogen, J.A., Tiwari-Woodruff, S.K., 2019. Analogues of ER $\beta$ ligand chloroindazole exert immunomodulatory and remyelinating effects in a mouse model of multiple sclerosis. Sci. Rep. 9, 503. https://doi.org/10. 1038/s41598-018-37420-x.

Karki, P., Smith, K., Johnson, J., Lee, E., 2014. Astrocyte-derived growth factors and estrogen neuroprotection: role of transforming growth factor- $\alpha$ in estrogen-induced upregulation of glutamate transporters in astrocytes. Mol. Cell. Endocrinol. 389, 58-64. https://doi.org/10.1016/j.mce.2014.01.010.

Khalaj, A.J., Hasselmann, J., Augello, C., Moore, S., Tiwari-Woodruff, S.K., 2016. Nudging oligodendrocyte intrinsic signaling to remyelinate and repair: estrogen receptor ligand effects. J. Steroid Biochem. Mol. Biol. 160, 43-52. https://doi.org/10.1016/j jsbmb.2016.01.006.

Khan, M.M., Wakade, C., de Sevilla, L., Brann, D.W., 2015. Selective estrogen receptor modulators (SERMs) enhance neurogenesis and spine density following focal cerebral ischemia. J. Steroid Biochem. Mol. Biol. 146, 38-47. https://doi.org/10.1016/j. jsbmb.2014.05.001.

Khan, M., Shah, S.A., Kim, M.O., 2018. 17ß-Estradiol via SIRT1/Acetyl-p53/NF-kB signaling pathway rescued postnatal rat brain against acute ethanol intoxication. Mol. Neurobiol. 55, 3067-3078. https://doi.org/10.1007/s12035-017-0520-8.

Kipp, M., Hochstrasser, T., Schmitz, C., Beyer, C., 2016. Female sex steroids and glia cells: impact on multiple sclerosis lesion formation and fine tuning of the local neurodegenerative cellular network. Neurosci. Biobehav. Rev. 67, 125-136. https://doi.org/ 10.1016/j.neubiorev.2015.11.016.

Klores, M., Moon, J.T., Duncan, K.A., 2017. Expression of glial CBP in steroid mediated neuroprotection in male and female zebra finches. J. Chem. Neuroanat. 79, 32-37. https://doi.org/10.1016/j.jchemneu.2016.11.002.

Kodama, L., Gan, L., 2019. Do microglial sex differences contribute to sex differences in neurodegenerative diseases? Trends Mol. Med. https://doi.org/10.1016/j.molmed. 2019.05.001. pii: S1471-4914(19)30103-0.

Koh, P.O., 2014. Estradiol ameliorates the reduction in parvalbumin expression induced by ischemic brain injury. Neurosci. Lett. 574, 36-40. https://doi.org/10.1016/j. neulet.2014.05.006.

Kokras, N., Pastromas, N., Papasava, D., de Bournonville, C., Cornil, C.A., Dalla, C., 2018. Sex differences in behavioral and neurochemical effects of gonadectomy and aromatase inhibition in rats. Psychoneuroendocrinology 87, 93-107. https://doi.org/ 10.1016/j.psyneuen.2017.10.007.

Koss, W.A., Haertel, J.M., Philippi, S.M., Frick, K.M., 2018. Sex differences in the rapid cell signaling mechanisms underlying the memory-enhancing effects of $17 \beta$-estradiol. eNeuro 5 (5). https://doi.org/10.1523/ENEURO.0267-18.2018. pii: ENEURO.026718.2018.

Krentzel, A.A., Meitzen, J., 2018. Biological sex, estradiol and striatal medium spiny neuron physiology: a mini-review. Front. Cell. Neurosci. 12, 492. https://doi.org/10. 3389/fncel.2018.00492.

Kulkarni, J., Butler, S., Riecher-Rössler, A., 2019. Estrogens and SERMS as adjunctive treatments for schizophrenia. Front. Neuroendocrinol. 53, 100743. https://doi.org/ 10.1016/j.yfrne.2019.03.002.

Kumar, S., Patel, R., Moore, S., Crawford, D.K., Suwanna, N., Mangiardi, M., TiwariWoodruff, S.K., 2013. Estrogen receptor $\beta$ ligand therapy activates PI3K/Akt/mTOR signaling in oligodendrocytes and promotes remyelination in a mouse model of multiple sclerosis. Neurobiol. Dis. 56, 131-144. https://doi.org/10.1016/j.nbd.2013. 04.005 .

Kuroki, Y., Fukushima, K., Kanda, Y., Mizuno, K., Watanabe, Y., 2001. Neuroprotection by estrogen via extracellular signal-regulated kinase against quinolinic acid-induced cell death in the rat hippocampus. Eur. J. Neurosci. 13, 472-476.

Labandeira-Garcia, J.L., Rodriguez-Perez, A.I., Valenzuela, R., Costa-Besada, M.A. Guerra, M.J., 2016. Menopause and Parkinson's disease. Interaction between estrogens and brain renin-angiotensin system in dopaminergic degeneration. Front. Neuroendocrinol. 43, 44-59. https://doi.org/10.1016/j.yfrne.2016.09.003.

Lebesgue, D., Chevaleyre, V., Zukin, R.S., Etgen, A.M., 2009. Estradiol rescues neurons from global ischemia-induced cell death: multiple cellular pathways of neuroprotection. Steroids 74, 555-561. https://doi.org/10.1016/j.steroids.2009.01.003.

Lebesgue, D., Traub, M., De Butte-Smith, M., Chen, C., Zukin, R.S., Kelly, M.J., Etgen, A.M., 2010. Acute administration of non-classical estrogen receptor agonists attenuates ischemia-induced hippocampal neuron loss in middle-aged female rats. PLoS One 5, e8642. https://doi.org/10.1371/journal.pone.0008642.

Lee, E., Sidoryk-Wêgrzynowicz, M., Wang, N., Webb, A., Son, D.S., Lee, K., Aschner, M., 2012. GPR30 regulates glutamate transporter GLT-1 expression in rat primary astrocytes. J. Biol. Chem. 287, 26817-26828. https://doi.org/10.1074/jbc.M112. 341867.

Li, J., Siegel, M., Yuan, M., Zeng, Z., Finnucan, L., Persky, R., Hurn, P.D., McCullough, L.D., 2011. Estrogen enhances neurogenesis and behavioral recovery after stroke. J. Cereb. Blood Flow Metab. 31, 413-425. https://doi.org/10.1038/jcbfm.2010.181.

Li, L., Chen, J., Sun, S., Zhao, J., Dong, X., Wang, J., 2017. Effects of estradiol on autophagy and Nrf-2/ARE signals after cerebral ischemia. Cell Physiol. Biochem. 41, 2027-2036. https://doi.org/10.1159/000475433.

Li, R., He, P., Cui, J., Staufenbiel, M., Harada, N., Shen, Y., 2013. Brain endogenous estrogen levels determine responses to estrogen replacement therapy via regulation of BACE1 and NEP in female Alzheimer's transgenic mice. Mol. Neurobiol. 47, 857-867. https://doi.org/10.1007/s12035-012-8377-3.

Lin, C.W., Chen, B., Huang, K.L., Dai, Y.S., Teng, H.L., 2016. Inhibition of autophagy by estradiol promotes locomotor recovery after spinal cord injury in rats. Neurosci. Bull. 32, 137-144. https://doi.org/10.1007/s12264-016-0017-x.

Liu, F., Benashski, S.E., Xu, Y., Siegel, M., McCullough, L.D., 2012a. Effects of chronic and acute oestrogen replacement therapy in aged animals after experimental stroke. J. Neuroendocrinol. 24, 319-330. https://doi.org/10.1111/j.1365-2826.2011.02248.x.

Liu, S.B., Han, J., Zhang, N., Tian, Z., Li, X.B., Zhao, M.G., 2011. Neuroprotective effects of oestrogen against oxidative toxicity through activation of G-protein-coupled receptor 30 receptor. Clin. Exp. Pharmacol. Physiol. 38, 577-585. https://doi.org/10. 1111/j.1440-1681.2011.05549.x.

Liu, S.B., Zhang, N., Guo, Y.Y., Zhao, R., Shi, T.Y., Feng, S.F., Wang, S.Q., Yang, Q., Li, X.Q., Wu, Y.M., Ma, L., Hou, Y., Xiong, L.Z., Zhang, W., Zhao, M.G., 2012b. G-protein-coupled receptor 30 mediates rapid neuroprotective effects of estrogen via depression of NR2B-containing NMDA receptors. J. Neurosci. 32, 4887-4900. https:// doi.org/10.1523/JNEUROSCI.5828-11.2012.

López Rodríguez, A.B., Mateos Vicente, B., Romero-Zerbo, S.Y., Rodriguez-Rodriguez, N., Bellini, M.J., Rodriguez de Fonseca, F., Bermudez-Silva, F.J., Azcoitia, I., GarciaSegura, L.M., Viveros, M.P., 2011. Estradiol decreases cortical reactive astrogliosis after brain injury by a mechanism involving cannabinoid receptors. Cereb. Cortex 21, 2046-2055. https://doi.org/10.1093/cercor/bhq277.

Lu, H., Ma, K., Jin, L., Zhu, H., Cao, R., 2018. 17ß-estradiol rescues damages following traumatic brain injury from molecule to behavior in mice. J. Cell Physiol. 233 1712-1722. https://doi.org/10.1002/jcp.26083.

Luciani, P., Deledda, C., Rosati, F., Benvenuti, S., Cellai, I., Dichiara, F., Morello, M., Vannelli, G.B., Danza, G., Serio, M., Peri, A., 2008. Seladin-1 is a fundamental mediator of the neuroprotective effects of estrogen in human neuroblast long-term cell cultures. Endocrinology 149, 4256-4266. https://doi.org/10.1210/en.2007 1795.

Luciani, P., Deledda, C., Benvenuti, S., Cellai, I., Modi, G., Fibbi, B., Danza, G., Vannelli, G.B., Peri, A., 2012. Relationship between the neuroprotective effects of insulin-like growth factor-1 and $17 \beta$-oestradiol in human neuroblasts. J. Neuroendocrinol. 24, 1304-1310. https://doi.org/10.1111/j.1365-2826.2012.02343.x.

Ma, Y., Guo, H., Zhang, L., Tao, L., Yin, A., Liu, Z., Li, Y., Dong, H., Xiong, L., Hou, W., 2016. Estrogen replacement therapy-induced neuroprotection against brain ischemiareperfusion injury involves the activation of astrocytes via estrogen receptor $\beta$. Sci. Rep. 6, 21467. https://doi.org/10.1038/srep21467.

Madinier, A., Wieloch, T., Olsson, R., Ruscher, K., 2014. Impact of estrogen receptor beta activation on functional recovery after experimental stroke. Behav. Brain Res. 261, 282-288. https://doi.org/10.1016/j.bbr.2013.12.046.

Mannella, P., Brinton, R.D., 2006. Estrogen receptor protein interaction with phosphatidylinositol 3-kinase leads to activation of phosphorylated Akt and extracellular signal-regulated kinase $1 / 2$ in the same population of cortical neurons: a unified 
mechanism of estrogen action. J. Neurosci. 26, 9439-9447.

Marin, R., Diaz, M., 2018. Estrogen interactions with lipid rafts related to neuroprotection. Impact of brain ageing and menopause. Front. Neurosci. 12 (128). https://doi org/10.3389/fnins.2018.00128.

Marin, R., Casañas, V., Pérez, J.A., Fabelo, N., Fernandez, C.E., Diaz, M., 2013. Oestrogens as modulators of neuronal signalosomes and brain lipid homeostasis related to protection against neurodegeneration. J. Neuroendocrinol. 25, 1104-1115. https://doi.org/10.1111/jne.12068.

Marino, M., Galluzzo, P., Ascenzi, P., 2006. Estrogen signaling multiple pathways to impact gene transcription. Curr. Genomics 7, 497-508.

Martin-Jiménez, C., Gaitán-Vaca, D.M., Areiza, N., Echeverria, V., Ashraf, G.M., González, J., Sahebkar, A., Garcia-Segura, L.M., Barreto, G.E., 2019. Astrocytes mediate protective actions of estrogenic compounds after traumatic brain injury. Neuroendocrinology 108, 142-160. https://doi.org/10.1159/000495078.

McCullough, L.D., Blizzard, K., Simpson, E.R., Oz, O.K., Hurn, P.D., 2003. Aromatase cytochrome P450 and extragonadal estrogen play a role in ischemic neuroprotection. J. Neurosci. 23, 8701-8705.

McCullough, L.D., Mirza, M.A., Xu, Y., Bentivegna, K., Steffens, E.B., Ritzel, R., Liu, F., 2016. Stroke sensitivity in the aged: sex chromosome complement vs. gonadal hormones. Aging (Albany NY) 8, 1432-1441. https://doi.org/10.18632/aging.100997.

McFarland, K., Price, D.L., Davis, C.N., Ma, J.N., Bonhaus, D.W., Burstein, E.S., Olsson, R., 2013. AC-186, a selective nonsteroidal estrogen receptor $\beta$ agonist, shows gender specific neuroprotection in a Parkinson's disease rat model. ACS Chem. Neurosci. 4, 1249-1255. https://doi.org/10.1021/cn400132u.

Medway, C., Combarros, O., Cortina-Borja, M., Butler, H.T., Ibrahim-Verbaas, C.A., de Bruijn, R.F., Koudstaal, P.J., van Duijn, C.M., Ikram, M.A., Mateo, I., Sánchez-Juan, P., Lehmann, M.G., Heun, R., Kölsch, H., Deloukas, P., Hammond, N., Coto, E., Alvarez, V., Kehoe, P.G., Barber, R., Wilcock, G.K., Brown, K., Belbin, O., Warden, D.R., Smith, A.D., Morgan, K., Lehmann, D.J., 2014. The sex-specific associations of the aromatase gene with Alzheimer's disease and its interaction with IL10 in the Epistasis Project. Eur. J. Hum. Genet. 22, 216-220. https://doi.org/10.1038/ejhg. 2013.116.

Mehos, C.J., Nelson, L.H., Saldanha, C.J., 2016. A quantification of the injury-induced changes in central aromatase, oestrogenic milieu and steroid receptor expression in the Zebra Finch. J. Neuroendocrinol. 28, 12348. https://doi.org/10.1111/jne.12348.

Meitzen, J., Britson, K.A., Tuomela, K., Mermelstein, P.G., 2019. The expression of select genes necessary for membrane-associated estrogen receptor signaling differ by sex in adult rat hippocampus. Steroids 142, 21-27. https://doi.org/10.1016/j.steroids. 2017.09.012

Melcangi, R.C., Giatti, S., Garcia-Segura, L.M., 2016. Levels and actions of neuroactive steroids in the nervous system under physiological and pathological conditions: sexspecific features. Neurosci. Biobehav. Rev. 67, 25-40. https://doi.org/10.1016/j. neubiorev.2015.09.023

Mendez, P., Wandosell, F., Garcia-Segura, L.M., 2006. Cross-talk between estrogen receptors and insulin-like growth factor-I receptor in the brain: cellular and molecular mechanisms. Front. Neuroendocrinol. 27, 391-403.

Miller, N.R., Jover, T., Cohen, H.W., Zukin, R.S., Etgen, A.M., 2005. Estrogen can act via estrogen receptor alpha and beta to protect hippocampal neurons against global ischemia-induced cell death. Endocrinology 146, 3070-3079.

Moore, S., Patel, R., Hannsun, G., Yang, J., Tiwari-Woodruff, S.K., 2013. Sex chromosome complement influences functional callosal myelination. Neuroscience 245, 166-178. https://doi.org/10.1016/j.neuroscience.2013.04.017.

Morales, L.B., Loo, K.K., Liu, H.B., Peterson, C., Tiwari-Woodruff, S., Voskuhl, R.R., 2006. Treatment with an estrogen receptor alpha ligand is neuroprotective in experimental autoimmune encephalomyelitis. J. Neurosci. 26, 6823-6833.

Morissette, M., Le Saux, M., D'Astous, M., Jourdain, S., Al Sweidi, S., Morin, N., EstradaCamarena, E., Mendez, P., Garcia-Segura, L.M., Di Paolo, T., 2008. Contribution of estrogen receptors alpha and beta to the effects of estradiol in the brain. J. Steroid Biochem. Mol. Biol. 108, 327-338.

Munive, V., Santi, A., Torres-Aleman, I., 2016. A concerted action of estradiol and insulin like growth factor I underlies sex differences in mood regulation by exercise. Sci. Rep. 6, 25969. https://doi.org/10.1038/srep25969.

Na, W., Lee, J.Y., Kim, W.S., Yune, T.Y., Ju, B.G., 2015. 17ß-Estradiol ameliorates tight junction disruption via repression of MMP transcription. Mol. Endocrinol. 29, 1347-1361. https://doi.org/10.1210/ME.2015-1124.

Nelson, L.H., Warden, S., Lenz, K.M., 2017. Sex differences in microglial phagocytosis in the neonatal hippocampus. Brain Behav. Immun. 64, 11-22. https://doi.org/10. 1016/j.bbi.2017.03.010

Nilsen, J., 2008. Estradiol and neurodegenerative oxidative stress. Front. Neuroendocrinol. 29, 463-475. https://doi.org/10.1016/j.yfrne.2007.12.005.

Nixon, E., Simpkins, J.W., 2012. Neuroprotective effects of nonfeminizing estrogens in retinal photoreceptor neurons. Invest. Ophthalmol. Vis. Sci. 53, 4739-4747. https:// doi.org/10.1167/iovs.12-9517.

Nuzzo, M.T., Fiocchetti, M., Totta, P., Melone, M.A.B., Cardinale, A., Fusco, F.R., Gustincich, S., Persichetti, F., Ascenzi, P., Marino, M., 2017. Huntingtin polyQ mutation impairs the 17ß-estradiol/neuroglobin pathway devoted to neuron survival. Mol. Neurobiol. 54, 6634-6646. https://doi.org/10.1007/s12035-016-0337-x.

Oberlander, J.G., Woolley, C.S., 2016. 17ß-Estradiol acutely potentiates glutamatergic synaptic transmission in the hippocampus through distinct mechanisms in males and females. J. Neurosci. 36, 2677-2690. https://doi.org/10.1523/JNEUROSCI.4437-15. 2016.

Ospina, J.A., Brevig, H.N., Krause, D.N., Duckles, S.P., 2004. Estrogen suppresses IL1beta-mediated induction of COX-2 pathway in rat cerebral blood vessels. Am. J. Physiol. Heart. Circ. Physiol. 286, H2010-H2019.

Pansiot, J., Pham, H., Dalous, J., Chevenne, D., Colella, M., Schwendimann, L., Fafouri, A., Mairesse, J., Moretti, R., Schang, A.L., Charriaut-Marlangue, C., Gressens, P.,
Baud, O., 2016. Glial response to $17 \beta$-estradiol in neonatal rats with excitotoxic brain injury. Exp. Neurol. 282, 56-65. https://doi.org/10.1016/j. expneurol.2016.05.024.

Pedersen, A.L., Brownrout, J.L., Saldanha, C.J., 2018. Neuroinflammation and neurosteroidogenesis: reciprocal modulation during injury to the adult zebra finch brain. Physiol. Behav. 187, 51-56. https://doi.org/10.1016/j.physbeh.2017.10.013.

Pérez-Álvarez, M.J., Maza Mdel, C., Anton, M., Ordoñez, L., Wandosell, F., 2012. Postischemic estradiol treatment reduced glial response and triggers distinct cortical and hippocampal signaling in a rat model of cerebral ischemia. J. Neuroinflammation 9 , 157. https://doi.org/10.1186/1742-2094-9-157.

Perez-Alvarez, M.J., Villa Gonzalez, M., Benito-Cuesta, I., Wandosell, F.G., 2018. Role of mTORC1 controlling proteostasis after brain ischemia. Front. Neurosci. 12, 60. https://doi.org/10.3389/fnins.2018.00060.

Pietranera, L., Brocca, M.E., Roig, P., Lima, A., Garcia-Segura, L.M., De Nicola, A.F., 2015 Estrogens are neuroprotective factors for hypertensive encephalopathy. J. Steroid Biochem. Mol. Biol. 146, 15-25. https://doi.org/10.1016/j.jsbmb.2014.04.001.

Pietranera, L., Correa, J., Brocca, M.E., Roig, P., Lima, A., Di Giorgio, N., Garcia-Segura, L.M., De Nicola, A.F., 2016. Selective oestrogen receptor agonists rescued hippocampus parameters in male spontaneously hypertensive rats. J. Neuroendocrinol. 28. https://doi.org/10.1111/jne.12415.

Platania, P., Seminara, G., Aronica, E., Troost, D., Catania, M.V., Sortino, M.A., 2005 17beta-estradiol rescues spinal motoneurons from AMPA-induced toxicity: a role for glial cells. Neurobiol. Dis. 20, 461-470.

Qu, N., Wang, L., Liu, Z.C., Tian, Q., Zhang, Q., 2013. Oestrogen receptor $\alpha$ agonist improved long-term ovariectomy-induced spatial cognition deficit in young rats. Int. J. Neuropsychopharmacol. 16, 1071-1082. https://doi.org/10.1017/ S1461145712000958.

Quesada, A., Lee, B.Y., Micevych, P.E., 2008. PI3 kinase/Akt activation mediates estrogen and IGF-1 nigral DA neuronal neuroprotection against a unilateral rat model of Parkinson's disease. Dev. Neurobiol. 68, 632-644. https://doi.org/10.1002/dneu. 20609.

Rao, A.K., Dietrich, A.K., Ziegler, Y.S., Nardulli, A.M., 2011. 17ß-Estradiol-mediated increase in $\mathrm{Cu} / \mathrm{Zn}$ superoxide dismutase expression in the brain: a mechanism to protect neurons from ischemia. J. Steroid Biochem. Mol. Biol. 127, 382-389. https://doi. org $/ 10.1016 / j$ j.jsbmb.2011.06.008.

Raval, A.P., Saul, I., Dave, K.R., DeFazio, R.A., Perez-Pinzon, M.A., Bramlett, H., 2009. Pretreatment with a single estradiol-17beta bolus activates cyclic-AMP response element binding protein and protects CA1 neurons against global cerebral ischemia. Neuroscience 160, 307-318. https://doi.org/10.1016/j.neuroscience.2009.02.065.

Recabarren-Leiva, D., Alarcón, M., 2018. New insights into the gene expression associated to amyotrophic lateral sclerosis. Life Sci. 193, 110-123. https://doi.org/10.1016/j. lfs.2017.12.016.

Rettberg, J.R., Yao, J., Brinton, R.D., 2014. Estrogen: a master regulator of bioenergetic systems in the brain and body. Front. Neuroendocrinol. 35, 8-30. https://doi.org/10. 1016/j.yfrne.2013.08.001.

Rocca, W.A., Grossardt, B.R., Shuster, L.T., 2014. Oophorectomy, estrogen, and dementia: a 2014 update. Mol. Cell. Endocrinol. 389, 7-12. https://doi.org/10.1016/j.mce. 2014.01.020.

Rodriguez-Perez, A.I., Dominguez-Meijide, A., Lanciego, J.L., Guerra, M.J., LabandeiraGarcia, J.L., 2013. Inhibition of Rho kinase mediates the neuroprotective effects of estrogen in the MPTP model of Parkinson's disease. Neurobiol. Dis. 58, 209-219. https://doi.org/10.1016/j.nbd.2013.06.004.

Rong, W., Wang, J., Liu, X., Jiang, L., Wei, F., Zhou, H., Han, X., Liu, Z., 2012. 17ß estradiol attenuates neural cell apoptosis through inhibition of JNK phosphorylation in SCI rats and excitotoxicity induced by glutamate in vitro. Int. J. Neurosci. 122, 381-387. https://doi.org/10.3109/00207454.2012.668726.

Ruiz-Palmero, I., Hernando, M., Garcia-Segura, L.M., Arevalo, M.A., 2013. G proteincoupled estrogen receptor is required for the neuritogenic mechanism of $17 \beta$-estradiol in developing hippocampal neurons. Mol. Cell. Endocrinol. 372, 105-115. https://doi.org/10.1016/j.mce.2013.03.018.

Ruszkiewicz, J.A., Miranda-Vizuete, A., Tinkov, A.A., Skalnaya, M.G., Skalny, A.V., Tsatsakis, A., Aschner, M., 2019. Sex-specific differences in redox homeostasis in brain norm and disease. J. Mol. Neurosci. 67, 312-342. https://doi.org/10.1007/ s12031-018-1241-9.

Saldanha, C.J., Duncan, K.A., Walters, B.J., 2009. Neuroprotective actions of brain aromatase. Front. Neuroendocrinol. 30, 106-118. https://doi.org/10.1016/j.yfrne. 2009.04.016.

Saraceno, G.E., Bellini, M.J., Garcia-Segura, L.M., Capani, F., 2018. Estradiol activates PI3K/Akt/GSK3 pathway under chronic neurodegenerative conditions triggered by perinatal asphyxia. Front. Pharmacol. 9, 335. https://doi.org/10.3389/fphar.2018. 00335.

Saravia, F.E., Beauquis, J., Revsin, Y., Homo-Delarche, F., de Kloet, E.R., De Nicola, A.F., 2006. Hippocampal neuropathology of diabetes mellitus is relieved by estrogen treatment. Cell. Mol. Neurobiol. 26, 943-957.

Sareddy, G.R., Zhang, Q., Wang, R., Scott, E., Zou, Y., O'Connor, J.C., Chen, Y., Dong, Y., Vadlamudi, R.K., Brann, D., 2015. Proline-, glutamic acid-, and leucine-rich protein 1 mediates estrogen rapid signaling and neuroprotection in the brain. Proc. Natl. Acad. Sci. USA 112, E6673-E6682. https://doi.org/10.1073/pnas.1516729112.

Schaeffer, V., Meyer, L., Patte-Mensah, C., Eckert, A., Mensah-Nyagan, A.G., 2010. Sciatic nerve injury induces apoptosis of dorsal root ganglion satellite glial cells and selectively modifies neurosteroidogenesis in sensory neurons. Glia 58, 169-180. https:// doi.org/10.1002/glia.20910.

Scharfman, H.E., MacLusky, N.J., 2014. Differential regulation of BDNF, synaptic plasticity and sprouting in the hippocampal mossy fiber pathway of male and female rats. Neuropharmacology 76 Pt C, 696-708. https://doi.org/10.1016/j.neuropharm.2013. 04.029.

Schwarz, J.M., Nugent, B.M., McCarthy, M.M., 2010. Developmental and hormone- 
induced epigenetic changes to estrogen and progesterone receptor genes in brain are dynamic across the life span. Endocrinology 151, 4871-4881. https://doi.org/10. 1210/en.2010-0142.

Scott, E., Zhang, Q.G., Wang, R., Vadlamudi, R., Brann, D., 2012. Estrogen neuroprotection and the critical period hypothesis. Front. Neuroendocrinol. 33, 85-104. https://doi.org/10.1016/j.yfrne.2011.10.001.

Sehara, Y., Sawicka, K., Hwang, J.Y., Latuszek-Barrantes, A., Etgen, A.M., Zukin, R.S., 2013. Survivin is a transcriptional target of STAT3 critical to estradiol neuroprotection in global ischemia. J. Neurosci. 33, 12364-123474. https://doi.org/10.1523/ JNEUROSCI.1852-13.2013.

Seney, M.L., Chang, L.C., Oh, H., Wang, X., Tseng, G.C., Lewis, D.A., Sibille, E., 2013. The role of genetic sex in affect regulation and expression of GABA-related genes across species. Front. Psych. 4, 104. https://doi.org/10.3389/fpsyt.2013.00104.

Sengelaub, D.R., Xu, X.M., 2018. Protective effects of gonadal hormones on spinal motoneurons following spinal cord injury. Neural Regen. Res. 13, 971-976. https://doi. org /10.4103/1673-5374.233434.

Sharma, K., Mehra, R.D., 2008. Long-term administration of estrogen or tamoxifen to ovariectomized rats affords neuroprotection to hippocampal neurons by modulating the expression of Bcl-2 and Bax. Brain Res. 1204, 1-15. https://doi.org/10.1016/j. brainres.2008.01.080.

Shay, D.A., Vieira-Potter, V.J., Rosenfeld, C.S., 2018. Sexually dimorphic effects of aromatase on neurobehavioral responses. Front. Mol. Neurosci. 11, 374. https://doi. org /10.3389/fnmol.2018.00374.

Sherwin, B.B., 1988. Estrogen and/or androgen replacement therapy and cognitive functioning in surgically menopausal women. Psychoneuroendocrinology 13, 345-357.

Sierra, A., Azcoitia, I., Garcia-Segura, L., 2003. Endogenous estrogen formation is neuroprotective in model of cerebellar ataxia. Endocrine 21, 43-51.

Simpkins, J.W., Yi, K.D., Yang, S.H., Dykens, J.A., 2010. Mitochondrial mechanisms of estrogen neuroprotection. Biochim. Biophys. Acta 1800, 1113-1120. https://doi.org/ 10.1016/j.bbagen.2009.11.013.

Slowik, A., Lammerding, L., Zendedel, A., Habib, P., Beyer, C., 2018. Impact of steroid hormones $\mathrm{E} 2$ and $\mathrm{P}$ on the NLRP3/ASC/Casp1 axis in primary mouse astroglia and BV-2 cells after in vitro hypoxia. J. Steroid Biochem. Mol. Biol. 183, 18-26. https:// doi.org/10.1016/j.jsbmb.2018.05.003.

Smith, J.A., Zhang, R., Varma, A.K., Das, A., Ray, S.K., Banik, N.L., 2009. Estrogen partially down-regulates PTEN to prevent apoptosis in VSC4.1 motoneurons following exposure to IFN-gamma. Brain Res. 1301, 163-170. https://doi.org/10.1016/j. brainres.2009.09.016.

Sohrabji, F., 2015. Estrogen-IGF-1 interactions in neuroprotection: ischemic stroke as a case study. Front. Neuroendocrinol. 36, 1-14. https://doi.org/10.1016/j.yfrne.2014. 05.003.

Sohrabji, F., Okoreeh, A., Panta, A., 2019. Sex hormones and stroke: beyond estrogens. Horm. Behav. 111, 87-95. https://doi.org/10.1016/j.yhbeh.2018.10.010.

Sortino, M.A., Chisari, M., Merlo, S., Vancheri, C., Caruso, M., Nicoletti, F., Canonico, P.L., Copani, A., 2004. Glia mediates the neuroprotective action of estradiol on betaamyloid-induced neuronal death. Endocrinology 145, 5080-5086.

Sørvik, I.B., Solum, E.J., Labba, N.A., Hansen, T.V., Paulsen, R.E., 2018. Differential effects of some novel synthetic oestrogen analogs on oxidative PC12 cell death caused by serum deprivation. Free Radic. Res. 52, 273-287. https://doi.org/10.1080/ 10715762.2018.1430363.

Spence, R.D., Wisdom, A.J., Cao, Y., Hill, H.M., Mongerson, C.R., Stapornkul, B., Itoh, N., Sofroniew, M.V., Voskuhl, R.R., 2013. Estrogen mediates neuroprotection and antiinflammatory effects during EAE through ER $\alpha$ signaling on astrocytes but not through ER $\beta$ signaling on astrocytes or neurons. J. Neurosci. 33, 10924-11033. https://doi.org/10.1523/JNEUROSCI.0886-13.2013.

Sribnick, E.A., Del Re, A.M., Ray, S.K., Woodward, J.J., Banik, N.L., 2009. Estrogen attenuates glutamate-induced cell death by inhibiting $\mathrm{Ca} 2+$ influx through L-type voltage-gated Ca2 + channels. Brain Res. 1276, 159-170. https://doi.org/10.1016/j. brainres.2009.04.022.

Srivastava, D.P., Evans, P.D., 2013. G-protein oestrogen receptor 1: trials and tribulations of a membrane oestrogen receptor. J. Neuroendocrinol. 25, 1219-1230. https://doi. org/10.1111/jne.12071.

Stary, C.M., Xu, L., Li, L., Sun, X., Ouyang, Y.B., Xiong, X., Zhao, J., Giffard, R.G., 2017. Inhibition of miR-181a protects female mice from transient focal cerebral ischemia by targeting astrocyte estrogen receptor- $\alpha$. Mol. Cell. Neurosci. 82, 118-125. https:// doi.org/10.1016/j.mcn.2017.05.004.

Stone, D.J., Rozovsky, I., Morgan, T.E., Anderson, C.P., Finch, C.E., 1998. Increased synaptic sprouting in response to estrogen via an apolipoprotein E-dependent mechanism: implications for Alzheimer's disease. J. Neurosci. 18, 3180-3185.

Struble, R.G., Cady, C., Nathan, B.P., McAsey, M., 2008. Apolipoprotein E may be a critical factor in hormone therapy neuroprotection. Front. Biosci. 13, 5387-5405.

Suzuki, S., Brown, C.M., Wise, P.M., 2009. Neuroprotective effects of estrogens following ischemic stroke. Front. Neuroendocrinol. 30, 201-211. https://doi.org/10.1016/j. yfrne.2009.04.007.

Tabatadze, N., Huang, G., May, R.M., Jain, A., Woolley, C.S., 2015. Sex differences in molecular signaling at inhibitory synapses in the hippocampus. J. Neurosci. 35, 11252-11265. https://doi.org/10.1523/JNEUROSCI.1067-15.2015.

Takao, T., Flint, N., Lee, L., Ying, X., Merrill, J., Chandross, K.J., 2004. 17beta-estradiol protects oligodendrocytes from cytotoxicity induced cell death. J. Neurochem. 89, 660-673.

Taylor, L.C., Puranam, K., Gilmore, W., Ting, J.P., Matsushima, G.K., 2010. 17beta-estradiol protects male mice from cuprizone-induced demyelination and oligodendrocyte loss. Neurobiol. Dis. 39, 127-137. https://doi.org/10.1016/j.nbd.2010.03. 016.

Thakkar, R., Wang, R., Sareddy, G., Wang, J., Thiruvaiyaru, D., Vadlamudi, R., Zhang, Q.,
Brann, D., 2016. NLRP3 inflammasome activation in the brain after global cerebral ischemia and regulation by 17 $\beta$-estradiol. Oxid. Med. Cell. Longev. 2016, 8309031.

Thakkar, R., Sareddy, G.R., Zhang, Q., Wang, R., Vadlamudi, R.K., Brann, D., 2018. PELP1: a key mediator of oestrogen signalling and actions in the brain. $\mathrm{J}$. Neuroendocrinol. https://doi.org/10.1111/jne.12484.

Tripanichkul, W., Sripanichkulchai, K., Duce, J.A., Finkelstein, D.I., 2007. 17Beta-estradiol reduces nitrotyrosine immunoreactivity and increases SOD1 and SOD2 immunoreactivity in nigral neurons in male mice following MPTP insult. Brain Res. 1164, 24-31.

VanRyzin, J.W., Marquardt, A.E., Argue, K.J., Vecchiarelli, H.A., Ashton, S.E., Arambula, S.E., Hill, M.N., McCarthy, M.M., 2019. Microglial phagocytosis of newborn cells is induced by endocannabinoids and sculpts sex differences in juvenile rat social play. Neuron 102, 435-449.e6. https://doi.org/10.1016/j.neuron.2019.02.006.

Vasconsuelo, A., Milanesi, L., Boland, R., 2013. Actions of $17 \beta$-estradiol and testosterone in the mitochondria and their implications in aging. Ageing Res. Rev. 12, 907-917. https://doi.org/10.1016/j.arr.2013.09.001.

Vegeto, E., Belcredito, S., Ghisletti, S., Meda, C., Etteri, S., Maggi, A., 2006. The endogenous estrogen status regulates microglia reactivity in animal models of neuroinflammation. Endocrinology 147, 2263-2272.

Veiga, S., Garcia-Segura, L.M., Azcoitia, I., 2003. Neuroprotection by the steroids pregnenolone and dehydroepiandrosterone is mediated by the enzyme aromatase. J. Neurobiol. 56, 398-406.

Velísková, J., 2006. The role of estrogens in seizures and epilepsy: the bad guys or the good guys? Neuroscience 138, 837-844.

Vousden, D.A., Corre, C., Spring, S., Qiu, L.R., Metcalf, A., Cox, E., Lerch, J.P., Palmert, M.R., 2018. Impact of $\mathrm{X} / \mathrm{Y}$ genes and sex hormones on mouse neuroanatomy. Neuroimage 173, 551-563. https://doi.org/10.1016/j.neuroimage.2018.02.051.

Walters, B.J., Alexiades, N.G., Saldanha, C.J., 2011. Intracerebral estrogen provision increases cytogenesis and neurogenesis in the injured zebra finch brain. Dev. Neurobiol. 71, 170-181. https://doi.org/10.1002/dneu.20839.

Wandosell, F., Varea, O., Arevalo, M.A., Garcia-Segura, L.M., 2012. Oestradiol regulates $\beta$-catenin-mediated transcription in neurones. J. Neuroendocrinol. 24, 191-194. https://doi.org/10.1111/j.1365-2826.2011.02186.x.

Wang, J., Yu, R., Han, Q.Q., Huang, H.J., Wang, Y.L., Li, H.Y., Wang, H.M., Chen, X.R. Ma, S.L., Yu, J., 2018a. G-1 exhibit antidepressant effect, increase of hippocampal ERs expression and improve hippocampal redox status in aged female rats. Behav. Brain Res. https://doi.org/10.1016/j.bbr.2018.07.017.

Wang, R., Zhang, Q.G., Han, D., Xu, J., Lü, Q., Zhang, G.Y., 2006. Inhibition of MLK3 MKK4/7-JNK1/2 pathway by Akt1 in exogenous estrogen-induced neuroprotection against transient global cerebral ischemia by a non-genomic mechanism in male rats. J. Neurochem. 99, 1543-1554.

Wang, S., Ren, P., Li, X., Guan, Y., Zhang, Y.A., 2011. 17 $\beta$-estradiol protects dopaminergic neurons in organotypic slice of mesencephalon by MAPK-mediated activation of antiapoptosis gene BCL2. J. Mol. Neurosci. 45, 236-245. https://doi.org/10.1007/ s12031-011-9500-z.

Wang, W., Le, A.A., Hou, B., Lauterborn, J.C., Cox, C.D., Levin, E.R., Lynch, G., Gall, C.M., 2018b. Memory-related synaptic plasticity is sexually dimorphic in rodent hippocampus. J. Neurosci. 38, 7935-7951. https://doi.org/10.1523/JNEUROSCI.0801-18. 2018.

Wei, Q., Liang, X., Peng, Y., Yu, D., Zhang, R., Jin, H., Fan, J., Cai, W., Ren, C., Yu, J., 2018. 17ß-estradiol ameliorates oxidative stress and blue light-emitting diode-induced retinal degeneration by decreasing apoptosis and enhancing autophagy. Drug Des. Devel. Ther. 12, 2715-2730. https://doi.org/10.2147/DDDT.S176349.

Wen, Y., Yang, S., Liu, R., Perez, E., Yi, K.D., Koulen, P., Simpkins, J.W., 2004. Estrogen attenuates nuclear factor-kappa B activation induced by transient cerebral ischemia. Brain Res. 1008, 147-154.

Wu, K.J., Yu, S., Lee, J.Y., Hoffer, B., Wang, Y., 2017. Improving neurorepair in stroke brain through endogenous neurogenesis-enhancing drugs. Cell Transplant. 26 1596-1600. https://doi.org/10.1177/0963689717721230.

Wynne, R.D., Walters, B.J., Bailey, D.J., Saldanha, C.J., 2008. Inhibition of injury-induced glial aromatase reveals a wave of secondary degeneration in the songbird brain. Glia 56, 97-105.

Xiang, J., Liu, X., Ren, J., Chen, K., Wang, H.L., Miao, Y.Y., Qi, M.M., 2018. How does estrogen work on autophagy? Autophagy 15, 197-211. https://doi.org/10.1080/ 15548627.2018.1520549.

Xiao, Q., Luo, Y., Lv, F., He, Q., Wu, H., Chao, F., Qiu, X., Zhang, L., Gao, Y., Huang, C. Wang, S., Zhou, C., Zhang, Y., Jiang, L., Tang, Y., 2018. Protective effects of 17ßestradiol on hippocampal myelinated fibers in ovariectomized middle-aged rats. Neuroscience 385, 143-153. https://doi.org/10.1016/j.neuroscience.2018.06.006.

Xin, X.Y., Pan, J., Wang, X.Q., Ma, J.F., Ding, J.Q., Yang, G.Y., Chen, S.D., 2011. 2 methoxyestradiol attenuates autophagy activation after global ischemia. Can. J. Neurol. Sci. 38, 631-638.

Xu, P., Cao, X., He, Y., Zhu, L., Yang, Y., Saito, K., Wang, C., Yan, X., Hinton, A.O., Zou, F., Ding, H., Xia, Y., Yan, C., Shu, G., Wu, S.P., Yang, B., Feng, Y., Clegg, D.J., DeMarchi, R., Khan, S.A., Tsai, S.Y., DeMayo, F.J., Wu, Q., Tong, Q., Xu, Y., 2015. Estrogen receptor- $\alpha$ in medial amygdala neurons regulates body weight. J. Clin. Invest. 125, 2861-2876. https://doi.org/10.1172/JCI80941.

Xu, Y., López, M., 2018. Central regulation of energy metabolism by estrogens. Mol. Metab. 15, 104-115. https://doi.org/10.1016/j.molmet.2018.05.012.

Xu, Y., Zhang, W., Klaus, J., Young, J., Koerner, I., Sheldahl, L.C., Hurn, P.D., MartínezMurillo, F., Alkayed, N.J., 2006. Role of cocaine- and amphetamine-regulated transcript in estradiol-mediated neuroprotection. Proc. Natl. Acad. Sci. USA 103, 14489-14494.

Yang, L.C., Zhang, Q.G., Zhou, C.F., Yang, F., Zhang, Y.D., Wang, R.M., Brann, D.W., 2010. Extranuclear estrogen receptors mediate the neuroprotective effects of estrogen in the rat hippocampus. PLoS One 5, e9851. https://doi.org/10.1371/journal.pone. 
0009851.

Yanguas-Casás, N., Crespo-Castrillo, A., de Ceballos, M.L., Chowen, J.A., Azcoitia, I., Arevalo, M.A., Garcia-Segura, L.M., 2018. Sex differences in the phagocytic and migratory activity of microglia and their impairment by palmitic acid. Glia 66 522-537. https://doi.org/10.1002/glia.23263.

Yao, J., Chen, S., Cadenas, E., Brinton, R.D., 2011. Estrogen protection against mitochondrial toxin-induced cell death in hippocampal neurons: antagonism by progesterone. Brain Res. 1379, 2-10. https://doi.org/10.1016/j.brainres.2010.11.090.

Yao, M., Nguyen, T.V., Pike, C.J., 2007. Estrogen regulates Bcl-w and Bim expression: role in protection against beta-amyloid peptide-induced neuronal death. J. Neurosci. 27, $1422-1433$

Yazğan, Y., Nazıroğlu, M., 2017. Ovariectomy-induced mitochondrial oxidative stress, apoptosis, and calcium ion influx through TRPA1, TRPM2, and TRPV1 are prevented by $17 \beta$-estradiol, tamoxifen, and raloxifene in the hippocampus and dorsal root ganglion of rats. Mol. Neurobiol. 54, 7620-7638. https://doi.org/10.1007/s12035016-0232-5.

Yi, K.D., Simpkins, J.W., 2008. Protein phosphatase 1, protein phosphatase 2A, and calcineurin play a role in estrogen-mediated neuroprotection. Endocrinology 149, 5235-5243. https://doi.org/10.1210/en.2008-0610.

Yu, X., Rajala, R.V., McGinnis, J.F., Li, F., Anderson, R.E., Yan, X., Li, S., Elias, R.V., Knapp, R.R., Zhou, X., Cao, W., 2004. Involvement of insulin/phosphoinositide 3kinase/Akt signal pathway in 17 beta-estradiol-mediated neuroprotection. J. Biol. Chem. 279, 13086-13094.

Yu, T.S., Washington, P.M., Kernie, S.G., 2016. Injury-induced neurogenesis: mechanisms and relevance. Neuroscientist 22, 61-71. https://doi.org/10.1177/ 1073858414563616.

Yuan, L.J., Wang, X.W., Wang, H.T., Zhang, M., Sun, J.W., Chen, W.F., 2019. G proteincoupled estrogen receptor is involved in the neuroprotective effect of IGF-1 against MPTP/MPP ${ }^{+}$-induced dopaminergic neuronal injury. J. Steroid Biochem. Mol. Biol. 192, 105384. https://doi.org/10.1016/j.jsbmb.2019.105384.

Yue, X., Lu, M., Lancaster, T., Cao, P., Honda, S., Staufenbiel, M., Harada, N., Zhong, Z., Shen, Y., Li, R., 2005. Brain estrogen deficiency accelerates Abeta plaque formation in an Alzheimer's disease animal model. Proc. Natl. Acad. Sci. USA 102 19198-19203.

Yun, J., Yeo, I.J., Hwang, C.J., Choi, D.Y., Im, H.S., Kim, J.Y., Choi, W.R., Jung, M.H., Han, S.B., Hong, J.T., 2018. Estrogen deficiency exacerbates A $\beta$-induced memory impairment through enhancement of neuroinflammation, amyloidogenesis and NF$\mathrm{\kappa B}$ activation in ovariectomized mice. Brain Behav. Immun. 73, 282-293. https://doi. org/10.1016/j.bbi.2018.05.013.

Zafer, D., Aycan, N., Ozaydin, B., Kemanli, P., Ferrazzano, P., Levine, J.E., Cengiz, P., 2019. Sex differences in hippocampal memory and learning following neonatal brain injury: is there a role for ER $\alpha$ ? Neuroendocrinology. https://doi.org/10.1159/ 000499661.

Zendedel, A., Mönnink, F., Hassanzadeh, G., Zaminy, A., Ansar, M.M., Habib, P., Slowik, A., Kipp, M., Beyer, C., 2018. Estrogen attenuates local inflammasome expression and activation after spinal cord injury. Mol. Neurobiol. 55, 1364-1375. https://doi.org/ 10.1007/s12035-017-0400-2.
Zhang, B., Subramanian, S., Dziennis, S., Jia, J., Uchida, M., Akiyoshi, K., Migliati, E., Lewis, A.D., Vandenbark, A.A., Offner, H., Hurn, P.D., 2010. Estradiol and G1 reduce infarct size and improve immunosuppression after experimental stroke. J. Immunol. 184, 4087-4094. https://doi.org/10.4049/jimmunol.0902339.

Zhang, Q.G., Wang, R., Khan, M., Mahesh, V., Brann, D.W., 2008. Role of Dickkopf-1, an antagonist of the Wnt/beta-catenin signaling pathway, in estrogen-induced neuroprotection and attenuation of tau phosphorylation. J. Neurosci. 28, 8430-8441. https://doi.org/10.1523/JNEUROSCI.2752-08.2008.

Zhang, Q.G., Raz, L., Wang, R., Han, D., De Sevilla, L., Yang, F., Vadlamudi, R.K., Brann, D.W., 2009. Estrogen attenuates ischemic oxidative damage via an estrogen receptor alpha-mediated inhibition of NADPH oxidase activation. J. Neurosci. 29, 13823-13836. https://doi.org/10.1523/JNEUROSCI.3574-09.2009.

Zhang, Q.G., Wang, R., Tang, H., Dong, Y., Chan, A., Sareddy, G.R., Vadlamudi, R.K., Brann, D.W., 2014. Brain-derived estrogen exerts anti-inflammatory and neuroprotective actions in the rat hippocampus. Mol. Cell. Endocrinol. 389, 84-91.

Zhang, Z., Qin, P., Deng, Y., Ma, Z., Guo, H., Guo, H., Hou, Y., Wang, S., Zou, W., Sun, Y., Ma, Y., Hou, W., 2018. The novel estrogenic receptor GPR30 alleviates ischemic injury by inhibiting TLR4-mediated microglial inflammation. J. Neuroinflammation 15, 206. https://doi.org/10.1186/s12974-018-1246-x.

Zhang, Z.L., Qin, P., Liu, Y., Zhang, L.X., Guo, H., Deng, Y.L., Hou, Y.S., Wang, L.Y., Miao, Y., Ma, Y.L., Hou, W.G., 2017. Alleviation of ischaemia-reperfusion injury by endogenous estrogen involves maintaining Bcl-2 expression via the ER $\alpha$ signaling pathway. Brain Res. 1661, 15-23. https://doi.org/10.1016/j.brainres.2017.02.004.

Zhao, L., Brinton, R.D., 2007. Estrogen receptor alpha and beta differentially regulate intracellular $\mathrm{Ca}(2+)$ dynamics leading to ERK phosphorylation and estrogen neuroprotection in hippocampal neurons. Brain Res. 1172, 48-59.

Zhao, T.Z., Shi, F., Hu, J., He, S.M., Ding, Q., Ma, L.T., 2016. GPER1 mediates estrogeninduced neuroprotection against oxygen-glucose deprivation in the primary hippocampal neurons. Neuroscience 328, 117-126. https://doi.org/10.1016/j. neuroscience.2016.04.026.

Zheng, J., Zhang, P., Li, X., Lei, S., Li, W., He, X., Zhang, J., Wang, N., Qi, C., Chen, X., Lu, H., Liu, Y., 2013. Post-stroke estradiol treatment enhances neurogenesis in the subventricular zone of rats after permanent focal cerebral ischemia. Neuroscience 231, 82-90. https://doi.org/10.1016/j.neuroscience.2012.11.042.

Zhou, L., Lehan, N., Wehrenberg, U., Disteldorf, E., von Lossow, R., Mares, U., Jarry, H., Rune, G.M., 2007. Neuroprotection by estradiol: a role of aromatase against spine synapse loss after blockade of GABA(A) receptors. Exp. Neurol. 203, 72-81.

Zhu, H., Han, X., Ji, D., Lv, G., Xu, M., 2012. Estrogen inhibits lipid peroxidation after hypoxic-ischemic brain damage in neonatal rats. Neural Regen. Res. 7, 2424-2431. https://doi.org/10.3969/j.issn.1673-5374.2012.31.003.

Zhu, Y., Zhang, Q., Zhang, W., Li, N., Dai, Y., Tu, J., Yang, F., Brann, D.W., Wang, R, 2017. Protective effect of $17 \beta$-estradiol upon hippocampal spine density and cognitive function in an animal model of vascular dementia. Sci. Rep. 7, 42660. https:// doi.org/10.1038/srep42660.

Zup, S.L., Madden, A.M., 2016. Gonadal hormone modulation of intracellular calcium as a mechanism of neuroprotection. Front. Neuroendocrinol. 42, 40-52. https://doi.org/ 10.1016/j.yfrne.2016.02.003. 